\title{
Porosimetric membrane characterization techniques: a review
}

Melike Begum Tanis-Kanbur ${ }^{\mathrm{a}, \mathrm{b}, \mathrm{c}}$, René I. Peinador ${ }^{\mathrm{d}}$, José I. Calvo ${ }^{\mathrm{e}}$, Antonio Hernández ${ }^{\mathrm{e}}$, Jia Wei Chew ${ }^{\mathrm{a}, \mathrm{c}, *}$

\footnotetext{
${ }^{a}$ School of Chemical and Biomedical Engineering, Nanyang Technological University, 637459, Singapore

${ }^{b}$ Interdisciplinary Graduate School, Nanyang Technological University, 639798, Singapore

c Singapore Membrane Technology Centre, Nanyang Environment and Water Research Institute, Nanyang Technological University, 637141, Singapore

${ }^{d}$ Institut de la Filtration et des Techniques Séparatives (IFTS), Rue Marcel Pagnol, 47510, Foulayronnes, France

${ }^{e}$ Surfaces and Porous Materials (SMAP), Associated Research Unit to CSIC, UVainnova bldg, P ${ }^{\circ}$ de Belén 11 and Institute of Sustainable Processes (ISP), Dr. Mergelina s/n, University of Valladolid, 47071, Valladolid, Spain.

* Corresponding author. School of Chemical and Biomedical Engineering, Nanyang Technological University, 637459, Singapore.

E-mail address: JChew@ntu.edu.sg (J.W. Chew).
}

\begin{abstract}
Membrane technology is of significant importance in water treatment applications, and also gaining momentum in other separations, due to advantages such as environmentally friendly operation, less complex and lower-cost operating conditions compared to alternative options. To provide for sustainable and efficient membrane-based applications, the selection of appropriate membranes is crucial. Such a selection is based on membrane characterization, which offers critical information on parameters such as porosity, average pore size and pore size distribution (PSD). The two main classes of characterization methods are direct and indirect, with the latter having a theoretical basis, being more affordable, and also generally being able to characterize larger membrane areas compared to the direct techniques. This study reviews the indirect membrane characterization methods, the key theoretical backgrounds of which are the Young-Laplace equation, Kelvin equation, Gibbs-Thomson equation, and spectroscopy-based equations. The mathematical details are first presented, followed by the measurement details and relevant experimental requirements, and finally the studies on membrane characterization via indirect methods. The advantages and limitations of each method are also discussed. For a complete understanding of the membrane, indirect methods
\end{abstract}


may need to be complemented with direct ones and also with appropriate retention experiments of the real feeds of interest.

Keywords: Membrane characterization; pore-size distribution (PSD); porosity; porosimetry; porometry 


\section{Contents}

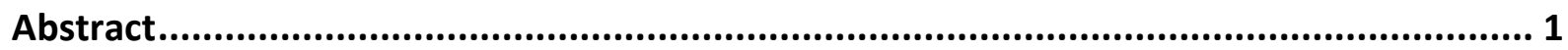

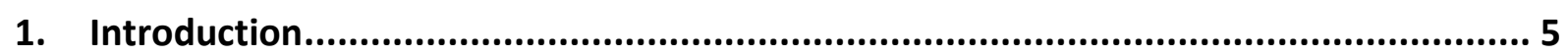

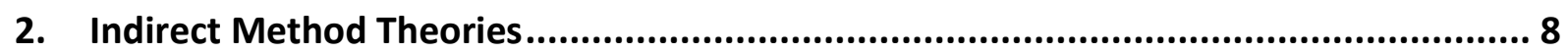

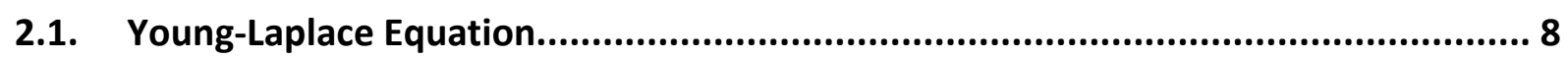

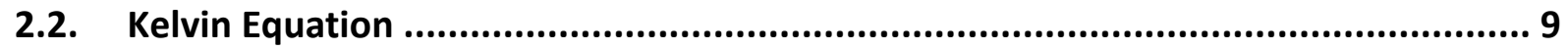

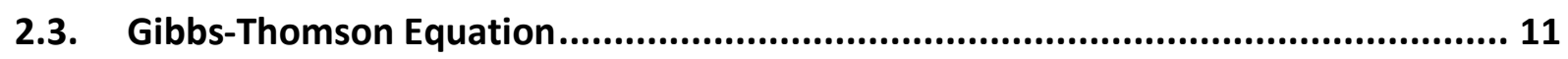

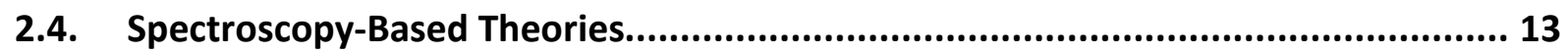

2.4.1. Positron Annihilation Lifetime Spectroscopy (PALS) ...................................... 13

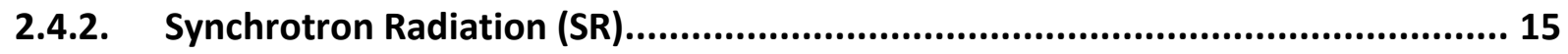

3. Young-Laplace Equation-Based Techniques .......................................................... 15

3.1. Liquid Displacement Porosimetry (LDP) ........................................................... 15

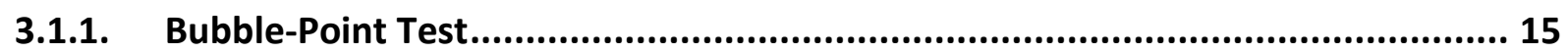

3.1.2. Gas-Liquid Displacement Porosimetry (GLDP) ............................................ 17

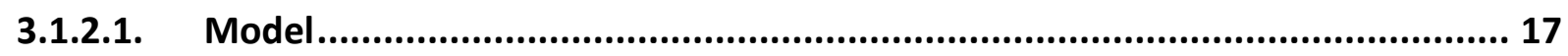

3.1.2.2. Commercial Equipment................................................................... 17

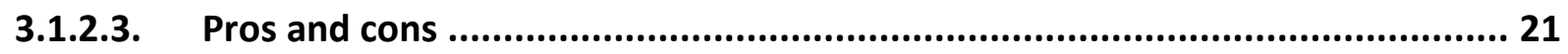

3.1.3. Liquid-Liquid Displacement Porosimetry (LLDP) ............................................ 24

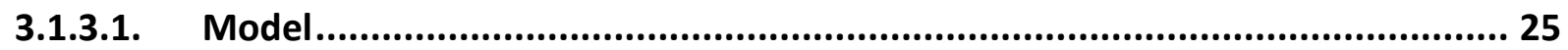

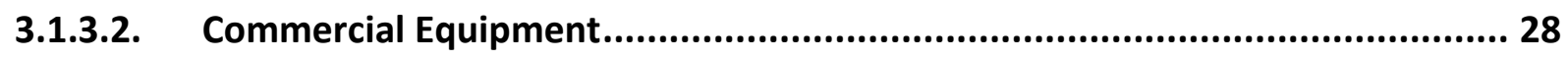

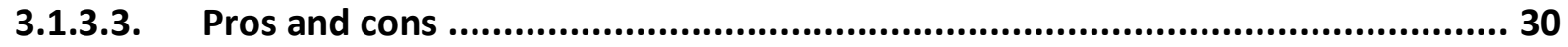

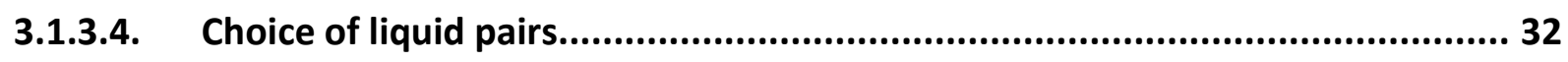

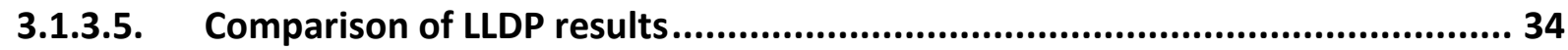

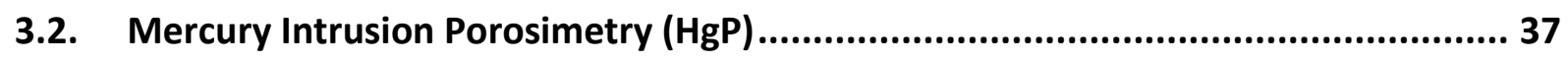

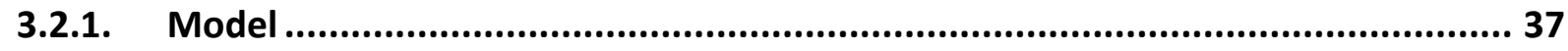

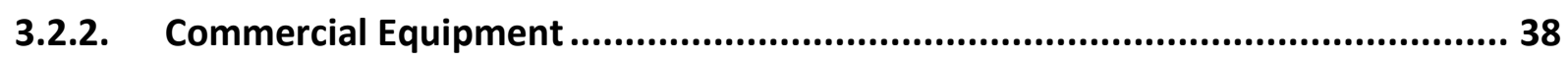

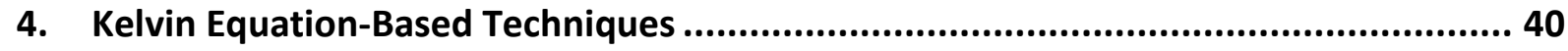

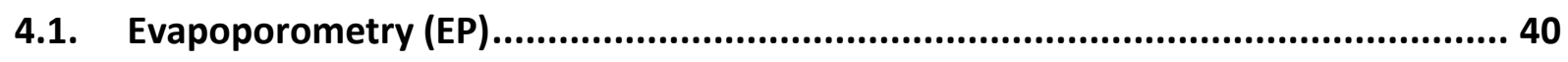

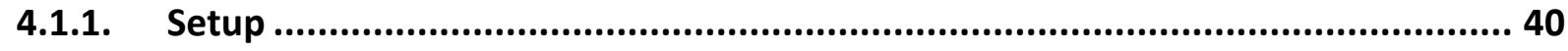

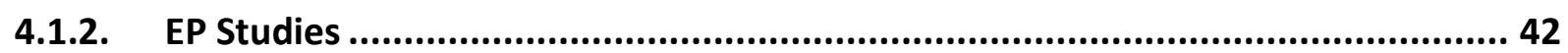




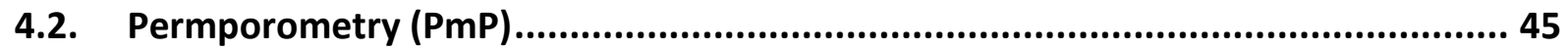

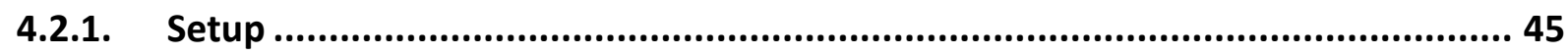

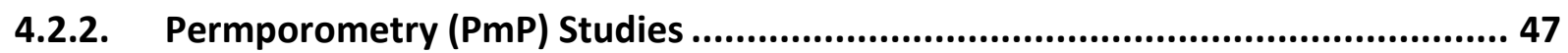

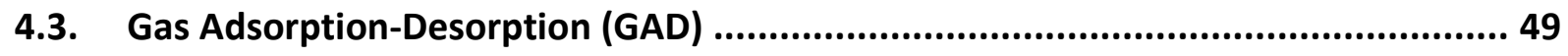

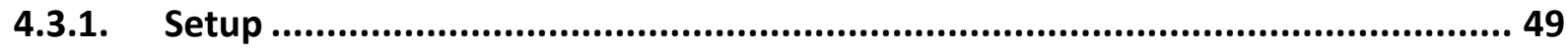

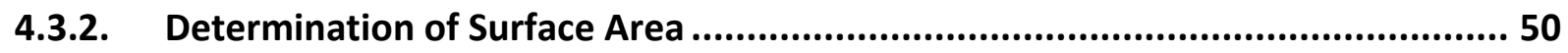

4.3.3. Determination of Mean Pore Size and Pore Size Distribution (PSD) ................... 51

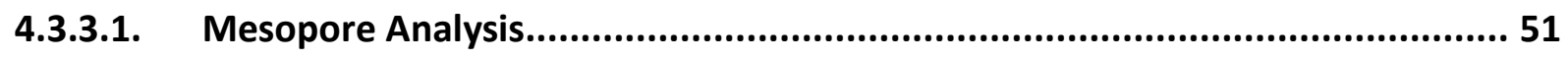

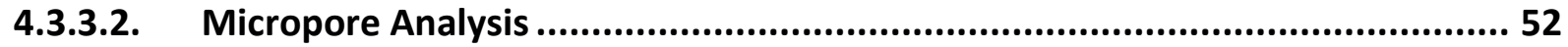

4.3.4. Determination of Overall Porosity …........................................................ 52

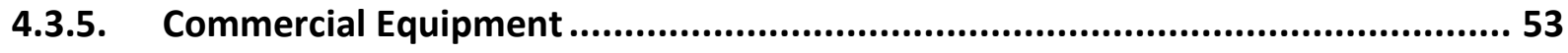

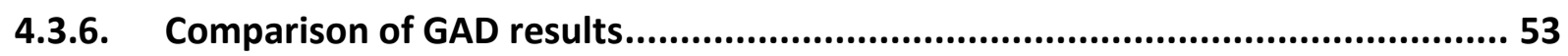

5. Gibbs-Thomson Equation-Based Techniques ..................................................... 55

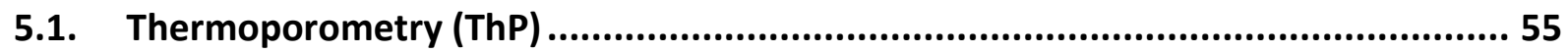

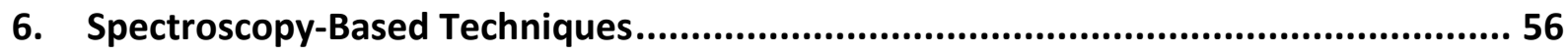

6.1. Positron Annihilation Lifetime Spectroscopy (PALS) .......................................... 56

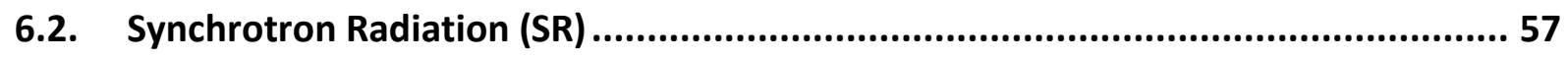

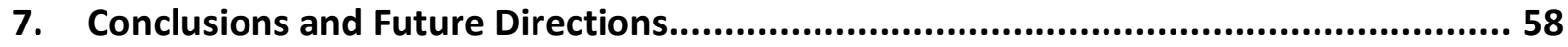

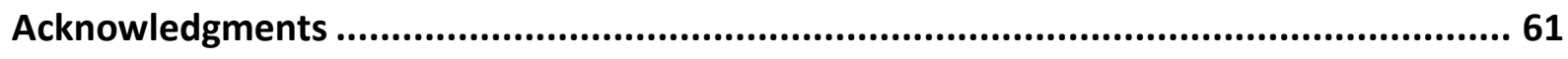

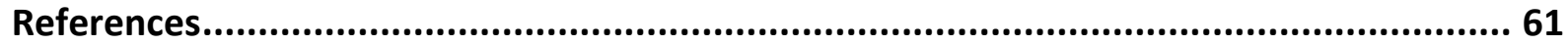




\section{Introduction}

Porous materials have widespread applications in many industrial and research fields. In particular, membranes are simple, easy-to-operate, and allow for environmentally friendly applications with inexpensive operating costs and fewer effluents; hence, they have been gaining importance as an affordable and feasible alternative to conventional separation means [1]. Loeb and Sourirajan [2] developed the first asymmetric membrane in the early 1960s, unveiling the complex procedures to overcome the challenges encountered during membrane fabrication. Apart from the cellulose acetate membrane that made seawater desalination through reverse osmosis the most dominant process for water supply, innumerable processes in which membranes are used for wide-ranging separation have sprouted.

To ensure selectivity and permeability in a wide range of separations, membranes differ significantly in structure and constitution, and consequently in their functional behaviors. Therefore, it is necessary to adequately characterize the membranes so that they can be properly selected and/or adjusted for each existing or potential application. This knowledge is also important for membrane manufacturers to optimize the fabrication parameters during membrane production for a given separation. Besides, membrane fouling, which causes decrements in permeate flux over time, is a significant disadvantage in the practical operations of membranes. Hence, appropriate membrane characterization is a fundamental step in membrane production, and one of the key factors to better understand the fouling behavior and stability of the membrane [3]. Characterization of a membrane should lead to "the most complete knowledge of its constitution, structure and functional behavior, obtained through the combined and critical use of adequate methods and techniques”, and thereby allow for prediction of performance [4].

In membrane applications, the size of the pores present in a membrane is a key factor in determining its possible applications and capabilities, since typically the pores act as sieves to govern which feed constituents pass through and which get retained by the membrane. Pore size characterization includes the determination of (average) pore diameter and pore size distribution (PSD). The average pore size of the membrane filter allows for a priori determination of the approximate size of the molecules that would be retained, but a more complete knowledge of the PSD is required if more precise knowledge of rejection is needed. The methods for membrane pore characterization can be classified into two classes, namely, direct and indirect. 
Direct methods include microscopy techniques to observe the membrane morphological details, such as cross-sectional area, surface porosity, pore size, pore shape and PSD [5]. This group spans all techniques based on microscopic inspection of surface or cross-section of the membranes, such as scanning electron microscopy (SEM), field emission scanning electron microscopy (FESEM), scanning tunneling microscopy (STM), atomic force microscopy (AFM), and transmission electron microscopy (TEM) [6-9]. Although the direct methods provide benefits such as real-time observation, they also bring some drawbacks like limited observation area or necessity for coating with a conductive material (particularly for SEM and FESEM) [24]. To circumvent the drawbacks, the indirect characterization methods, which rely on some theoretical basis to convert measurements into PSDs [9], are also popular for membrane characterization.

The indirect techniques that give such complete information about PSD can be generally be termed porometries (or porosimetries, which is more tied to membrane porosity). The techniques advanced in the past decades (mostly during the 20th century) can give reasonably complete and accurate PSD determination for a given membrane filter, based on the acquisition and interpretation of specific physical phenomena. Also, indirect approaches include those based on spectroscopy measurements. Even though spectroscopy are categorized as direct characterization techniques, the collected spectroscopy images can be used with mathematical expressions to allow for the characterization of sub-nanometer pores, which are not detectable by other indirect approaches. The underlying equations and associated techniques are listed as follows:

- Young-Laplace Equation: Liquid Displacement Porometries (LDP), Mercury Intrusion Porosimetry (HgP)

- Kelvin Equation: Evapoporometry (EP), Permporometry (PmP), Gas AdsorptionDesorption (GAD)

- Gibbs-Thomson Equation: Thermoporometry (ThP)

- Spectroscopy-based: Positron Annihilation Lifetime Spectroscopy (PALS), Synchrotron Radiation (SR)

Indirect methods are rooted in a mathematical background, allow for the observation of a larger membrane sample, and the non-spectroscopy methods are generally less expensive than the direct ones. Table 1 overviews the indirect membrane pore size characterization techniques reviewed here. 
Table 1. Indirect membrane pore size characterization techniques reviewed in this study.

\begin{tabular}{|c|c|c|}
\hline Theoretical Basis & Technique & Various Embodiments \\
\hline \multirow{6}{*}{ Young Laplace Equation } & \multirow{5}{*}{ Liquid Displacement Porosimetry (LDP) } & Gas-Liquid Displacement \\
\hline & & Porosimetry (GLDP) \\
\hline & & Bubble Point Test \\
\hline & & Liquid-Liquid Displacement \\
\hline & & Porosimetry (LLDP) \\
\hline & Mercury Porosimetry (HgP) & \\
\hline Gibbs-Thompson Equation & Thermoporometry (ThP) & \\
\hline \multirow{4}{*}{ Kelvin Equation } & Permoporometry (PmP) & \\
\hline & \multirow[t]{2}{*}{ Evapoporometry (EP) } & $\begin{array}{l}\text { EP in both dead-end and continuous } \\
\text { pores }\end{array}$ \\
\hline & & EP only for continuous pores (AEP) \\
\hline & Gas Adsorption Desorption (GAD) & \\
\hline \multirow{3}{*}{ Spectroscopy-based } & Positron Annihilation Lifetime & \\
\hline & Spectroscopy (PALS) & \\
\hline & Synchrotron Radiation (SR) & \\
\hline
\end{tabular}

The projected techniques in Table 1 each have specific protocols that may vary based on the membrane type and application. Past review studies have summarized the membrane characterization techniques in various applications. One of the oldest reviews is the one by Kim et al.[25]. Six different ultrafiltration membranes made of either polysulfone or cellulose were characterized by using the thermoporometry, permporometry, and molecular weight cut-off methods. The descriptions of mathematical backgrounds, operating conditions and experimental setups were presented. Nakao [5] performed another review of the characterization techniques classified as microscopic methods, bubble pressure and gas transport method, mercury porosimetry, permporometry, and thermoporometry. A detailed literature study was done, and the theoretical backgrounds were presented along with the experimental procedure and evaluation of the results. At the beginning of 2000, Zhao et al. [26] updated the literature with a review on hollow-fiber membrane characterization via microscopic techniques, thermoporometry, water permeability, and molecular gas transport models. Recently, Rahman et al. [27] summarized the indirect membrane pore size characterization techniques specifically for ceramic membranes. The experimental procedures and results of the gas adsorption-desorption, themroporometry, permporometry, bubble point, liquid 
displacement method, and mercury porosimetry techniques were explained and compared to one another. Several other reviews and books on membrane characterization have been published over the years, from more recent papers [28-30] to books [31], or book chapters [4]. All the foregoing review studies enlightened researchers about the characterization techniques available to provide both structural and performance-related information of the membranes [2933].

Following the outcomes and discussions of the review studies to date, this study was aimed at presenting an updated, comprehensive, and more detailed review of the indirect membrane pore size characterization methods. The current study compiled past to present studies on the indirect methods depicted in Table 1, including both conventional ones and newer ones like evapoporometry (EP), along with the spectroscopy-based ones that allows for characterization of sub-nanometer pores. Also, in order to give a better understanding of the relationship between the experimental procedure and mathematical background, this study gives the theoretical backgrounds of the indirect methods with their derivations, an analysis of the assumptions and basis, as well as the different operational modes and the commercial setups available for each technique. Finally, some results demonstrating the features, potential and drawbacks of each technique will be commented on. In the following pages, the theories, techniques, and studies are presented in sequence; then, some perspectives are given.

\section{Indirect Method Theories}

\subsection{Young-Laplace Equation}

The Young-Laplace equation, which describes the pressure difference across the interface between two static fluids, is of fundamental importance in the study of the capillary phenomena. In its more general form, the Young-Laplace equation expresses the pressure difference $(\Delta P)$ at the interface between two immiscible fluids for a general geometry as:

$$
\Delta P=2 \gamma H
$$

where $\gamma$ is the interfacial surface tension of the immiscible fluids and $H$ the interface curvature. Based on geometric considerations, this curvature can be obtained from two main curvature radii as:

$$
H=\frac{1}{2}\left(\frac{1}{r_{1}}+\frac{1}{r_{2}}\right)
$$

where $r_{1}$ and $r_{2}$ are the principal radii of curvatures for the interface. For the case of a cylindrical tube (i.e., the ideal membrane pore), the Young-Laplace equation must be modified to include 
the contact angle $(\theta)$ between the spherical meniscus formed in the inner pore and the pore wall, such that the pressure differential $\Delta P$ for a pore of diameter $d$ is given by:

$$
\Delta P=\frac{4 \gamma \cos \theta}{d}
$$

where $\gamma$ is the interfacial surface tension of the immiscible liquids, and $\theta$ is the contact angle between the interface and the pore wall. For the case of a membrane, which is made up of a myriad of pores that can be simplified as straight-through cylinders with a range of diameters, Eq. (3) can be applied to determine the PSD by measuring the range of $\Delta P$ values [9].

\subsection{Kelvin Equation}

The Kelvin equation is used in various indirect membrane characterization techniques such as evapoporometry (EP), permporometry, and gas adsorption-desorption. The derivation of the Kelvin equation accounts for the effect of surface curvature on the thermodynamic equilibrium of a pure liquid. As illustrated in Fig. 1, the interface between the liquid and its vapor phase can either be planar (Fig. 1a) or a positive curvature (Fig. 1b).
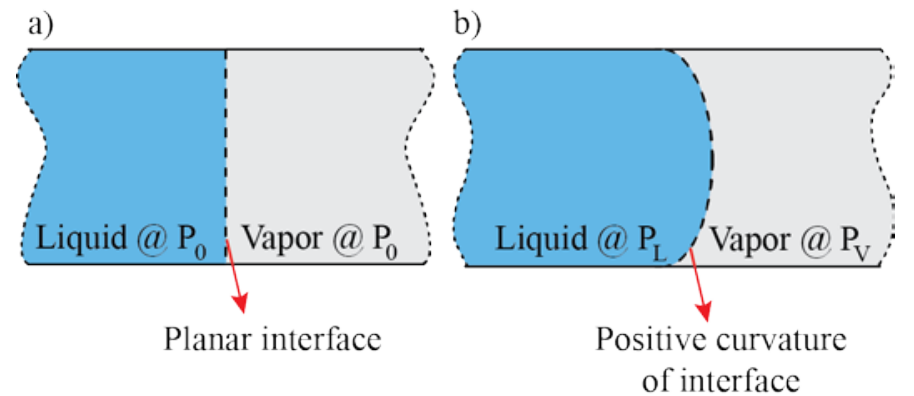

Fig. 1: Thermodynamic equilibrium of a pure liquid with its vapor phase: (a) planar interface, and (b) positive curvature interface.

The chemical potential of a liquid and its vapor phase must be equal to each other at thermodynamic equilibrium, as defined in Eq. (4):

$$
d \mu_{L}=d \mu_{V}
$$

where $\mu$ denotes chemical potential, and the subscripts $L$ and $V$ represent the liquid and vapor phases, respectively. The liquid and vapor phases have the same total pressure at $P_{0}$, but a positive curvature (Fig. 1b) means that the liquid phase has a higher pressure $\left(P_{L}\right)$ than the vapor phase $\left(P_{V}\right)$. For a planar interface (Fig. 1a), incorporating the ideal gas law gives:

$$
V_{V} d P=V_{L} d P \Rightarrow V_{L} d P=R T \frac{d P}{P}
$$


where molar volume is denoted by $V$. By assuming constant liquid density, integrating Eq. (5) allows us to relate the pressure for a positive curvature (Fig. 1b) to that for a plane (Fig. 1a):

$$
V_{L}\left(P_{L}-P_{0}\right)=R T \ln \frac{P_{V}}{P_{0}}
$$

Re-arrangement of Eq. (6) gives:

$$
V_{L}\left(P_{L}-P_{V}\right)-V_{L}\left(P_{0}-P_{V}\right)=R T \ln \frac{P_{V}}{P_{0}}
$$

Invoking the Young-Laplace equation:

$$
P_{L}-P_{V}=\left(\frac{1}{r_{1}}+\frac{1}{r_{2}}\right) \gamma \cos \theta
$$

where $r_{1}$ and $r_{2}$ are the principal radii of curvature of the curved interface, $\theta$ is the liquid contact angle in a pore (at the gas-liquid interface), and $\gamma$ is the surface tension. Assuming $r_{1}=r_{2}=r$ for a hemispherical interface in a pore, Eq. (7) can be re-expressed as

$$
\frac{2 V_{L} \gamma \cos \theta}{r}-V_{L}\left(P_{0}-P_{V}\right)=R T \ln \frac{P_{V}}{P_{0}}
$$

Neglecting the second term on the left-hand side, because it is significantly smaller than the first term, gives the Kelvin equation:

$$
\ln \frac{P_{V}}{P_{0}}=\frac{2 V_{L} \gamma \cos \theta}{R T r}
$$

If the liquid phase has negative curvature (as opposed to the positive one in Fig. 1b), the righthand side of the Kelvin equation (Eq. (10)) takes on a negative sign:

$$
\ln \frac{P_{V}}{P_{0}}=-\frac{2 V_{L} \gamma \cos \theta}{R T r}
$$

For the EP method for membrane PSD characterization, the Kelvin equation is adapted as follows:

$$
\ln \frac{P_{A}}{P_{A}^{0}}=-\frac{4 V \gamma \cos \theta}{d R T}
$$

where $T$ is the absolute temperature during the EP experiments, $V$ is the molar volume of liquid, $P_{A}^{0}$ and $P_{A}$ are the normal vapor pressure and vapor pressure of the volatile wetting liquid, respectively.. According to Eq. (12), the vapor pressure of the liquid is related to the diameter of the pores, and therefore the pore diameters $(d)$ of the membrane can be calculated if the range of $P_{A}$ values are known. The ratio of vapor pressures in Eq. (9) is equivalent to the ratio of the evaporation rates, since the driving force for evaporation from the pores is the differential vapor 
pressures. Hence, instead of $P_{A}$, Eq. (12) can be defined by the evaporation rate above a flat liquid layer without a vapor-pressure depression, $W_{A}$, as shown in the following:

$$
d=-\frac{4 V \gamma \cos \theta}{R T \ln \frac{W_{A}}{W_{A}^{0}}}
$$

The evaporation rate, $\mathrm{W}_{\mathrm{A}}$, can be determined via the mass change in the test cell holding the membrane. Per the evapoporometry (EP) method, placement of the test cell on a load cell or a high-resolution microbalance permits this determination. The Kelvin equation underlies the evapoporometry, permporometry, and gas adsorption-desorption methods.

\subsection{Gibbs-Thomson Equation}

The Gibbs-Thomson equation, which underlies the thermoporometry technique for characterizing membrane PSD, describes the thermodynamic equilibrium conditions of the solid, liquid, and gas phases of a pure substance inside the porous medium. The liquid amount in the porous material depends on the pore size and inherently affects the interfaces during phase transformation. Brun et al. [34] presented a detailed derivation by using a combination of theoretical, numerical and experimental approaches. To develop the Gibbs-Thomson Equation-based means for pore size characterization, all the phases of a substance are denoted by the subscripts of $i, j$ and $k$. The Gibbs-Duhem equations are expressed as follows for the phases and interphases, respectively:

$$
\begin{aligned}
& S_{i} d T-V_{i} d P_{i}+m_{i} d \mu_{i}=0 \\
& S_{i j} d T-A_{i j} d \gamma_{i j}+m_{i j} d \mu_{i j}=0
\end{aligned}
$$

where $S$ is entropy, $T$ is temperature, $\mu$ is chemical potential, $m$ is mass, $\gamma$ is interfacial tension, $V$ is volume, and $P$ is pressure. It should be noted that the second term of Eq. (15) is obtained via the Laplace equation that defines the pressure difference with respect to the interfacial tension, area and volume:

$$
P_{j}-P_{i}=\gamma_{i j} \frac{d A_{i j}}{d V_{j}}
$$

At the thermodynamic equilibrium of a pure substance at the triple point, all the chemical potentials (phases and interphases) become equal to one another, as expressed in the following differential equation:

$$
\left(\frac{s_{S}-s_{V}}{v_{S}-v_{V}}-\frac{s_{L}-s_{S}}{v_{L}-v_{S}}\right) d T=\frac{V_{V}}{v_{V}-v_{S}} d\left(\gamma_{S V} \frac{d A_{S V}}{d V_{V}}\right)-\frac{V_{L}}{v_{L}-v_{S}} d\left(\gamma_{S L} \frac{d A_{S L}}{d V_{L}}\right)
$$


where the solid, liquid, and gas phases are denoted by the subscripts $S, L$, and $V$, respectively. According to Eq. (16), the term $\frac{d A_{i j}}{d V_{j}}$, which can be defined as the curvature of two of the three interphases, must be known to find the temperature at the triple point. This is challenging for a porous medium [34], but it can be assessed in the region where the gas-solid interphase is planar, whereby the term $\frac{d A_{S V}}{d V_{V}}$ approaches zero and $v_{V} \gg v_{L}$. Also, the term $s_{S}-s_{L}$ can be defined as the solidification entropy of the condensate, $\Delta S_{f}$, and thereby Eq. (17) can be rewritten as follows:

$$
\Delta S_{f} d T=V_{L} d\left(\gamma_{S L} \frac{d A_{S L}}{d V_{L}}\right)=0
$$

The term $\frac{d A_{S L}}{d V_{L}}$ is defined as $-2 / R_{n}$, where $R_{n}$ is the curvature radius of the spherical solidliquid interphase. Hereby, we obtain:

$$
\frac{1}{R_{n}}=\frac{1}{2 \gamma_{S L}} \int_{T_{0}}^{T} \frac{\Delta S_{f}}{V_{L}} d T
$$

The solidification entropy of the condensate, $\Delta S_{f}$, is not a measurable term, but it can be expressed via thermodynamic state functions. Assuming incompressible flow, $\Delta S_{f}$ is defined as [34]:

$$
\Delta S_{f}=\Delta S_{o}+\int_{T_{0}}^{T} \frac{c_{S}-c_{L}}{T} d T+\left[\left(\frac{\partial v_{L}}{\partial T}\right)_{P}-\left(\frac{\partial v_{S}}{\partial T}\right)_{P}\right]\left(P_{S}-P_{0}\right)+\left[\left(\frac{\partial v_{L}}{\partial T}\right)_{P}\right]\left(P_{L}-P_{S}\right)
$$

where $\Delta S_{o}$ is the normal solidification entropy, $c$ the specific heat capacity at constant pressure, $P_{S}$ the vapor pressure of the undivided solid at the corresponding temperature, $T$. Following the Laplace equation (Eq. (16)), Eq. (19) and Eq. (20), the relationship between $R_{n}$ and temperature can be defined as:

$$
P_{S}-P_{L}=\frac{2 \gamma_{S L}}{R_{n}}=\int_{T_{0}}^{T} \frac{\Delta S_{f}}{V_{L}} d T
$$

Eq. (18) simply deduces that the relationship between the curvature radius of the solid-liquid interphase and the temperature can be explained if the solidification entropy of the condensate can be solved. According to the abovementioned theoretical development, the term $\Delta S_{f}$ can be calculated for liquids with respect to their thermophysical properties that define the state functions (see Eq. (17))[34]. As for the solid-liquid interphase, the curvature radius is also called the radius of the critical nucleus for the applied liquids. To determine $R_{n}$, it is required to find the peripheral layer thickness of the condensate that does not undergo a change of state. For this purpose, a calorimeter is used and the required values of the terms $\gamma_{S L}$ and $R_{n}$ can be 
obtained for the corresponding liquid. In addition to $\gamma_{S L}$ and $R_{n}$, the pore radii, $R_{p}$, can also be determined. By this way, the term $R_{p}$ can be measured via the triple point temperature depressions at the solidification and fusion cases. It must be noted that these measurements are unique for the liquids. In the thermoporometry methods, which use the foregoing theoretical explanation, the temperature depressions are observed by using thermograms at both solidification and fusion cases. Following the thermogram observations, calorimetry measurement, and theory, the relationship between $R_{p}$ and temperature can be expressed in Eq. (22) and the equation of the distribution curve in Eq. (23):

$$
\begin{aligned}
& R_{p}=-\frac{A}{\Delta T}+B \\
& \frac{\Delta V}{\Delta R_{p}}=k \frac{\Delta T^{2}}{W_{a}} y
\end{aligned}
$$

where $A$ and $B$ are the constants obtained from the numerical solutions (e.g., $A=64.67$ and $B=0.57$ for water [34]), $k$ the sensitivity of the calorimeter setup, and $W_{a}$ is the apparent energy (e.g., solidification energy).

\subsection{Spectroscopy-Based Theories}

\subsubsection{Positron Annihilation Lifetime Spectroscopy (PALS)}

Positron Annihilation Spectroscopy (PAS), which was developed for electronic structures, is a direct observation method that can be used for membrane pore size characterization through analytical modeling of the collected images [35, 36]. Compared to the well-known direct observation methods like TEM and SEM, PAS can better determine sub-nanometer-scale membrane pores, which makes it attractive for reverse osmosis (RO) and tight NF membranes. When PAS is used to analyze membranes or other porous materials, the technique is usually named Positron Annihilation Lifetime Spectroscopy (PALS) [35], which is based on measuring the lifetime spectrum of positrons [37, 38]. PALS is superior to other established indirect methods such as GAD and similar differential scanning calorimeter approaches due to the advantage of detecting sub-nanometer pores [30, 39], thereby allowing the characterization of the active skin layer of RO and tight NF membranes.

In PALS analysis, positrons are injected into the RO membrane sample, and either annihilated with the electrons to two $\gamma$ rays, or combined with the electrons to form a positronium (Ps) atom with a vacuum binding energy of $\sim 6.8 \mathrm{eV}$ [40]. Two different Ps states exist, namely, antiparallel-spun (para-Ps or p-Ps) and parallel-spun (ortho-Ps or o-Ps) with respect to the 
spinning positioning of the positrons and electrons. In the p-Ps state, the total spin is 0 and the intrinsic lifetime $\left(\tau_{p-P s}\right)$ is approximately $0.125 \mathrm{~ns}$ with two- $\gamma$ decays, while the total spin is equal to 1 and the intrinsic lifetime $\left(\tau_{o-P s}\right)$ is up to 142 ns with three or more $\gamma$ decays. In polymeric membranes, $\tau_{o-P S}$ is 1 to 5 ns since the positron is annihilated with one of the surrounding electrons in an opposite spin [35, 40]. The free-volume holes in the membrane can be detected by PAS data because the annihilation photons move in these open spaces. Earlier studies [41, 42] correlated the measured $\tau_{o-P s}$ with the free-volume hole radius, $r_{f v}$, as shown in Eq. (24):

$$
\tau_{o-P s}=\left[\lambda\left(1-\frac{r_{f v}}{r_{f v}+\Delta r_{f v}}+\frac{1}{2 \pi} \sin \frac{2 \pi r_{f v}}{r_{f v}+\Delta r_{f v}}\right)\right]^{-1}
$$

where $\lambda=2 \mathrm{~ns}^{-1}$ is the annihilation rate of spin-averaged Ps and $\Delta r_{f v}=1.656 \AA^{3}$ is the valid homogeneous layer for polymers [40]. As with other indirect methods, the holes are assumed spherical structures so that the radius can be defined as $r_{f v-0}=r_{f v}+\Delta r_{f v}$. For this assumption, the volume of the spherical structure can be written as in Eq. (25):

$$
V_{F}=\frac{4 \pi r_{f v^{3}}}{3}
$$

PALS achieves very sensitive results, but it must be noted that the operating conditions should be maintained well for accurate results, because fluctuations of the operating parameters can negatively affect measurements and result in uncertainties [43]. The simplified experimental setup schematic of the PALS method is shown in Fig. 2.

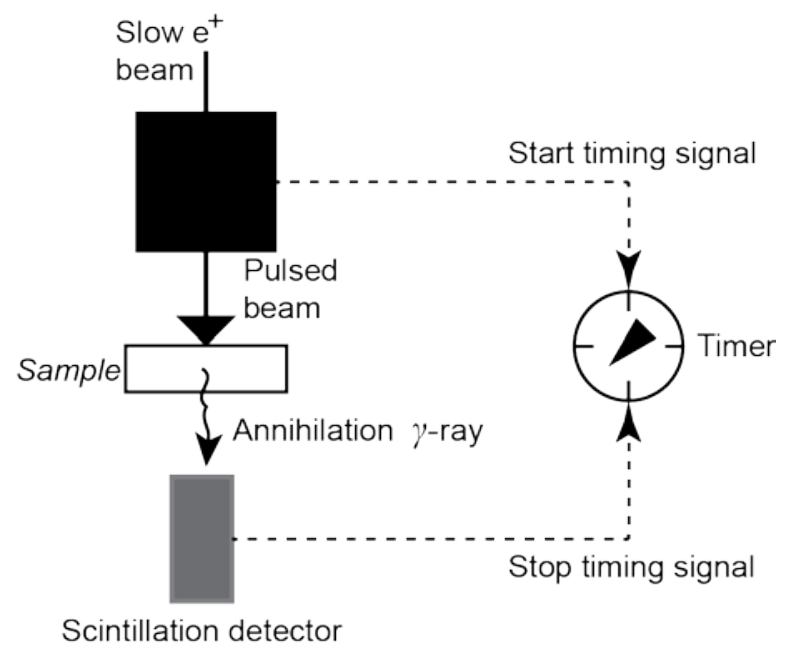


Fig. 2: Simplified experimental schematic of the PALS technique (redrawn and modified from Ref.

[35]).

\subsubsection{Synchrotron Radiation (SR)}

Synchrotron radiation (SR) is the electromagnetic radiation produced by a synchrotron storage ring that accelerates charged particles nearly to the speed of light when those charged particles, relativistic electrons, are expedited in a circular path by strong magnetic fields [44, 45]. After passing through the membrane, the electrons are detected and the intensity image allows for interpretation of number and size of pores. SR sources provide opportunities for real-time studies, owing to their spectral properties such as continuous wavelength spectrum generation and luminosities production with a large range of spectrum [46]. Therefore, it provides chemical imaging analysis with high resolution [47], which can be used towards membrane pore size characterization, in the same manner as other membrane microscopic images.

\section{Young-Laplace Equation-Based Techniques}

\subsection{Liquid Displacement Porosimetry (LDP)}

Liquid displacement porosimetry (LDP) consists of gas-liquid displacement porosimetry (GLDP) and liquid-liquid displacement porosimetry (LLDP) techniques. Their very first use was for the bubble point test, which will be presented first.

\subsubsection{Bubble-Point Test}

As the first technique based on the Young-Laplace equation (Section 2.1), the Bubble Point method was used to analyze the size of the pores present in a filter [48]. The method is now commonly used by membrane manufacturers to assure the integrity of their products. Several devices have been developed by the main membrane companies which commercialized them as Integrity Tests (i.e., obtain the maximum pore size and compare with the expected value to determine the suitability of the membrane for use), for example, Integritest 5 (Millipore), BP Tester (PMI), Flowstar IV (Palltronic) or Sartocheck 5 (Sartorius) [49]. They are based on the primal idea of Bechhold [48].

The chief problem with using this technique as the integrity test is the relatively high surface tension of the air-liquid interface. In the original work by Bechhold [48], water was used as an impregnating fluid. Since the water-air interface has a surface tension of $72.8 \mathrm{mN} / \mathrm{m}$, a pressure of around 15 bar is needed to analyze a membrane with a maximum pore size of $0.2 \mu \mathrm{m}$. Later 
on, researchers found better wetting fluids, but even using typical halogenated fluids to wet the membrane (which assure almost perfect membrane wetting with low contact angles that, for practical purposes, can be taken as zero), the surface tension with air is around $16 \mathrm{mN} / \mathrm{m}$, which means that analyzing a membrane having a maximum pore size of $5 \mathrm{~nm}$ requires a pressure of 64 bar. Such high pressures could lead to membrane structure distortion, compromising the feature that the technique is supposed to characterize. Because of the high pressures associated with small pore sizes, the Bubble-Point Test is commonly used for microfiltration (MF) and ultrafiltration (UF) membranes.

According to the Young-Laplace equation (Section 2.1), the pressure needed for the first air bubbles to appear corresponds to the displacement of the liquid in the largest pores by the gas. Obviously, further increases in gas pressure do not serve to give information about smaller pores, since new air bubbles cannot be distinguished from initial ones. Therefore, the method cannot be considered suitable to obtain the PSD of a membrane, except in the idealized case of a completely homoporous membrane (i.e., all the pores are of exactly equal sizes).

The bubble point technique was firstly applied to characterize larger membrane sample areas [50, 51]. It successfully tested the cartridges with polypropylene capillaries and flat polyamide membranes which have filtration areas from $0.5 \mathrm{~m}^{2}$ to $6 \mathrm{~m}^{2}$ [52]. The method was also used for the characterization of several track-etched microporous polycarbonate membranes with nominal pore sizes ranging between 0.1 - $5.0 \mu \mathrm{m}$ [53] as well as ceramic membranes with different configurations (namely, flat sheet and tubular alumina membranes) [54]. Moreover, it has been used for the characterization of supported ionic liquid membranes by using different porous flat sheet supports [55]. Appropriate membrane cells have been designed to analyze all possible membrane configurations, from flat to tubular or hollow fibers with this technique [56]. In addition to membrane studies, the method was used to characterize the PSD of various geotextile samples $[57,58]$. There were some efforts made to improve the measurement method of the technique including a modification of the conventional bubble point method to determine the narrowest constriction in a tortuous pore (i.e., pore-throat) of membranes [59]. Instead of relating the first bubble to the largest pore throat as in the conventional bubble-point test, the modified method is based on the relation between the last bubble and the largest pore-mouth. Also, a numerical method was developed to analyze the bubble point test by considering the surface tension effect at the gas-liquid interface and validated with experimental results of track-etched polycarbonate membranes [60]. 


\subsubsection{Gas-Liquid Displacement Porosimetry (GLDP)}

\subsubsection{Model}

The original idea on bubble-point [48] only served for the evaluation of the maximum pore size present in a filter, but the technique can be easily extended to obtain information on the whole PSD through increasing further the pressure after the first appearing bubbles. As the pressure progressively increases beyond the bubble point, successive pores of decreasing sizes gradually empty, giving rise to the GLDP technique, which is a combination of the bubble point test and solvent permeability method to obtain the PSD of the membrane [61]. The method was later improved to take into account the surface energy at the gas-liquid interface [62, 63]. In effect, GLDP involves the measurement of the gas flow through the membrane pores to get information on the PSD. To convert the gas flow increments into the contribution of newly opened pores, a transport model is needed. A simple choice could be to use the Hagen-Poiseuille law for convective flow inside capillaries, mostly valid at the typical applied pressures and pore sizes involved. However, this model predicts a linear relationship between flow and pressure in all ranges, whereas experimentally some non-linearity of the flow curve as pressure increases can be observed. This is because the Knudsen diffusion model should be factored in for pores whereby the mean free path of the gas molecules, $\lambda$, is much lower than the capillary diameter. In fact, calculations usually consider some sort of combination between both models of flow. Schneider and Uchytil [64] showed the discrepancy between GLDP results and real pores due to the improper consideration of the gas transport models involved. Hernández et al. [53] proposed to resolve such discrepancies between flow models by incorporating a smooth transition from Knudsen diffusive flow to Poiseuille convective one. With such an approach, GLDP calculation resulted in a much more accurate agreement with actual PSD and porosities of the test membranes. Another approach by Shao et al. [65] proposed that the contribution of Knudsen diffusion in GLDP can be effectively suppressed by an appropriate selection of the pore-filling liquid. Departing from the simple idea of Erbe [61] and using different modeling for PSD calculation, several commercial types of equipment were developed, including automatic data acquisition coupled with subsequent derivations of PSD.

\subsubsection{Commercial Equipment}

The first commercial equipment appearing in the market was the Coulter Porometer, but this successful equipment (especially the improved version, Coulter Porometer II) shortly ended fabrication and Beckman, which acquired the porometry division of Coulter, discontinued its 
production. Among other GLDP devices, that of PMI (Advanced Capillary Flow Porometer its latest version) deserves a commentary, since it is one of the first in the market that claims to characterize pores down to almost the nanometer range. Other air-liquid porometer manufacturers are Quantachrome (featuring Porometer 3G) and Porometer (a company originated at Benelux Scientific which features the Porolux 1000 as the latest version).

From an experimental point of view, all types of GLDP equipment in the market use a quite similar approach. The first step involves filling the membrane to be analyzed with a liquid that enters all the pores. Then, the membrane is placed in a dead-end cell and subjected to increasing pressures by controlled air supply. As pressure increases, it reaches a value corresponding to the bubble point of the Bechhold method, when the biggest pores in the membrane are opened and the air starts to flow through. As pressure continues to build up steeply, pores of decreasing sizes are progressively emptied and the flow of air through the membrane increases. A flow meter placed downstream allows determining the successive gas flow increments. The pressure applied and the size of the pores opened at each pressure are related through the Young-Laplace equation (Eq. (3)), whereby the contact angle at the air-liquid-membrane interface plays a key role. The contact angle depends on membrane-liquid interaction, and therefore different wetting liquids with appropriate hydrophilicity/hydrophobicity characteristics should be used for analyzing different membranes. However, in practice, the choice of liquid is very complicated and risky, as very often the membrane characteristics are not known. Therefore, generally, a more or less standardized liquid, which exhibits both hydrophobic and hydrophilic radicals and thus able to wet reasonably well all kinds of membrane materials, is used. Other desirable features of wetting liquids include low surface tension, low vapor pressure, and low reactivity. Perfluoro halogenated compounds are the most successful liquids that meet such requirements and accordingly most GLDP manufacturers usually supply these liquids (e.g., Porofil ${ }^{\circledR}$, Silwick ${ }^{\circledR}$, Porewick ${ }^{\circledR}$, Galwick ${ }^{\circledR}$, with the latest based on different configurations of Fluorinert ${ }^{\circledR}$ ) to their customers [53]. It should be noted that these liquids pose environmental and health concerns, and therefore they should be properly managed, stored, and disposed.

A plot of airflow downstream of the membrane versus applied pressure is usually called a wet flow curve, as shown in Fig. 3. Most GLDP equipments perform a second run starting from the initial pressure and repeating again all pressure steps. Once more airflow values are recorded, the plot of these new values results in the dry flow curve. From the comparison of the PSD's of both curves, other important related parameters such as porosity, mean pore size, mean flow pore, or estimations of membrane permeability are obtained. A combination of convective flow (Hagen-Poiseuille) and diffusive flow (Knudsen) models are used for converting flow-pressure 
information into the contribution of each pore size to the total permeability [53]. This method is also known as Capillary Flow Porometry [66], Liquid Extrusion Porosimetry [67], or Flow Permporometry [68], but all of them refer to the same procedure. Most equipment use some form of a data-smoothing algorithm for the typically more than 200 pressure steps in a complete analysis to result in approximately Gaussian PSDs.

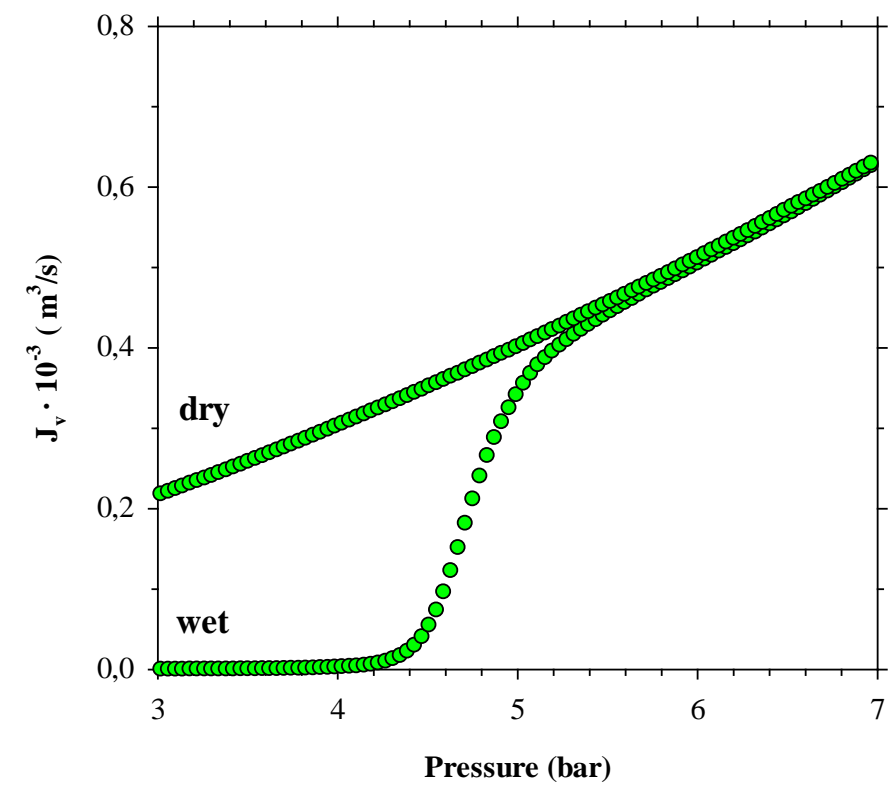

Fig. 3: A representative wet flow curve (modified and redrawn from Ref. [69]).

After the appearance in the market of the automated setups, the GLDP technique has been extensively applied for membrane characterization. Thanks to its capabilities, not only can synthetic membranes be studied through GLDP, but it can also be used to obtain porosity information for many other porous materials, although only information about pores traversing both sample sides (i.e., only pores that contribute to flow) can be obtained. The upper pore size limit can be extended to 200 microns, which makes this method possible to use to characterize all kinds of sieving filters, along with woven and non-woven textiles [4]. Regarding the lower limit of applicability, it depends strongly on the properties of the wetting liquid (namely, both contact angle and surface tension), but for most liquids and commercial porosimeters, the technique can be used down to $50 \mathrm{~nm}$ by using applied pressures of 14 - 15 bar. Some companies offer GLDP porosimeters that are able to measure pore sizes as small as $13 \mathrm{~nm}$, but it is worth noting that pressures as high as 34 bar would be needed, which increases the risk of membrane failure and structure distortion. For such smaller pores (roughly under $50 \mathrm{~nm}$ ), LLDP (which will be detailed in the next section) offers advantages in terms of lower applied pressure and 
accuracy that should make it more practical compared to GLDP. It has been used to obtain PSDs for many research or commercial membranes [70], including flat-sheet [71], nanofibrous [66, 72], and hollow fiber [73] membranes. A number of researchers used GLDP to characterize ceramic membranes, including the maximum pore size of porous $\mathrm{Ti}_{3} \mathrm{SiC}_{2}$ [74], the mean pore size of the $\mathrm{Al}_{2} \mathrm{O}_{3}$ tube substrate coated with pencil lead and carbon membrane [75], and porethroat size [59]. Also, in the literature, some patents related to different applications of GLDP can be found [52, 76]. A recent work by Mourhatch et al. used porometry to determine the PSD of silicon carbides, approximately modeled as a bundle of capillaries [77]. The technique has been also used to study membrane fouling [78-80], accounting for the decrease of mean pore size and shifting of PSD due to foulant deposition inside the pores. As a reference technique for porous membrane characterization, it has been quite often used to evaluate pore size characteristics of membranes compared to different techniques (e.g. HgP, SEM, porometry, image analysis) [68]. Recent papers continue to model the gas flow to increase the accuracy of pore number calculations [81, 82]. As a reliable and robust method for the characterization of MF membranes, fibers, and non-woven textiles, GLDP has become a recommended standard $[83,84]$. The GLDP has been also used to test the accuracy of newly proposed characterization methods due to its recognized reliability [85].

The Liquid Extrusion Porosimetry is a variation of the GLDP technique based on the contact between the sample to be analyzed and a membrane having pores much smaller than the sample, known as a capillary barrier membrane. The sample and capillary barrier membranes are completely immersed in the wetting fluid, and the wetting fluid is extruded from the sample under gas pressure [86].

Jen and Gupta developed the method to be applied for different porous samples for PMI [87]. This setup has been used by Manickam and McCutcheon [67] to study several types of nonwoven MF membranes. The method can be simplified also to determine the Liquid Entry Pressure (LEP)[88], and the PSD of hydrophobic samples [89]. The method has been used recently to determine the capillary pressure (imbibition and drainage curves) for polymer electrolyte membrane fuel cells (PEMFC), which is an important parameter to assess the performance of a fuel cell [90]. IFTS (Institut de la Filtration et des Techniques Séparatives) has designed a commercial setup to accomplish such LEP characterization adapted for the fuel cell. 


\subsubsection{Pros and cons}

The GLDP offers some advantages over other PSD characterization methods, including (i) nondestructive [68]; (ii) as a flow-based PSD technique, it determines the smallest diameter in continuous pores that are open to flow; and (iii) minimal sample preparation, small footprint and simple procedure [9]. On the other hand, drawbacks include: (i) indirect and thereby requires assumption of pore geometry; (ii) limited accuracy in measuring pressure and flow rates; (iii) problematic for low-porosity samples; (iv) PSD compromised by interconnecting pores and affected by choice of wetting liquid [91]; and (v) inability to characterize biofouling layer and difficult to correct for adsorbed t-layer.

A quite common criticism against GLDP and related techniques is that the method cannot distinguish between different inner pore geometries [68], but only determines the narrowest section across the pore (i.e., throat diameter). Certainly, this criticism is true and therefore the technique is limited in properly analyzing inter-connected pores. But this drawback is not as critical for most membranes applications, where pores act as sieves (which is very often the case), and thus the smallest pore cross-section dictates the feed constituents that pass through or get retained by the membrane, consequently determining the performance in terms of separation extent and selectivity. Certainly, for other uses of membranes (not as sieves), as for example membrane contactors, where the inner structure is more important than active layer pores, the researcher could use different membrane characterization techniques that give a better picture of the inner pores. Another important criticism against liquid displacement porometries, raised against both GLDP and LLDP, concerns the assumption of certain geometry to interpret and convert measured data into PSD. Effectively, when using any transport model (Knudsen, Poiseuille, or a combination of both), generally it is assumed that pores are perfect cylindrical capillaries crossing the membrane normally from one side to another. However, the cylindrical geometry is only true for very few test membranes, while more complicated geometries exist for most membranes. This problem has been circumvented sometimes by using different kinds of structural parameters, with a more or less empirical basis, to account for the differences between the actual geometry and the cylindrical one. These issues are similar to the usual criticism attributed to all the Washburn equation-based (which defines the differential capillary fluid flow rate in a cylindrical tube) techniques. To have a clearer idea about the pertinence of such an assumption, some comments are warranted. Notably, pores are often so irregularly shaped that they cannot be considered any sort of tube but are rather tortuous pathways that remain open between the complex structures formed during the membrane manufacturing process. These pathways, along with cross-sections clearly differing from 
circular ones, exhibit significant variability of the diameter so it is almost impossible to mimic any portion of any ideal tube. Since the Laplace equation gives the highest pressure that is needed to intrude the fluid inside the porous structure, the pressure corresponds to the pressure required to pass the narrowest section of the pore. Even for non-tube-shaped pores, the crosssections of some portion of the pore, particularly around the neck, can be considered more or less constant (see Fig. 4). The Washburn equation refers to such cross-sections, and so gives information about the minimum section found inside the pore, which governs the flux and separation potential of that pore.

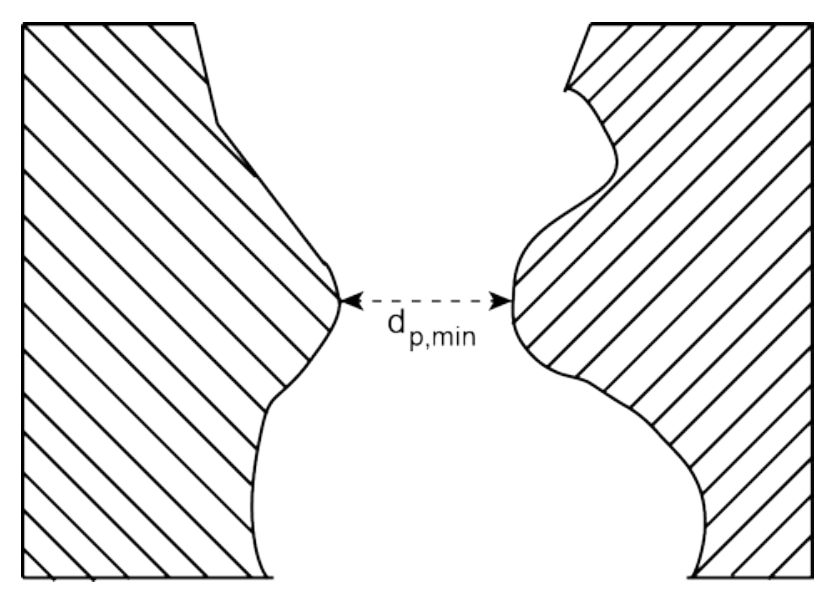

Fig. 4: A simplified cross-sectional view of a non-cylindrical-shaped pore structure.

Regarding the shape of this cross-section, it is expected to be very different from a circular one, such that the Washburn equation again loses validity. Nevertheless, if we consider the original Young-Laplace equation, even an irregularly shaped meniscus should have a curvature that could be defined from the principal curvature radii $\left(R_{1}\right.$ and $\left.R_{2}\right)$. Those radii are related to the dimensions of the cross-section of the pore, with one of them corresponding to the maximum dimension and the other to the minimum dimension found in that section. These could be length and width for a rectangular section or major and minor axes for an ellipsoidal one. When we substitute the complete Young-Laplace equation for a simplified one, we are considering that we move from an irregular shape to a circular one, in such a way that both have the same area. The error made in such approximation can be more or less evaluated. In effect, if $R_{d}$ is between both extreme curvature radii, then we have:

$$
\begin{aligned}
& R_{1} \approx R_{d}-\Delta R \\
& R_{2} \approx R_{d}+\Delta R
\end{aligned}
$$


So, the corresponding term in the precise Young-Laplace equation is:

$$
\frac{1}{R_{1}}+\frac{1}{R_{2}} \approx \frac{1}{R_{d}-\Delta R}+\frac{1}{R_{d}+\Delta R}=\frac{1}{R_{d}}\left(\frac{1}{1-\frac{\Delta R}{R_{d}}}+\frac{1}{1+\frac{\Delta R}{R_{d}}}\right)
$$

where the incremental term, $\Delta R / R_{d}$, could be very small. This expression can be extended as a sum of power factors as follows:

$$
\begin{aligned}
& \frac{1}{1-\frac{\Delta R}{R_{d}}}=1+\frac{\Delta R}{R_{d}}+\frac{1}{2}\left(\frac{\Delta R}{R_{d}}\right)^{2}+\ldots \\
& \frac{1}{1+\frac{\Delta R}{R_{d}}}=1-\frac{\Delta R}{R_{d}}+\frac{1}{2}\left(\frac{\Delta R}{R_{d}}\right)^{2}-\cdots
\end{aligned}
$$

which leads to:

$$
\frac{1}{R_{1}}+\frac{1}{R_{2}} \approx \frac{2}{R_{d}}+\frac{2}{R_{d}}\left(\frac{\Delta R}{R_{d}}\right)^{2}
$$

The second term on the right-hand side can be neglected, supposing that $\left(\Delta R / R_{d}\right)<<1$. This assumption can easily hold true for most of the typical pore geometries, except for slit-shaped pores in which $R_{1}=R_{d}$, and $R_{2} \rightarrow \infty$. So, the Young-Laplace equation becomes:

$$
\Delta p=\frac{\gamma}{R_{d}}
$$

This is the circular geometry that usually assumed, though such pores are not so frequently found. What we are obtaining when using the simplified Laplace equation is a pore size that somehow averages the extreme real dimensions of the actual pores. This can be easily assumed as a convenient standard while leaving to researchers the effort to make more accurate approximations when needed.

An error also stems from converting the directly measured data for each technique (differential flows for both gas-liquid and liquid-liquid porometries, or differential intruded volumes for mercury porosimetry) into PSDs. Usually, the differential distributions experimentally obtained in the commercial devices using each technique are subsequently converted into distributions (relative or absolute) of pore numbers, which requires a suitable model for the pore geometry 
in such a way that each flow or volume is converted into the corresponding number of pores contributing to that differential value. As already mentioned, this step is commonly accomplished by using a capillary pore model for the pores or even considering the CarmanKozeny equation for granular structures or other convenient transport models. There is no need to explain again the errors that this procedure can give, as far as it would convert the technique in question into a model-dependent source of information. In that sense, a reasonable idea, at least for standardization procedures, could be to give these distributions as directly measured values, leaving to the user the interpretation of the actual shape of the pores which can be then easily converted in absolute pore numbers. Correspondingly, most PSDs could be compared directly using both flow and volume differential distributions, giving the range (maximum, minimum and mean pore size) along with the shape of the distribution (skewed, log-normal or Gaussian distributions) for ready comparison among membranes.

Another source of error found in the interpretation of GLDP results is tied to the need to know the actual pore length to calculate the absolute number of pores of each size. This length is usually identified with the membrane thickness for symmetric membranes and active layer thickness for asymmetric ones. In either case, an assumption is made that the pores are normal to the membrane surface with no tortuosity. But the actual thickness is challenging to evaluate (especially for asymmetric membranes), and furthermore the pore length cannot be accurately quantified by filter thickness in view of tortuosity. Recent work has improved data interpretation by determining the tortuosity factor for each pore class in the distribution [92]. Another important point of controversy is associated with the contact angle to be used, which is a difficult-to-evaluate parameter that is not always known for each membrane material and structural configuration.

\subsubsection{Liquid-Liquid Displacement Porosimetry (LLDP)}

After the reasonable success of the GLDP technique, particularly with commercial devices flourishing in the market, the next natural step should have been to extend the technique to lower pore sizes. As commented in the previous section, the typical lower size range of GLDPbased porometers is approximately $50 \mathrm{~nm}$, which restricts the application to MF membranes or very open UF ones. For analyzing membranes with pores smaller than $50 \mathrm{~nm}$ (as usually found in typical UF or NF membranes), the air-liquid interface requires high pressure that would impact the membrane structure. To this end, Liquid-Liquid Displacement Porosimetry (LLDP) circumvents the drawback by making use of a liquid-liquid interface (rather than a gas-liquid interface) inside the pores. 


\subsubsection{Model}

Since the transport mechanisms of liquids and gases are not the same, the approaches used to convert GLDP data into PSD are not valid for LLDP and must be adapted to account for the liquid transport features. In fact, the liquid transport, being convective at the pressure conditions used, needs only a simple Hagen-Poiseuille model for convective transport inside capillary tubes in most cases. Two different approaches to making such conversion can be used, both leading to similar results. The first one is based on a graphical (or numerical) calculation of the successive permeability increments, after which the Hagen-Poiseuille model is used to determine the number of pores needed to get such permeability increment as the liquids in the bigger pores are displaced [93-95]. The second involves a differential method for continuous calculation that can be also adapted for a group of discrete data points [96]. Both methods lead to similar results as both make use of convective transport modeling. It is clear that LLDP shows many similarities with GLDP, with similar advantages and drawbacks. Recall that the only difference between the two techniques is the use of a gas-liquid-solid versus a liquid-liquidsolid interface, the latter of which results in a reduction of the surface tension of the corresponding interface. As a result, the size of the pores that can be detected at reasonable pressures is much smaller for the LLDP relative to the GLDP.

The LLDP uses two immiscible liquids to perform the porosimetric analysis. Between the two liquids, the one with a higher affinity with the membrane material is normally employed to wet the membrane (named as the wetting liquid, whose key role is to get the most complete possible wetting of the membrane by filling all the pores), while the other liquid (namely, the displacing liquid) with lower affinity displaces the wetting one. It is possible for the roles of these liquids to be switched depending on membrane characteristics [97]. The pore size of the membrane is calculated based on the applied pressure, which is a function of the interfacial tension between the two liquids. In this method, it is assumed that the pores are cylindrical and distributed nonuniformly. The pressure, $\Delta P$, to be applied to push the displacing liquid inside a pore of a given size, which is filled by the wetting liquid, can be described by the Young-Laplace equation [9] (see Eqs. (1) to (3)). The mechanism of displacement is determined by the actual pressure, the liquid surface tension, and the pore size, while the value of contact angle $\theta$ is considered to be zero based on the assumption that the membranes are completely wetted by the wetting liquid [97]. Similar to what happens at the gas-liquid interface, the displacement phase will not be expelled from any pore if the applied pressure is insufficient to override the interface surface tension for the biggest pore (more specifically, the narrowest section of the widest pore) present in the membrane. As shown in the case of $\Delta P<\Delta P_{\text {th }}$ in Fig. 5a, where $\Delta P_{\text {th }}$ is the threshold 
pressure (or the bubble point per GLDP nomenclature, even though in this case there is no bubble appearing across the membrane, but instead drops of the displacing liquid surrounded by the wetting one and normally indistinguishable from each other), the displacing liquid is unable to displace the wetting liquid from the pores. When the pressure is increased to $\Delta P_{t h}$ (Fig. 5b), the displacing phase can overcome the minimum surface tension and start to penetrate through the membrane (i.e., expel the wetting phase) via the largest pores $\left(d_{\max }\right)$. At this pressure, the flux of the permeating liquid permeating through the pore with radius $r_{\text {th }}$ will be $J_{t h}$. The pore with radius $r<r_{t h}$ will be permeated by the displacing liquid only if $\Delta P>\Delta P_{t h}$ (Fig. 5c) and any further pressure increase will give a proportional increase of the flux across the membrane.

a)

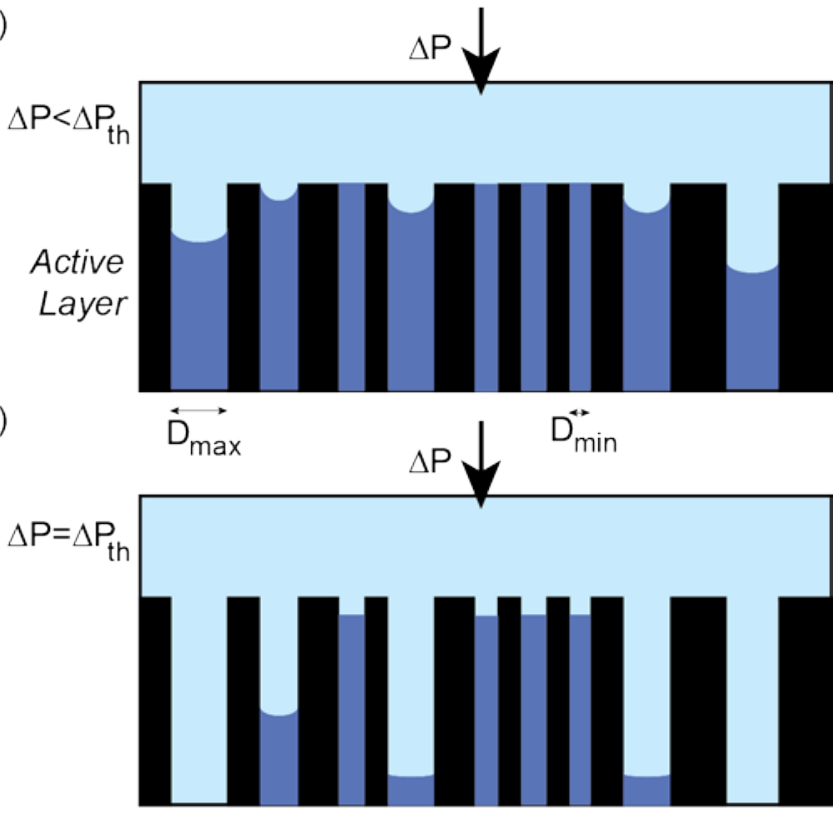

c)

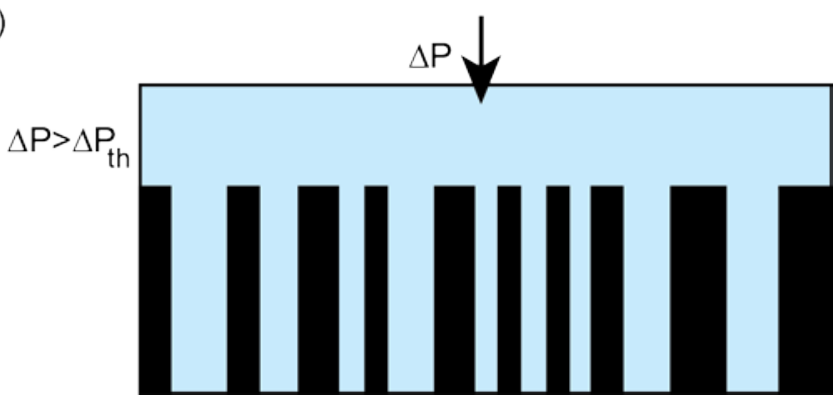

Fig.5: The gas-liquid interface for different membrane pore sizes at different pressures $(\triangle P)$ : (a) $\Delta P<\Delta P_{\text {th }}$ (b) $\Delta P=\Delta P_{\text {th }}$, and (c) $\Delta P>\Delta P_{\text {th }}$ [97]. $\Delta P_{\text {th }}$ is the threshold pressure, or the bubble point per GLDP nomenclature, even though in this case there is no bubble appearing across the membrane, but instead drops of the displacing liquid surrounded by the wetting one and normally indistinguishable from each other.

For each increasing pressure step, the corresponding flux $\left(J_{t h}\right)$ is measured to obtain the curve 
of flux versus pressure (Fig. 6), and thereby pore radius $r_{\text {th }}$ values represented by the permeability of the membrane (i.e., flow:pressure ratio) are obtained [9]. Therefore, by measuring the equilibrium pressure drop corresponding to each increment of flux, a PSD of the membrane can be evaluated in terms of the contribution of each pore size with liquid displaced to the whole membrane permeability (often termed as asymptotic permeability, which corresponds the point at which all the pores are emptied of the wetting liquid). We can calculate the contribution of each pressure-flow step in the permeability distribution, and eventually the pore number distribution from the threshold step until asymptotic permeability $(t h=1, \ldots, k$ ) (Fig. 6) ). It is common to assume that the geometry assumption is not so restrictive, since many pore geometries can be simplified to a bunch of more or less cylindrical pores [98] having a radius equal to the narrowest section of the actual pores found in the membrane matrix.

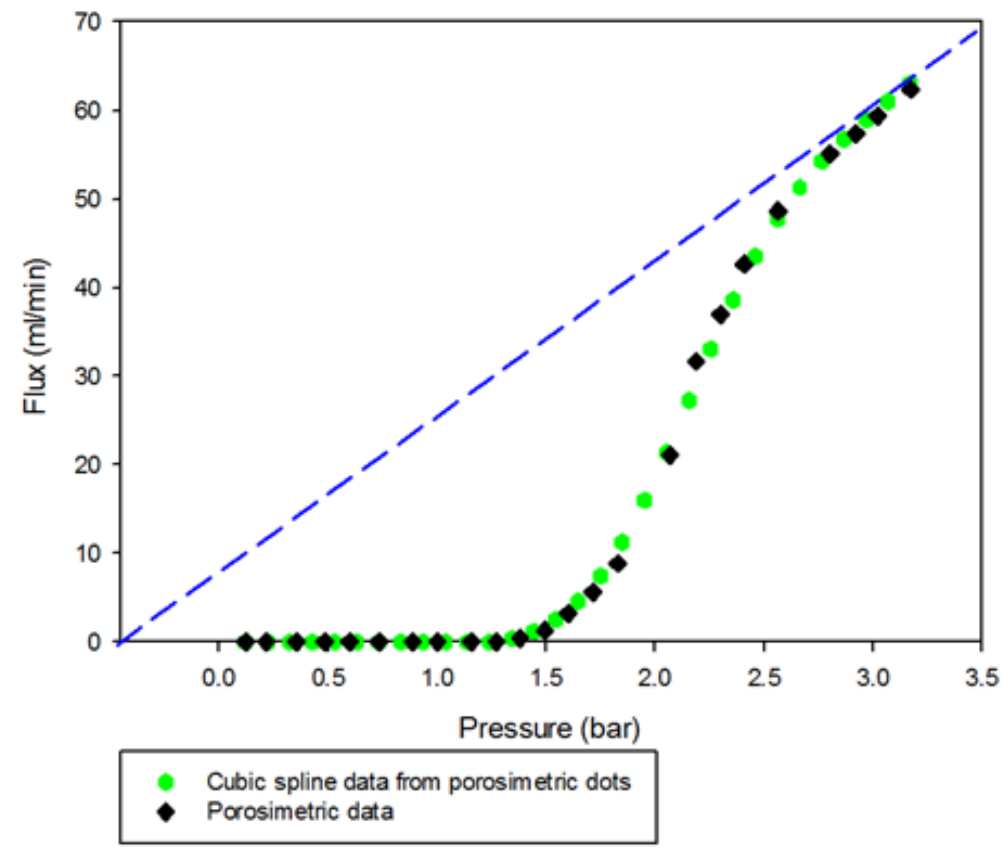

Fig. 6: A representative pressure vs flux curve[9].

With micro-sized pores, the laminar flow should prevail and hence the water flow rate $Q_{t h}$ drained from $d_{\max }$ can be described by Darcy's law:

$$
J_{t h}=\frac{k_{t h} A_{t h} \Delta P_{t h}}{\eta l}
$$

where $k_{t h}$ is the intrinsic permeability coefficient of the displacing liquid at $d_{\max }, A_{t h}$ is the total area of the largest pores, $\eta$ is the dynamic viscosity of the displacing fluid and $l$ the pore length (which corresponds to the active layer thickness) [99]. For convective transport of liquids (see 
Fig. 5), the Hagen-Poiseuille model for the flow-through capillary pores can be used to derive the PSD:

$$
J_{k}=\frac{N_{k} \pi r_{k}^{4} P_{k}}{8 \eta l}
$$

where $r_{k}$ is the pore diameter of the pores with liquids displaced in the $k^{\text {th }}$ step. For each increasing pressure step, $\Delta P_{k}$, a corresponding volumetric flow, $J_{k}$, was measured.

The algorithm developed by Grabar and Nikitine [96] is essentially a differential algorithm, which requires the continuous curve of permeability variation for derivation. In this case, to directly use the obtained experimental data, the following equation is employed:

$$
N_{k}(d)=\frac{8 \eta l}{\pi r_{k}^{5}} \Delta L_{k}
$$

where $N_{k}$ represents the number of pores of radius $r_{k}$, i.e., in the $k^{\text {th }}$ class per unit membrane surface; $\Delta L_{k}$ is the ratio of successive flow and pressure increments between two experimental consecutive points (i.e., $\left.\Delta L_{k}=\left(J_{k},-J_{k-1}\right) /\left(\Delta p_{i}-\Delta p_{i}-1\right)\right)$; and $L_{k}$ corresponds to the $k^{\text {th }}$ experimental permeability (i.e., $L_{k}=J_{k} / \Delta p_{k}$ ). $\Delta L_{k}$ and $L_{k}$ represent the porosimetric curve slope at the specific point, and the straight-line slope passing from this point to the origin, respectively. Eqs. (3) and (30) are the fundamental basis of LLDP, from which further analysis can be performed to better understand the internal structure of the membrane [100].

\subsubsection{Commercial Equipment}

The fluid displacement techniques have been considered, for years, as very promising solutions, because of advantages including non-destructive, very quick and reveal only pores that allow through flux (i.e., the only ones contributing to membrane permeation). It represented for many years the most reliable method to characterize PSD in the UF range. Nevertheless, LLDP has not found wider utility due to the lack of effective commercial devices available in the market. The available ones include the LLP 1100A (PMI), Poroliq 1000 series (Porometer) and FFP PRM-8410 (IFTS). Due to limited availability, most researchers interested in using LLDP have to develop their own laboratory-based equipment designed and fabricated in-house. Among the dominant researchers focussed on LLDP, some are co-authors on the present review [6, 101107]. Also, the group in Genoa, with which some of the authors developed a long-term collaboration, were very active on LLDP for many years [108-112].

These porosimeters used in LLDP analysis consist of an automated device developed in the laboratories of the Group of Surfaces and Porous Materials, SMAP, of the University of Valladolid and the group of Membrane Processes and Membrane Technology, MP\&TM, of the department Chemistry and Industrial Chemistry of the University of Genoa. Both porometers 
are completely automatized based on the VEE laboratory software [107], which includes software-controlled operation, data acquisition and data treatment running on the LabVIEW® platform. A detailed description of the equipment Fig. 7 and experimental procedure can be found elsewhere [97]. The main feature of the equipment is the use of a precise syringe pump (ISCO-500D), allowing accurate and very stable fluxes through a dead-end membrane cell without fluctuations, and thus negating the need for any sort of dampening.

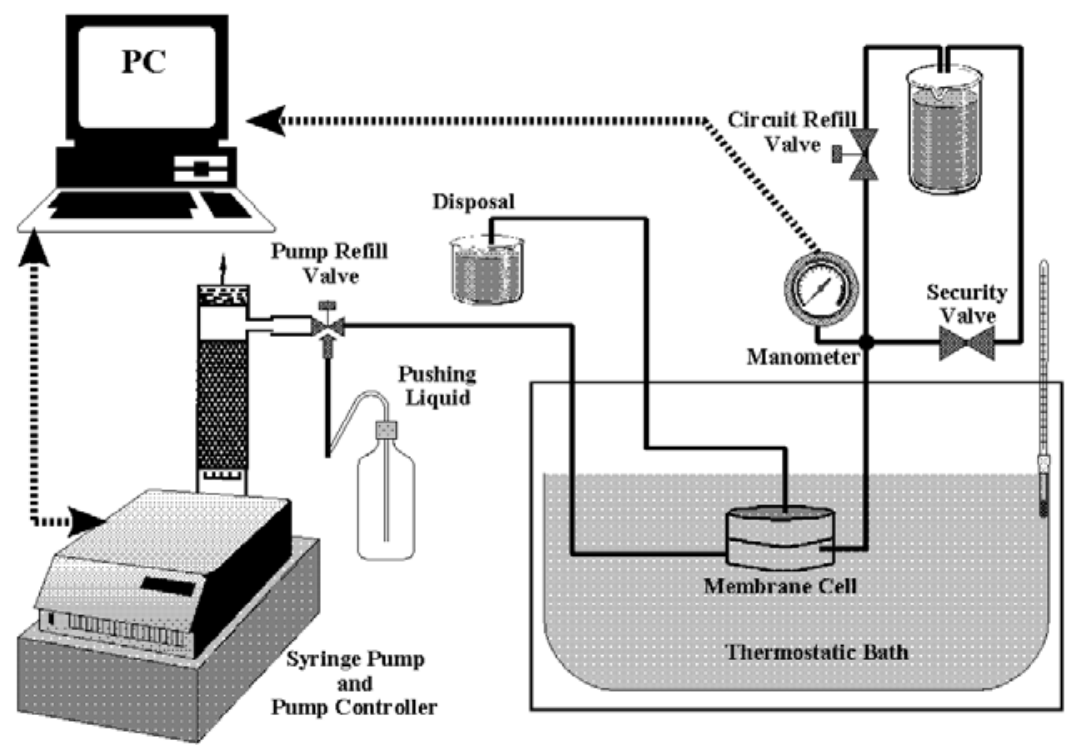

Fig. 7: Schematic diagram of the LLDP dispositive from SMAP and MP\&TM groups [97].

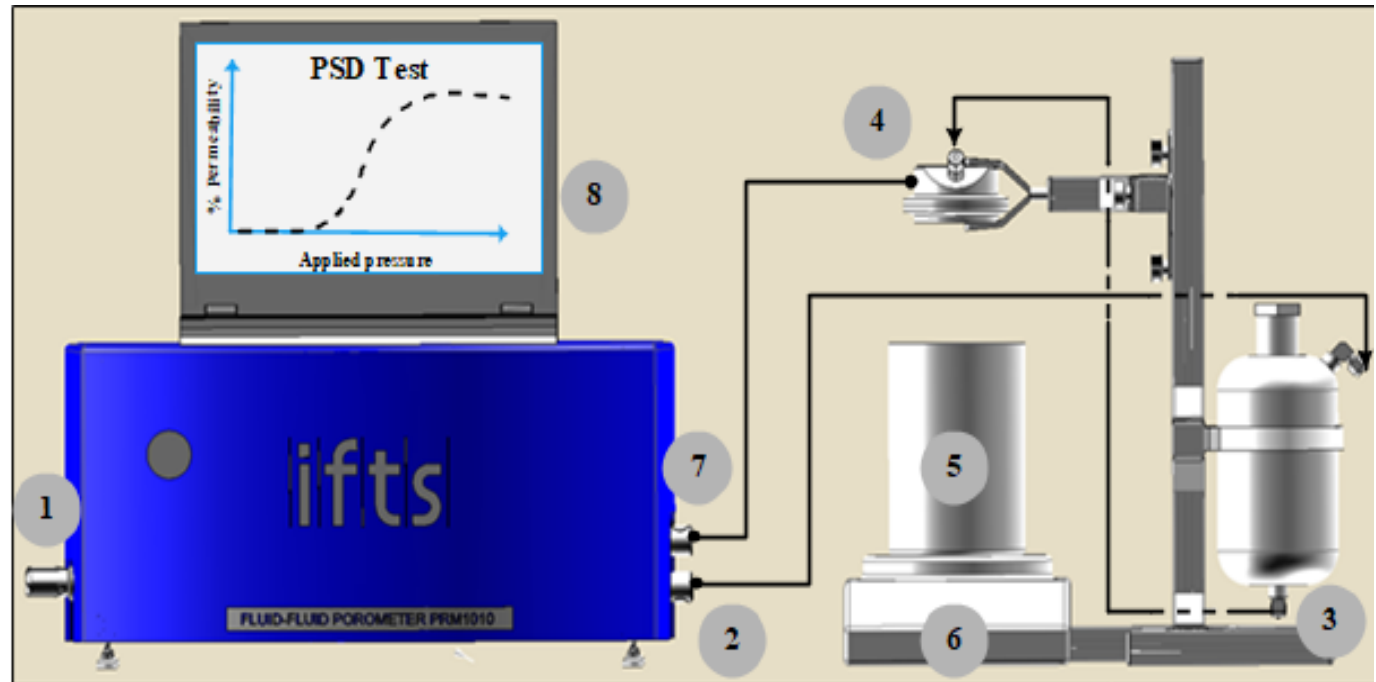

Fig. 8: Schematic diagram of the IFTS porometer : (1) Air supply; (2) Air pressure tank; (3) Feed line; (4) Membrane housing cell; (5) Disposal; (6) Analytical balance; (7) Retention line (pressure sensor); (8) IFTS LLDP software [9]. 
Another research setup is that from IFTS, which is based on an early patent by Thierry Courtois [111] and nowadays also marketed. One of the key features is an automated and commercialized pressure-constant device developed by IFTS (Fig. 8), allowing liquid permeation through polymeric membranes at a very accurate and stable pressure, and thereby enabling the detection of pore sizes as small as $2 \mathrm{~nm}$ in the characterization of porous membranes. The fluxes are measured using an analytical balance (Sartorius, Practum; resolution of $1 \mathrm{mg}$ ). This LLDPbased porometer is able to measure several structural and functional parameters of porous materials (including hollow fibers, tubular and flat sheet membranes), namely, mean pore diameter, PSD, solvent permeability, and droplet point.

\subsubsection{Pros and cons}

The advantages of LLDP are mostly common to GLDP: (i) LLDP only accounts for pores open to flux and test membranes in wet state, so reflects more closely the practical operation, such as MF, UF or NF; (ii) GLDP and LLDP cover most of the range of pore sizes usually found in synthetic membranes, with LLDP further able to analyze smaller pores in the nanometer range [110]; (iii) depending on membrane pore size and swelling propensity, different pairs of immiscible wetting liquid - displacing liquid pairs (Table 2) can be judiciously selected to give the best possible results [97]; (iv) LLDP allows for measuring of membranes of different types, including flat-sheet, tubular, or hollow fibers; (v) LLDP gives the complete PSD information in very reasonable times ( $1 \mathrm{~h}$ in most cases); and (vi) the capability to evaluate the active pores in the nanometer and subnanometer range makes it a convenient method to establish a standard. On the contrary, some drawbacks should be mentioned: (i) the assumption of cylindrical, parallel pores in the underlying Young-Laplace and Hagen-Poiseuille transport is not valid for most practical polymeric membranes; (ii) limited accuracy in measuring low flow rates; (iii) the selection of the best wetting liquid - displacing liquid pair is not straightforward; (iv) problematic membrane swelling when using wetting alcoholic mixtures; (v) inability to characterize biofouling layer and difficult to correct for adsorbed t-layer; (vi) the LLDP procedure needs careful sample preparation and analysis operation, which could easily lead to non-reproducible or inconsistent results if not properly carried out.

More specifically, LLDP is clearly sensitive to interactions between the membrane and the liquid pairs. Several liquid pairs (wetting-displacing fluids) can be selected to perform LLDP analysis (with the key ones listed in Table 2), with the selection based on expected values of membrane porosity and pore size range [9]. Liquid pairs, which have very low mutual interfacial tension and are completely (or at least almost completely) immiscible, are very 
suitable for testing membranes having pore sizes in the nanometer range, since these pores can be intruded by the displacing liquid at very low pressures that do not alter the membrane structure. For example, when analyzing a UF membrane having most of the pores below 50 nanometers, the isobutanol/water mixture (with a surface tension value of around $1.7 \mathrm{mN} / \mathrm{m}$ ) is a reasonable and quite common selection. According to the Cantor equation (Eq. (3) with $\cos \theta=1$, since $\theta=0^{\circ}$ for perfect wetting), the wetting liquid which fills a pore with radius of $0.034 \mu \mathrm{m}$ can be expelled by applying to the displacing liquid a pressure of 1 bar. Such a low pressure is beneficial, because it assures negligible membrane compaction, which represents an important source of error in LLDP measurements [73].

The membrane swelling and compaction (affecting especially the skin layer) phenomena during testing may markedly alter the permeation through the pore, and thus lead to unreliable results. Membranes are prone to swell when the porous material (very often polymeric) is in contact with organic solvents, and membrane compaction is an inevitable possibility at high testing pressures [113]. This effect could significantly affect the proper determination of the actual PSD of the membrane, which would affect the selection of appropriate membranes for effective separation.

Table 2: Main characteristics and composition of liquid pairs used in LLDP measurements.

\begin{tabular}{|c|c|c|c|c|}
\hline Study & Liquid pair & $\begin{array}{c}\text { Composition } \\
\text { (v/v) }\end{array}$ & $\begin{array}{c}\text { Interfacial } \\
\text { tension } \\
(\mathbf{m N} / \mathbf{m})\end{array}$ & $\begin{array}{c}\text { Temperature } \\
\left({ }^{\circ} \mathrm{C}\right)\end{array}$ \\
\hline $\begin{array}{l}\text { Grabar and Nikitine } \\
\text { [96] }\end{array}$ & water/isobutanol/methanol & $25 / 15 / 7$ & 0.35 & $18.7-24$ \\
\hline $\begin{array}{l}\text { Grabar and Nikitine } \\
\text { [96] }\end{array}$ & water/isobutanol/methanol & $5 / 4 / 1$ & 0.80 & $20-23$ \\
\hline Peinador et al. [114] & water/isobutanol/isopropanol & $50 / 35 / 15$ & 0.45 & $20-25$ \\
\hline Peinador et al. [114] & water/isobutanol/isopropanol & $5 / 4 / 1$ & 0.9 & $20-25$ \\
\hline $\begin{array}{l}\text { Grabar and Nikitine } \\
\text { [96] }\end{array}$ & water/isobutanol & $1 / 1$ & 2.2 & $18.7-21$ \\
\hline Calvo et al. [105] & water/isobutanol & $1 / 1$ & 2.0 & 25 \\
\hline Calvo et al. [105] & water/pentanol & $1 / 1$ & 4.80 & 25 \\
\hline Calvo et al. [105] & water/octanol & $1 / 1$ & 8.50 & 25 \\
\hline $\begin{array}{l}\text { Phillips and DiLeo } \\
\text { [115] }\end{array}$ & $\begin{array}{l}\text { CorrTest } @ \text { water/PEG 8000/ } \\
\left(\mathrm{NH}_{4}\right)_{2} \mathrm{SO}_{4}\end{array}$ & Not defined & $\sim 0.6$ & $20-25$ \\
\hline Peinador et al. [114] & water/PEG 1000/ $\mathrm{MgSO}_{4}$ & $\begin{array}{l}69 / 19 / 12 \\
\text { (mass \%) }\end{array}$ & 0.40 & $20-25$ \\
\hline Peinador et al. [114] & FC-43C/Isobutanol & $1 / 5$ & 4.8 & $20-25$ \\
\hline
\end{tabular}




\subsubsection{Choice of liquid pairs}

One of the earliest LLDP studies was performed by Erbe [61], in which two possibilities were explored: (i) using the initial air-water interface proposed by Bechhold [48], and (ii) a mixture of two immiscible liquids (namely, water and isobutyl alcohol, which was proposed by Bechhold to have a surface tension of 1,73 dyne/cm). Erbe reduced the pressure needed to analyze the original Bechhold bubble point for ultrafilters, thereby extending the method to reveal the whole membrane PSD. Concerning the use of alcoholic mixtures in water (Table 2), Germic et al. [116] pointed out the possible problems of membrane swelling due to the adsorption of alcohol inside the membrane matrix.

To circumvent the issue, Phillips and DiLeo [115] proposed a liquid porosimetric CorrTest ${ }^{\mathrm{TM}}$ based on prior wetting, as further developed by Millipore. They used two immiscible phases formed upon mixing polyethylene glycol 8000 (PEG-8000), ammonium sulfate, and water in specific mass proportions. The resulting PEG-rich phase and ammonium sulfate-rich phase corresponded to the wetting and intrusion fluids respectively. This biphasic systems formed by mixing two polymers, or a polymer and a salt, in water is known as aqueous two-phase systems (ATPS) [117]. Normally, it involves the preparation of the stock solutions of all the phase components, which are then mixed in appropriate amounts (by weight), and then the emulsion is allowed to separate into two phases under gravity or in a centrifuge after complete phase separation is achieved [118]. ATPS can be used not only for the separation of cells, membranes, viruses, proteins, nucleic acids and other biomolecules but also reduce droplet point pressure and incur no swelling for LLDP. The interfacial tension between the two aqueous phases plays a major role in the interfacial tension, which can be $3-4$ orders of magnitude smaller than conventional gas-liquid systems, for example, $<0.5 \mathrm{mN} / \mathrm{m}$ for ATPS compared to $\sim 72 \mathrm{mN} / \mathrm{m}$ for the air-water interface. The ultra-low surface tension of the ATPS mixture strongly depends on the phase diagram of ATPS [119-123] and also the molecular weight of the polymer.

Accordingly, we propose two immiscible fluids targeted at reducing polymer swelling, gives very low interfacial tension, and also good chemical compatibility with the LLDP components (i.e., avoid corrosion or degradation) and membrane, and have the properties of a Newtonian liquid with low displacement viscosity and low vapor pressure. To this end, mixtures of polyethylene glycol 1000 (PEG-1000), magnesium sulfate anhydrous, and water in specific mass proportions are promising in meeting all these requirements. In order to determine the interfacial tension, the spinning drop technique [118, 120] was used for different mixtures of polyethylene glycol (PEG) and magnesium sulfate. Specifically, the spinning drop tensiometer technique allows for measuring the interfacial tension between two liquid phases by analyzing 
the dimensions of a drop in a rotating capillary by the Vonnegut method [124, 125], and is a precise and simple measurement to determine extremely low interfacial tensions. Interfacial tension values for the ATPS samples of PEG1000 / $\mathrm{MgSO}_{4} / \mathrm{H}_{2} \mathrm{O}$ at several mass proportions have been found to range from 0.1 to $1 \mathrm{mN} / \mathrm{m}$, and the density difference between the two phases vary between 30 to $60 \mathrm{~g} / \mathrm{cm}^{3}$ at the temperature of $22{ }^{\circ} \mathrm{C}$. Fig. 9 shows the difference between the pressure versus flow curves generated by LLDP for the same sample (namely, Whatman-Anopore $0.02 \mu \mathrm{m}$ inorganic membrane) but using different liquid pairs. Specifically, the typical S-shaped curves, which end with a maximum slope (asymptotic permeability), are obtained when the wetting liquids in the consecutive pores of the membranes between the maximum pore size $d_{\max }$ (“droplet” point) and minimum pore size $d_{\min }$ are expelled by the flow of the displacing liquid. Clearly, the ATPS curve is leftwards of the isobutanol-water one, indicating lower pressures attributed to the lower surface tension. IFTS has successfully used ATPS in LLDP for both polymeric and inorganic membranes. More efforts need to be dedicated to the properties of interesting ternary mixtures, which would allow for the analysis of smaller pores, are less volatile and not so prone to have significant changes in composition during the test.

Particularly for the PES membrane, which is known to swell in isobutanol/water/methanol mixtures [113], measurements were conducted using an ATPS mixture that mitigated the swelling of the active layer $[115,126]$. The use of these fluids has several advantages compared to conventional alcohol-water two/three-phase systems typically employed for the pore-size characterization of ultrafiltration membranes. Firstly, both phases are aqueous, so the tendency for membranes to preferentially swell when in contact with one of the fluids is minimized. Secondly, both the PEG and ammonium sulfate are highly soluble in water, which greatly facilitates the flush-out of the compounds from the membrane structure after testing. ATPS mixtures also present some drawbacks: (i) they only work with hydrophilic membranes but not hydrophobic ones; and (ii) they have viscosities several times higher than water ( $1 \mathrm{cp}$ ), so the permeability has to be low to characterize the smaller pores reproducibly. 


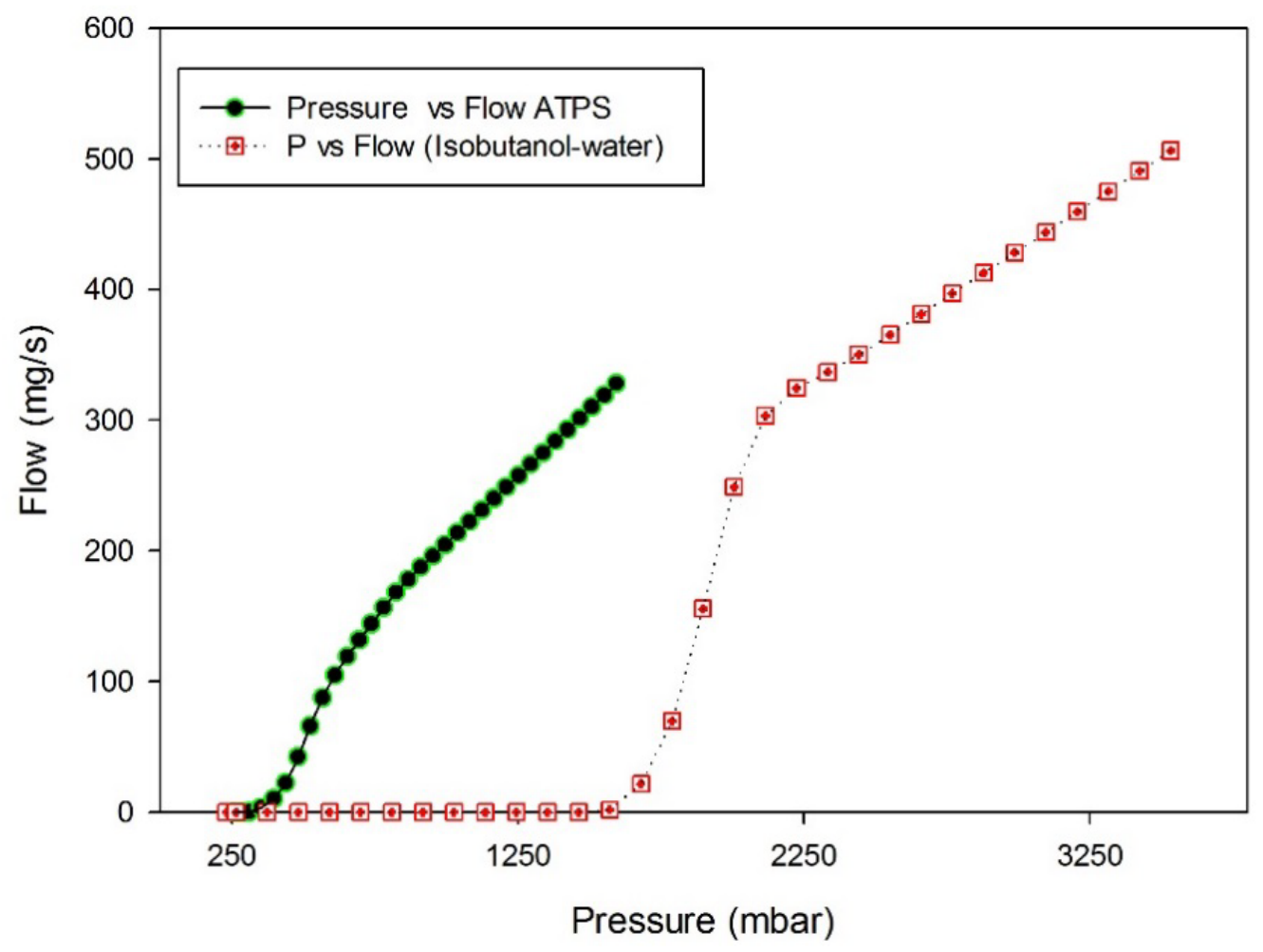

Fig. 9: Pressure vs flow curves for ATPS (PEG 1000/MgSO4/water) and isobutanol-water liquid couples for a Whatman-Anopore 0.02 um inorganic membrane [114].

\subsubsection{Comparison of LLDP results}

Table 3 summarizes the LLDP studies on pore size characterization. LLDP has demonstrated accuracy and reproducibility in the characterization of several commercial track-etched polycarbonate ultrafiltration (UF) membranes, giving a comprehensive picture of the membrane structure within hours [6]. Comparison with computerized image analysis of SEM (SEM-CIA) shows good agreement with respect to the mean pore radius, with LLDP giving $23.6 \mathrm{~nm}$ and SEM-CIA $24.0 \mathrm{~nm}$. On the other hand, not so satisfactory agreements have been obtained for porosity (averages of 1.4 and 2.1\% for LLDP and SEM-CIA, respectively) and total number of pores (i.e., LLDP gave $19.6 \times 10^{12}$ pores $/ \mathrm{m}^{2}$ and SEM-CIA gave $11.1 \times 10^{12}$ pores $/ \mathrm{m}^{2}$ ), primarily due to the uncertainties in the estimation of the active layer thickness in LLDP.

The same LLDP device was used to characterize two series of polymeric flat-sheet membranes made from PES and regenerated cellulose (NC) [97]. The results indicate agreement among different runs, and also very good agreement among different liquid mixtures. The LLDP results were compared with those from Nuclear Magnetic Porosimetry (NMR), which is a much more 
laborious and indirect method that reflects all the pores or voids present within the membranes including those not open to flux. The fair agreement should mean that similar PSDs are present within both open and closed pores. While the PES membranes were wetted with the isobutanolrich phase without any impact on the membrane structure, the NC membrane samples were strongly affected by the isobutanol phase that caused the active layer to be totally detached from the support, and thereby the ternary mixture of isobutanol/methanol/water was used for the NC samples. The possibility to choose among different liquid mixtures, and also to select the role that both liquids play in the porosimetric analysis is a great advantage. This allows for a choice among diverse degrees of hydrophilicity/hydrophobicity and corresponding surface tension to assure a proper wetting of the membrane pores without damaging the membrane structure, and thereby facilitates the analysis of many different membranes made of different materials. Another interesting study was performed related to the characterization of virus retention membranes, which indicate that the maximum pore size obtained by LLDP distributions can be correlated with key performance parameters like the bacteriophage log retention value (LRV) or dextran test cut-off values $[107,126]$. The correlation was found to be better when using the maximum pore size instead of minimum or mean pore sizes. This allows for predictive capability of the retention capabilities of a given membrane, without the necessity for timeconsuming and expensive retention, which is especially advantageous because it negates the need to work with active viruses or bacteriophages.

During the development of appropriate membranes, possible candidates have to be selected. Currently, this is done on the basis of results obtained in a battery of time-consuming and expensive solvent retention tests. Instead of those, LLDP could be used, at least for a first approach, to select the most appropriate candidates on which to perform complete characterizations [105]. This can significantly reduce the number of tests and the cost of characterization experiments. Also, the good correlation between LLDP maximum pore sizes and the other pore size tests suggests LLDP as a promising method for the rapid detection of maximum pore sizes, which eliminates the necessity for expensive and time-consuming solute retention tests for membrane manufacturers and $R \& D$ institutions.

Retention experiments, in spite of being the default procedure for membrane selection, are still not fully standardized, with different rigs and experimental procedures in different industrial or research labs giving significantly variable results. The comparison of PSDs obtained from LLDP techniques suggests that the PSD strongly correlates with retention capabilities and performance of the membrane, making LLDP a fast and reliable way to estimate the MWCO of the analyzed membranes. The preferred technique [105] can be standardized to make it an 
accurate and convenient way to asses possible applications for inorganic or polymeric samples without the necessity to perform complicated and time-consuming retention experiments. This approach is not intended to substitute retention tests as definitive characterization methods for manufacturers deciding the application of their membranes. On the contrary, LLDP can help to choose better candidates for selected applications among those developed in the research labs, and then the retention test of the real effluents to be separated performed on the shortlisted membrane candidates to validate LLDP estimations, thereby saving many expensive experiments.

Table 3: Summary of LLDP results.

\begin{tabular}{|c|c|c|c|}
\hline Study & $\begin{array}{l}\text { Membrane } \quad \text { Type } \\
\text { and Nominal pores } \\
\text { size / MWCO }\end{array}$ & $\begin{array}{l}\text { PSD measured / } \\
\text { MWCO }\end{array}$ & $\begin{array}{l}\text { Wetting/ } \\
\text { Displacement liquid }\end{array}$ \\
\hline Calvo et al. [6] & PC $0.05 \mu \mathrm{m}$ & $20-80 \mathrm{~nm} /$ not tested & $\begin{array}{l}\text { Water-rich phase / } \\
\text { İsobutanol-rich } \\
\text { phase }\end{array}$ \\
\hline Peinador et al. [97] & $\begin{array}{l}\text { PES, RC 5, } 10 \text { and } 30 \\
\text { kDa }\end{array}$ & $\begin{array}{l}10-50 \mathrm{~nm} / \\
\mathrm{kDa}\end{array}$ & $\begin{array}{l}\text { Water-rich phase/ } \\
\text { Methanol- } \\
\text { Isobutanol-rich } \\
\text { phase and } \\
\text { Isobutanol-rich } \\
\text { phase / Water-rich } \\
\text { phase }\end{array}$ \\
\hline Calvo et al. [104] & PS $20 \mathrm{kDa}$ & 4-20 nm / 1-50 kDa & $\begin{array}{l}\text { Water-rich phase / } \\
\text { İsobutanol-rich } \\
\text { phase }\end{array}$ \\
\hline Peinador et al. [107] & $\begin{array}{l}\text { PES (Virus } \\
\text { retention)/ No data }\end{array}$ & 5-50 nm / 100kDa & $\begin{array}{l}\text { İsobutanol-rich } \\
\text { phase / Water-rich } \\
\text { phase }\end{array}$ \\
\hline Giglia et al. [126] & $\begin{array}{l}\text { PES (Virus } \\
\text { retention)/ No data }\end{array}$ & $\begin{array}{l}\text { 5-50 nm / Not } \\
\text { defined }\end{array}$ & $\begin{array}{l}\text { Water-PEG } 8000- \\
\text { rich phase / Water- } \\
\text { ammonium sulfate- } \\
\text { rich phase. }\end{array}$ \\
\hline Calvo et al. [105] & $\begin{array}{l}\text { PES, PS, RC, } \\
\text { Zirconium oxide 5- } \\
300 \mathrm{kDa}\end{array}$ & 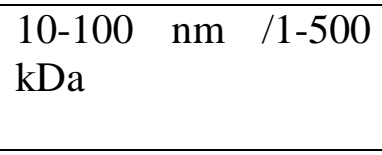 & $\begin{array}{l}\text { Water-rich phase / } \\
\text { İsobutanol-rich } \\
\text { phase }\end{array}$ \\
\hline $\begin{array}{l}\text { Tanis-Kanbur et al. } \\
\text { [9] }\end{array}$ & $\begin{array}{l}\text { Aluminum oxide } 100 \\
\text { nm, PES 300KDa, } \\
\text { PET no data, PTFE } \\
\text { no data, PVDF } \\
\text { 100kDa and Nylon } \\
\text { no data }\end{array}$ & $\begin{array}{l}\text { 80-150 nm for } \\
\text { Aluminum oxide, 20- } \\
70 \mathrm{~nm} \text { for PES, 15-40 } \\
\mathrm{nm} \text { for PET, 60-90 } \\
\text { for PTFE, 40-140 nm } \\
\text { for PVDF and 50-80 } \\
\text { nm for Nylon / 350- } \\
1460 \mathrm{kDa}\end{array}$ & $\begin{array}{l}\text { Water-rich phase/ } \\
\text { Isobutanol-rich } \\
\text { phase and vice-versa. }\end{array}$ \\
\hline
\end{tabular}




\subsection{Mercury Intrusion Porosimetry (HgP)}

\subsubsection{Model}

Mercury intrusion porosimetry (HgP) isamong the characterization methods that are based on the Young-Laplace equation. The main difference with the other two Young-Laplace based techniques (namely, GLDP and LLDP) is that, in this case, it is mercury (i.e., a non-wetting liquid) that is forced to enter the pores. The pressure necessary to overcome the interfacial forces can be related to the characteristic radius of each pore by using the previously elucidated Young-Laplace equation (in the form presented in Eq. (3)) and the corresponding contact angle [127, 128]. This equation, when used for HgP, is usually named the Washburn equation [129]. Since contact angles greater than $90^{\circ}$ (i.e., non-wetting fluids) lead to negative values of $\cos \theta$, the application of Eq. (3) results in negative pressure values. The meaning of this sign simply reflects the fact that mercury, a non-wetting liquid, needs to be forced into the pores.

Experimentally, the setup consists of a pressurized cell containing an adequate amount of the sample to be evaluated. By a stepped increase of applied pressure, mercury is forced to enter all the pores present in the membrane, and the amount of mercury intruded in the system is calculated through measurements of cell conductivity. The plot of intruded volume (more specifically, the differential increment of specific volume) versus applied pressure is usually embedded in a program and contains all information needed to obtain the PSD of the sample. Normally, HgP runs include a complete intrusion-extrusion cycle. In the extrusion part of the cycle, the previously intruded mercury is ejected from the sample during the depressurization step. All programs, irrespective of their highly variable shape that is dependant on the characteristics of the sample, present two common features, namely, some hysteresis and certain pore entrapment (e.g., dead-ended pores) [9].Usually, only intrusion curve data are used to get PSD, but both curves can be converted into number of pores. The differential distribution of specific intruded volumes is given by:

$$
D_{v}\left(d_{p}\right)=\frac{p}{d_{p}} \frac{d V}{d p}
$$

where $p$ is the applied pressure, $d_{p}$ is the corresponding pore diameter according to the YoungLaplace equation, $V$ corresponds to the specific volume (volume of mercury divided by sample weight) and $d V / d p$ is the derivative of specific intruded volume versus pressure. From this distribution the relative population of the pore in each class can be obtained as follows:

$$
n_{d}(j)=\frac{\frac{D_{v}\left(d_{p}\right)-\left[d_{p}(j)-d_{p}(j-1)\right]}{\left\{\left[d_{p}(j)-d_{p}(j-1)\right] / 2\right\}}}{\sum_{i=1}^{n}\left(\frac{D_{v}\left(d_{p}\right)-\left[d_{p}(j)-d_{p}(j-1)\right]}{\left\{\left[d_{p}(j)-d_{p}(j-1)\right] / 2\right\}^{2}}\right)}
$$


For a proper application of Eq. (3), two key parameters, namely, surface tension and contact angle of mercury with the given porous material, are needed. Values quoted in the literature for mercury contact angle range from 112 to $150^{\circ}$, but most HgP devices include a default value of $130^{\circ}$, which seems to be valid for most of the common porous materials, specifically for most membranes [127]. Regarding air-mercury surface tension, Honold and Skau [130], and some authors after them, used a value of $\gamma=0.474 \mathrm{~N} / \mathrm{m}$. Nowadays, a more precise value (i.e., $\gamma=$ $0.485 \mathrm{~N} / \mathrm{m}$ ) is usually quoted [131], with small variations with temperature.

\subsubsection{Commercial Equipment}

Many companies market HgP devices since these have broad applications on the characterization of all kinds of porous materials (i.e., not limited to membranes). Some of these companies are Carlo Erba (Macropore), Fisons (Porosimeter P2000), Anton Paar (Poremaster Series), PMI (M/NonM IP), Thermo Fisher (Pascal), Micromeritics (Autopore V) and Quantachrome Co. (PoreMaster). All devices include sophisticated software for automatic control of the measurement and calculation of all porosity-related information, along with appropriate derivation algorithms to get smoothened curves. In most of them, the amount of intruded mercury is determined by the fall of the level of the interface between mercury and compressing liquid. Typically, HgP tests require placing the porous sample into a container (i.e., penetrometer), evacuating the container to remove contaminant vapors, and then forcing the mercury to fill the container. Operationally, (1) the sample is evacuated and the penetrometer is then filled in the low-pressure port; (2) low-pressure analysis is performed up to the maximum pressure specified; then (3) the sample is moved to a high-pressure port where a high-pressure analysis is performed up to the higher pressure achievable or selected. Normally, the data acquisition software uses appropriate derivation algorithms to get smoothed curves. The maximum pressure of about 60,000 psia (414 MPa) is typical for commercial instruments, which will force mercury into pores down to about 0.003 microns in diameter. The volume of mercury that intrudes into the sample can be determined from measurements of the capacitance. The penetrometer is made of glass (i.e., an insulator), filled with mercury (i.e., a conductor) and plated outside with some conductor metal; this combination results in a co-axial capacitor whose capacitance changes as it becomes filled [132]. A remarkable feature of this technique lies in the fact that this single device covers a wide range of pore sizes, usually from 2-3 nm to 1000 microns. Notwithstanding, the smallest pores in this range need intrusion pressures as high as 4500 bar, which for most of the polymeric membranes results in pore structure distortion and thus false results. Due to this reason, HgP is scarcely used for the 
characterization of polymeric membranes. Another reason for limited use for polymeric membranes is because most such membranes, at least those intended for UF or NF, are asymmetric (i.e., a thin selective layer adhered onto a much more porous support). When performing a HgP analysis, most of the contribution of mercury intrusion comes from the very porous support, while the volume intruded in the active layer is much smaller such that these pores can hardly be distinguished in the resulting distribution.

Ceramic membranes resist higher pressures and also can be easily broken into small pieces to ensure sufficient number of pores in the measurement cell to have an accurate analysis. HgP has been quite often used to characterize ceramic materials [133, 134], including ceramic flatsheet [135] and hollow fiber membranes used in microreactors, membrane contactors or fuel cells [136-140]. Mercury porosimetry has primarily been used for porous characterization of powders and ceramics even before GLDP, and it was later found that the method is useful to determine the PSD of membranes.

Even though Nakao [5] reviewed several pore size characterization techniques, there was insufficient information about the HgP method. The method was originally proposed by Washburn $[127,129]$ in a brief note, without including experimental results or any prototype to perform the technique. Using the idea of Washburn, Ritter and Drake in 1945 developed the method, evaluated the contact angle for mercury and designed the experimental procedure to determine the porosity values of several porous materials, like diatomaceous earth, Coors porous plate, Pyrex glass, pelleted gel or activated clay [141]. The first use of mercury intrusion porosimetry to characterize membranes was in 1954 by Honold and Skau, who applied it to hydrosol type MF membrane filters [130]. After that, many research and industrial applications of the method have proved its reliability in determining PSDs, pore shape characteristics, specific surface areas, and porosities. Many of these applications can be found in the excellent review by Rootare [142]. As commented, mercury porosimetry has been used the longest for characterizing porous materials, especially powders, ceramic materials and zeolites, and in general materials that can be easily broken in small pieces that assure the measurement cell contains enough number of pores inside to have an accurate analysis. HgP, like GLDP, has acquired the recognition of being the recommended standard for measurements of pore volume and PSDs in the macro-mesoporous range (ASTM D4284, D2873, D4404 or DIN 66133) [143]. Most HgP applications that can be found in scientific literature are related with characterization of powders [144, 145], rocks [146], coal [147], zeolites [148], and similar porous materials [131, 149-151]. The newest research on HgP is related to the characterization of porous properties of batteries [152], catalytic materials [153], ceramics for inkjet technology [154] and 
electrolyzers [155]. It has also been used to validate porosity determination procedures [156], and to characterize several types of membranes [157-159]. Notably, it has been used to validate tortuosity calculations for polymeric membranes [160].

\section{Kelvin Equation-Based Techniques}

\subsection{Evapoporometry (EP)}

\subsubsection{Setup}

In the EP method, the pore size characterization of the membranes is determined via evaporation of a volatile, wetting liquid from the membrane pores by a desktop test setup (Fig. 10a). Some of the authors in this review are among those who have advanced the EP technique[9, 24, 161-164]. The EP setup comprises of an incubator to keep the temperature of the test cell constant (e.g., at $29^{\circ} \mathrm{C}$ ), a microbalance to measure the mass loss from the test cell due to evaporation with time (Fig. 11), a software to record the mass measurements every 10 seconds, and granular activated carbon (GAC) to reduce the vapor concentration of the volatile wetting liquids outside the test cell. The simplified schematic of the EP test cell, which can be made of aluminum or polytetrafluoroethylene (PTFE) to prevent wetting by the volatile liquid, is shown in Fig. 10b. Progressive evaporation of the volatile wetting liquid from the largest pores to the smallest pores can be ensured via supersaturation, which prevails above all the pores smaller than those evaporation-drained ones. Several volatile wetting liquids have been used, such as isopropyl alcohol (IPA), water, 1-butanol, acetone, ethanol, and ethylene glycol [164], with varying performances. In order to maintain the thermodynamic equilibrium saturation at the interface between the gas and liquid phases in the pores during evaporation, EP experiments have also been conducted in a test cell which has a lid with a small hole (Fig. 10b), whose size can be varied to control the evaporation process [161]. The evolution of the mass and evaporation rate in Fig. 11 displays the data collected during the EP analysis, from which three distinct regions can be demarcated, namely, transient, free-standing liquid evaporation and pore liquid evaporation. The free-standing liquid evaporation rate is constant with time, giving the kinetics of evaporation of the free liquid. 
a)

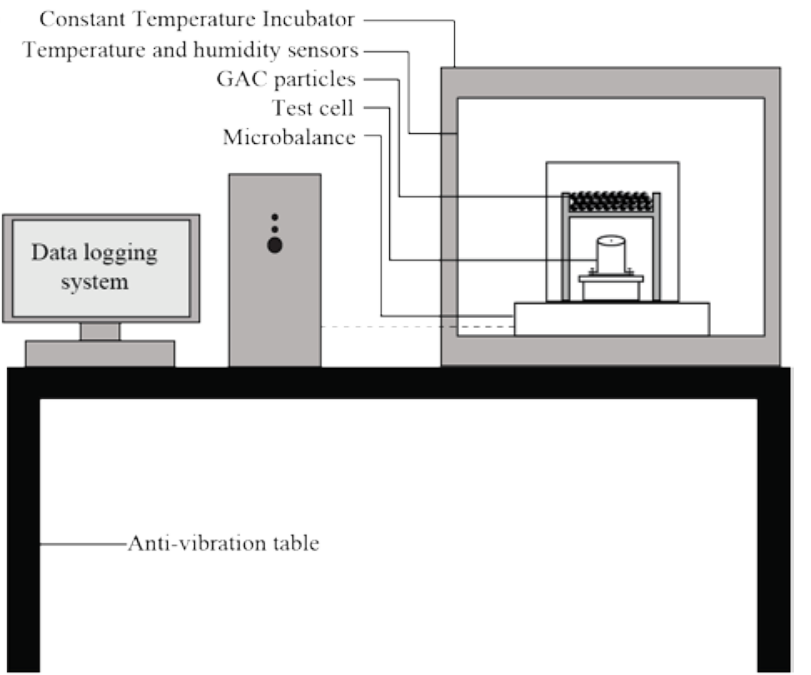

b)

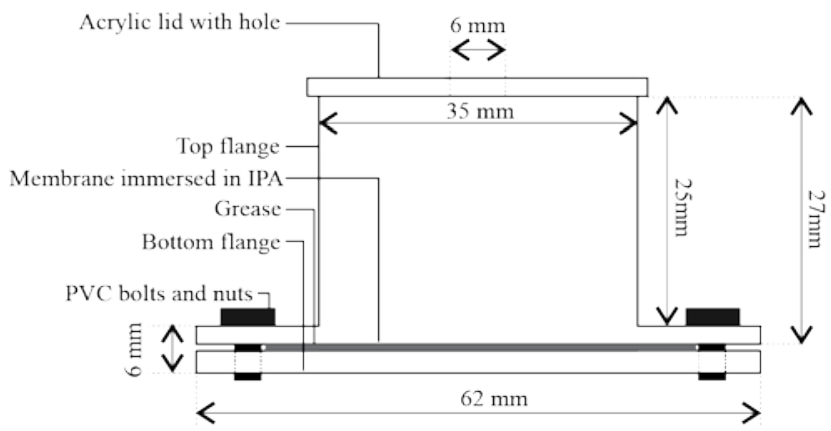

c)

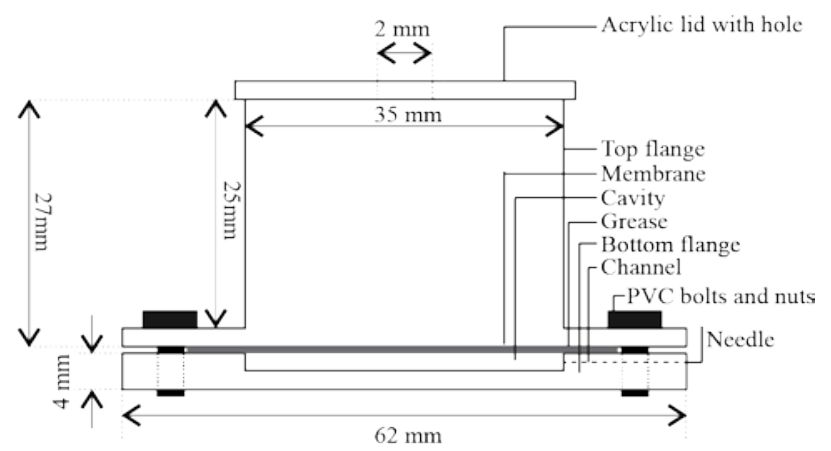

Fig. 10: Schematic of the (a) experimental setup; (b) EP test cell for traditional EP technique, and (c) EP test cell for adaptive EP technique(modified and redrawn from Refs. [9, 24]). 

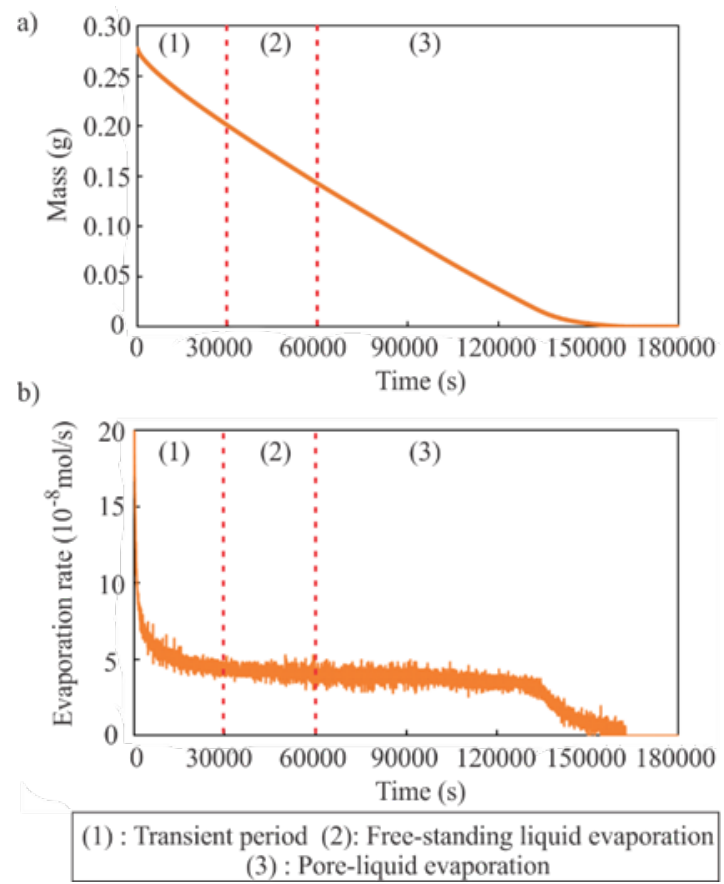

Fig. 11. Representative EP characterization plots of (a) mass versus time and (b) evaporation rate versus time[24].

Both dead-end and continuous pores of the membrane can be characterized by the EP technique. To characterize only the continuous pores, two modifications are needed: (i) in addition to the volatile wetting liquid, a non-volatile and non-wetting liquid has to be used; and (ii) the test cell is adapted such that both volatile and non-volatile liquids are injected into the test cell via a needle (Fig. 10c) [24].

\subsubsection{EP Studies}

The method was first proposed to measure the mass-based PSD of the track-etched polycarbonate and aluminum oxide membrane samples in the nominal pore size range of 10$200 \mathrm{~nm}$ in 2010 [165]. It was proposed for both flat-sheet and hollow-fiber membranes as a low-cost technique that can also characterize the membrane asymmetry $[165,166]$. Table 4 summarizes the EP studies to date.

Three different membrane types with different nominal pore sizes between 10 - $100 \mathrm{~nm}$, namely, polycarbonate (PC), polyvinylidene fluoride (PVDF) and aluminum oxide membranes, were analyzed [167]. An aluminum test cell with a $7.7 \mathrm{~cm}$ diameter was used as the test cell, but a lid was not used. It must be noted that the acrylic lid is not a mandatory part, but it decelerates the evaporation rate and allows more accurate characterization. IPA was preferred 
as the volatile wetting liquid. The mean pore size given by EP was found to agree very well with the previously applied indirect and direct methods, such as AFM, SEM, FESEM, and LDP, particularly for membranes with nominal pore sizes of $100 \mathrm{~nm}$. Therefore, EP was demonstrated to be able to provide accurate pore size characterization without any requirement of transmembrane pressure measurement, and for a reasonably large membrane area compared to the direct methods.

A subsequent study reported that both water and IPA as the volatile wetting liquids presented agreeable results with reasonable variability between runs [161]. Polyacrylonitrile (PAN) and PVDF hollow-fiber membranes were investigated by using both IPA and water as volatile wetting liquids. The test cell was made of Teflon ${ }^{\circledR}$ with an inside diameter of $4 \mathrm{~cm}$. GLDP gave smaller pore diameters than the EP for the more rubbery PVDF membrane, due to membrane compaction at the high operating pressures. On the other hand, GLDP gave larger pore diameters than the EP for the PAN membrane, since the GLDP was not able to analyze pores smaller than $14 \mathrm{~nm}$. In this study, the lid was proposed to decelerate the evaporation rate for better free-standing layer observation and for more accurate results. Aluminum oxide and polyethersulfone (PES) membranes with nominal pore sizes of $100 \mathrm{~nm}$ were assessed via this improved test setup design. The lid thickness was $2.7 \mathrm{~mm}$ and the hole diameter of the lid varied between 2 - $10 \mathrm{~mm}$ to adjust the evaporation rate, with slower rates proven to give smaller errors. In addition, the impact of different microbalances with different resolutions of 1 and 10 $\mu \mathrm{g}$ resolutions were investigated, with the latter being giving a larger average pore diameter due to the ability to reveal the larger pores.

A further study developed EP for characterizing tubular membranes whose active layers are on the lumen side [163]. Single-bore hollow fiber polyvinylpyrrolidone (PVP)/PES membranes and multi-bore hollow-fiber PES membranes were tested in the experiments. The test cell was made of Teflon ${ }^{\circledR}$, and IPA and 1-butanol were used as the volatile wetting liquids. The EP results were repeatable and agreed with manufacturer data, proving that EP is capable of characterizing lumen-side active layers.

In another study, Zamani et al. [164] focused on the investigation of the upper limit of EP-based pore size measurement range. While the lower limit of the pore size range measurable by EP is $4 \mathrm{~nm}$, which is governed by the Kelvin equation, the upper limit is related to the properties of the volatile wetting liquid, with larger surface tension and molar volume needed for the detection of larger pores. Between IPA and 1-butanol, the former was not able to accurately 
characterize the aluminum oxide membrane (Whatman, Anopore) with a nominal pore size of $200 \mathrm{~nm}$ due to detection of pores up to only $200 \mathrm{~nm}$, whereas the latter was able to due to detection of pores up to $360 \mathrm{~nm}$. This is because the larger surface tension and molar volume of 1-butanol relative to IPA caused a larger vapor-pressure depression, which allowed for the measurement of the larger pores as well as reduced the error involved with measuring the larger pores.

Akhondi et al. [162] evaluated using EP the effect of backwashing on the PSD. Although backwashing is a common membrane fouling mitigation technique, the quantification of the resulting PSD has not been done due to various limitations of other PSD characterization techniques, e.g., high pressure required of GLDP removes deposited foulants, sample treatment required before SEM imaging changes the deposits, liquids of LLDP may interact with foulants. EP is superior in this regard due to characterization at ambient conditions and the capacity to use water as the volatile wetting liquid. The EP results indicate that backwashing only removed the internal fouling of the larger pores and pore enlargement was evident particularly for more rubbery polymers.

Because the PSD results obtained via EP reflects both pores that are responsible for permeation (i.e., continuous pores, which are characterized by LDP techniques) and also that are not (i.e., dead-ended pores), a recent effort attempted to distinguish between the two pore types [24]. In this case, an additional non-wetting and non-volatile liquid (e.g., silicon oil) were used together with the volatile wetting liquid (e.g., ethanol). The volatile wetting liquid was injected via a needle into the bottom of the test setup to wet the membrane sample, after which the nonwetting and non-volatile liquid was injected with the same needle. This made sure that, during the EP test, the volatile wetting liquid is evaporated from continuous pores, which then become sealed by the other liquid. PES and PVDF membranes with nominal pore diameters of 28 and $35 \mathrm{~nm}$, respectively, were characterized, and the results indicate that the exclusion of the deadend pores led to average pore diameters of 9.3 and $14.5 \%$ lesser.

The most recent EP study involves a detailed comparative assessment between the EP and LLDP methods using five polymeric membranes (namely, nylon, PET, PES, PVDF, and PTFE) and one inorganic membrane (namely, aluminum oxide) [9]. The results indicate broader pore size ranges for EP and good agreement between the two methods only for three polymeric membranes. The discrepancy between the two methods for the other three membranes was tied to the higher pressure required of LLDP distorting the membrane structure. 
Table 4: Summary of the EP studies.

\begin{tabular}{|c|c|c|c|}
\hline Study & $\begin{array}{l}\text { Membrane } \\
\text { Type }\end{array}$ & Nominal pore size range & $\begin{array}{l}\text { Volatile } \\
\text { wetting } \\
\text { liquid }\end{array}$ \\
\hline Krantz et al. [167] & $\begin{array}{l}\text { PC, PVDF, } \\
\text { Aluminum oxide }\end{array}$ & $10-100 \mathrm{~nm}$ & IPA \\
\hline Akhondi et al. [168] & PAN and PVDF & $\begin{array}{l}35 \mathrm{~nm} \text { for PVDF, no data for } \\
\text { PAN }\end{array}$ & $\begin{array}{l}\text { Water and } \\
\text { IPA }\end{array}$ \\
\hline Akhondi et al. [161] & $\begin{array}{l}\text { Aluminum oxide } \\
\text { and PES }\end{array}$ & $100 \mathrm{~nm}$ & IPA \\
\hline Zamani et al. [163] & $\begin{array}{l}\text { PVP/PES and } \\
\text { PES }\end{array}$ & $\begin{array}{l}\text { Pores of PVP/PES smaller than } \\
300 \mathrm{~nm}, 90 \% \text { of the PES } \\
\text { membrane pores were smaller } \\
\text { than } 20 \mathrm{~nm}\end{array}$ & $\begin{array}{l}\text { IPA and 1- } \\
\text { butanol }\end{array}$ \\
\hline Zamani et al. [164] & Aluminum oxide & $100 \mathrm{~nm}$ and $200 \mathrm{~nm}$ & $\begin{array}{l}\text { IPA and 1- } \\
\text { butanol were } \\
\text { tested; } \\
\text { acetone, } \\
\text { ethanol, } \\
\text { ethylene } \\
\text { glycol, and } \\
\text { water were } \\
\text { discussed. }\end{array}$ \\
\hline Akhondi et al. [162] & PAN and PVDF & $\begin{array}{l}35 \mathrm{~nm} \text { for PVDF, no data for } \\
\text { PAN }\end{array}$ & $\begin{array}{l}\text { Deionized } \\
\text { water }\end{array}$ \\
\hline $\begin{array}{l}\text { Tanis-Kanbur et al. } \\
\text { [24] }\end{array}$ & PES and PVDF & $28 \mathrm{~nm}$ and $35 \mathrm{~nm}$ & $\begin{array}{l}\text { Ethanol } \\
\text { (volatile } \\
\text { wetting } \\
\text { liquid), silicon } \\
\text { oil (non- } \\
\text { volatile non- } \\
\text { wetting } \\
\text { liquid) }\end{array}$ \\
\hline $\begin{array}{l}\text { Tanis-Kanbur et al. } \\
\text { [9] }\end{array}$ & $\begin{array}{l}\text { Aluminum } \\
\text { oxide, PES, PET, } \\
\text { PTFE, PVDF, } \\
\text { and nylon }\end{array}$ & $\begin{array}{l}\text { No data for nylon, PTFE, and } \\
\text { PET. } 300 \mathrm{kDa} \text { for PES, } 100 \mathrm{kDa} \\
\text { for PVDF, and } 100 \mathrm{~nm} \text { for } \\
\text { Aluminum oxide }\end{array}$ & IPA \\
\hline
\end{tabular}

\subsection{Permporometry (PmP)}

\subsubsection{Setup}

Permporometry was firstly proposed by Eyraud in 1984 [169] and modified by Mey-Marom and Katz [170] and Katz [171] in 1986. It has an older history than the EP method in membrane applications and has been popularized since the early 90s [172, 173]. The experimental setup for the permporometry technique consists of four main sections, namely, gas flow system, 
diffusion cell, gas chromatograph with data recorder, and temperature control system, as illustrated in Fig. 12.

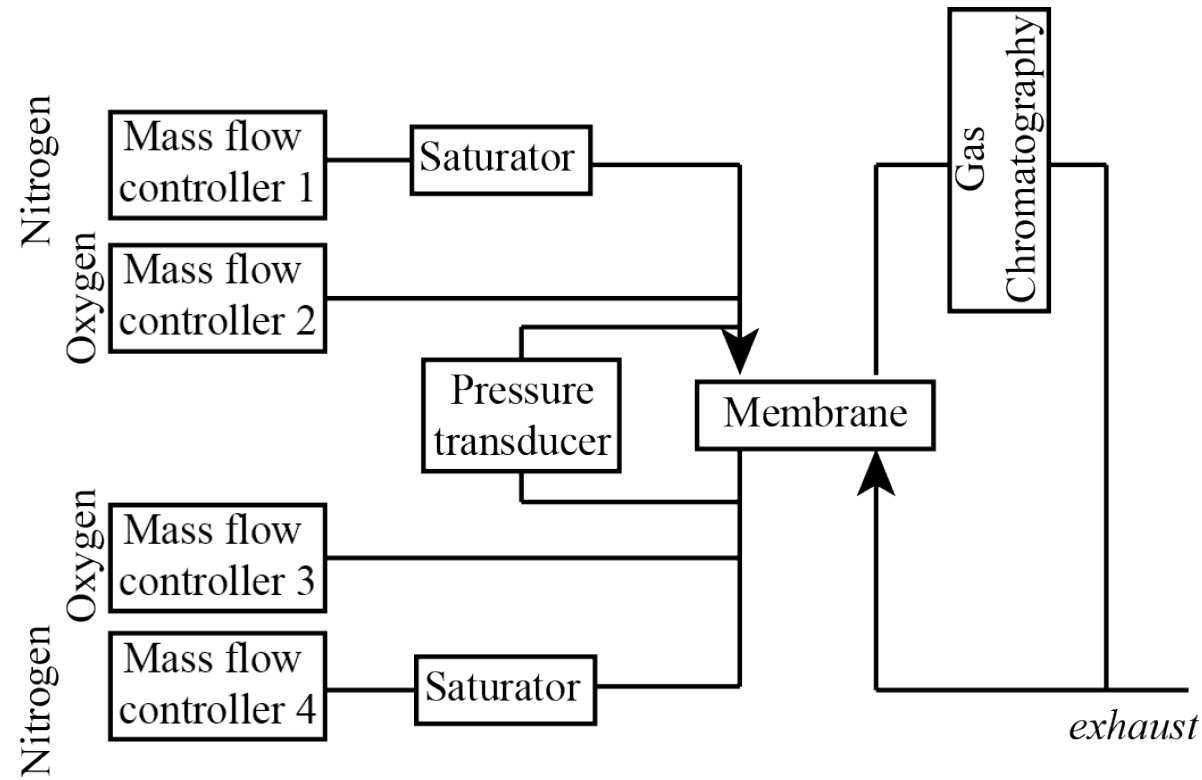

Fig. 12: Schematic of the permporometry setup (modified and redrawn from Ref. [174]).

The gas flow system consists of condensable gas generators, nitrogen gas, oxygen gas, mass flow controllers, pressure transducers, and gas mixers. For the membrane sample, the condensable gas and nitrogen are flushed at the active layer side, whereas the mixture of a condensable gas, nitrogen, and oxygen is flushed at the supporting layer side. The operating pressure of the diffusion cell can be adjusted to the atmospheric pressure. The condensable gas should be inert and wettable, as well as gives a reasonable vapor pressure and a high evaporation rate for accurate characterization. As a carrier gas, nitrogen gas is preferred. The reason behind using oxygen is to determine the gas diffusion through the membrane by using gas chromatography. The temperature must be kept constant during the experiments. In the diffusion cell, both membrane sides are flushed with the mixed gases that are saturated with the condensable gas. Thanks to capillary effect (condensation), all membranes pores are filled with the liquid phase of the condensable gas and there is no gas diffusion through the membrane. By decreasing the vapor pressure, gas diffusion proceeds from the larger to smaller pores. At the same time, the oxygen flow is measured via gas chromatography (and data recorder), and thereby the PSD can be plotted. It should be noted that the permporometry technique assumes the pore shape as cylindrical. More details on the permporometry setup and measurement detail can found in one of the cornerstone permporometry studies by Cao et al. [174]. 


\subsubsection{Permporometry (PmP) Studies}

There have been multiple efforts to improve the permporometry method. Despite some drawbacks, the permporometry method has been popularly used for membrane pore size characterization because of the advantage of determining the continuous (active) pores with a simple experimental setup. Schneider and Uchytil [64] proposed an improved permporometry method (i.e., the liquid expulsion permporometry) by accounting for the compressible nature of the gas and the distribution of the pore sizes. The new method was concluded to incur less systematic deviations in the resulting PSD than the traditional method. Moreover, Mourhatch et al. [77] developed a pore network model to take the pore interconnectivity into the account for the permporometry measurements, leading to more accurate pore size characterizations.

Table 5 provides a summary of the key permporometry-based pore size characterization studies. Germic et al. [116] found that the drying step during the permporometry test may result in a morphological change in the membrane structure after comparing the results with different direct and indirect methods such as FESEM and LDP. Cuperus et al. [172, 175] determined the active pore size of an anisotropic ultrafiltration membrane, a polyphenylene oxide (PPO) membrane, as well as ceramic, nuclepore, and polysulfone (PSf) membranes, demonstrating that permporometry gave reliable pore size estimations for all membrane types. Cao et al. [174] characterized ceramic membranes with the pore radius range from 2 to $10 \mathrm{~nm}$ via the permporometry and gas adsorption-desorption methods and found that the permporometry achieved reliable data for active (continuous) pores while gas adsorption-desorption was able to characterize both dead-ended and active pores. Huang et al. [176] implemented the permporometry method for ceramic membranes with nominal pore sizes ranging between 2 and $100 \mathrm{~nm}$ by using cyclohexane and carbon tetrachloride as condensable gas and observed good agreement with previous studies and gas adsorption-desorption. The impact of different condensable gases (namely, water, methanol, ethanol, carbon tetrachloride, hexane and isopropanol) on the pore size characterization was performed by Tsuru et al. [177]. The comparative study inferred that water, hexane and carbon tetrachloride displayed similar PSD trends for membrane average pore sizes of above $1 \mathrm{~nm}$. Another study of Tsuru et al. [178] focused on the effect of different gas carriers (namely, helium and nitrogen) with the condensable gas being water in the characterization of ceramic membranes with average pore sizes between 0.5 and $2 \mathrm{~nm}$. For larger pore sizes of $2 \mathrm{~nm}$, the PSD trends of helium and nitrogen were in good agreement. However, for smaller pore sizes, the PSDs of helium were shifted leftwards (i.e., smaller pores) compared to that of nitrogen, because the smaller pores allowed 
only helium permeation. Besides the aforementioned studies, many membrane fabrication studies used permporometry for pore size characterization.

Table 5: Summary of permporometry (PmP) studies.

\begin{tabular}{|c|c|c|}
\hline Study & Membrane Type & Purpose of Permporometry \\
\hline $\begin{array}{l}\text { Cuperus et al. } \\
\text { [172] }\end{array}$ & $\begin{array}{l}\text { Anisotropic } \\
\text { polyphenylene oxide } \\
\text { (PPO) membrane }\end{array}$ & $\begin{array}{l}\text { PSD, pore size, and top layer thickness were } \\
\text { explained via theory and experiments. }\end{array}$ \\
\hline $\begin{array}{l}\text { Cuperus et al. } \\
\text { [175] }\end{array}$ & $\begin{array}{l}\text { PPO, Nuclepore, } \\
\text { ceramic, and PSf } \\
\text { membranes }\end{array}$ & $\begin{array}{l}\text { Comparative permporometry study on various } \\
\text { membrane types to better determine the limitations } \\
\text { of the method. }\end{array}$ \\
\hline $\begin{array}{l}\text { Cao et al. } \\
\text { [174] }\end{array}$ & Ceramic membrane & $\begin{array}{l}\text { Performance assessment in the pore size range } \\
\text { between } 2 \text { and } 10 \mathrm{~nm} \text {. }\end{array}$ \\
\hline $\begin{array}{l}\text { Huang et al. } \\
{[176]}\end{array}$ & Ceramic membrane. & $\begin{array}{l}\text { Performance assessment in the pore size range } \\
\text { between } 2 \text { and } 100 \mathrm{~nm} \text {. Comparative work with the } \\
\text { gas adsorption-desorption method. }\end{array}$ \\
\hline $\begin{array}{l}\text { Germic et al. } \\
\text { [116] }\end{array}$ & $\begin{array}{l}\text { Polyacrylonitrile } \\
\text { membrane }\end{array}$ & $\begin{array}{l}\text { Comparison of permporometry with different } \\
\text { methods: SEM, LDP, gas adsorption-desorption. }\end{array}$ \\
\hline Kim et al. & $\begin{array}{l}\text { Regenerated } \\
\text { cellulose and } \\
\text { polysulfone } \\
\end{array}$ & $\begin{array}{l}\text { Comparative thermoporometry and permporometry } \\
\text { studies were conducted in the nominal pore size } \\
\text { range of } 2.6 \text { and } 14.1 \mathrm{~nm} \text {. }\end{array}$ \\
\hline $\begin{array}{l}\text { Tsuru et al. } \\
\text { [177] }\end{array}$ & $\begin{array}{l}\text { Lab-based ceramic } \\
\text { membranes (sol-gel } \\
\text { membranes) }\end{array}$ & $\begin{array}{l}\text { Various condensable gases were carried out: water, } \\
\text { methanol, ethanol, isopropanol, carbon } \\
\text { tetrachloride, and hexane. }\end{array}$ \\
\hline $\begin{array}{l}\text { Tsuru et al. } \\
\text { [178] }\end{array}$ & $\begin{array}{l}\text { Lab-based ceramic } \\
\text { membranes }\end{array}$ & $\begin{array}{l}\text { PSDs of nitrogen and helium-based permporometry } \\
\text { studies were compared. Water was selected as the } \\
\text { condensable liquid. }\end{array}$ \\
\hline $\begin{array}{l}\text { Nishiyama et } \\
\text { al. [179] }\end{array}$ & $\begin{array}{l}\text { Lab-based ceramic } \\
\text { membrane }\end{array}$ & $\begin{array}{l}\text { Characterization of the lab-fabricated ceramic } \\
\text { membrane. Helium and nitrogen were the } \\
\text { condensable and non-condensable gases, } \\
\text { respectively. }\end{array}$ \\
\hline $\begin{array}{l}\text { Chowdhury et } \\
\text { al. [180] }\end{array}$ & $\begin{array}{l}\text { Lab-based ceramic } \\
\text { membrane }\end{array}$ & $\begin{array}{l}\text { Characterization of the lab-fabricated ceramic } \\
\text { membrane. Hexane was used as the condensable } \\
\text { gas. }\end{array}$ \\
\hline $\begin{array}{l}\text { Wang et al. } \\
\text { [181] }\end{array}$ & $\begin{array}{l}\text { Lab-based ceramic } \\
\text { membrane }\end{array}$ & $\begin{array}{l}\text { The defect size distribution was characterized for } \\
\text { different ceramic membrane types. }\end{array}$ \\
\hline $\begin{array}{l}\text { Hedlund et al. } \\
\text { [182] }\end{array}$ & $\begin{array}{l}\text { Lab-based ceramic } \\
\text { membrane }\end{array}$ & $\begin{array}{l}\text { Permporometry was used to characterize the } \\
\text { ceramic membrane types with a different film } \\
\text { thickness range from } 300 \text { to } 1800 \mathrm{~nm} \text {. }\end{array}$ \\
\hline $\begin{array}{l}\text { Higgins et al. } \\
\text { [183] }\end{array}$ & $\begin{array}{l}\text { Lab-based ceramic } \\
\text { membrane }\end{array}$ & $\begin{array}{l}\text { Helium and nitrogen were used as the condensable } \\
\text { and non-condensable gases, respectively. }\end{array}$ \\
\hline $\begin{array}{l}\text { Chowdhury et } \\
\text { al. [184] }\end{array}$ & $\begin{array}{l}\text { Lab-based ceramic } \\
\text { membrane }\end{array}$ & $\begin{array}{l}\text { Characterization of the lab-fabricated ceramic } \\
\text { (zeolite) membrane. }\end{array}$ \\
\hline $\begin{array}{l}\text { Yang and } \mathrm{Li} \\
\text { [185] }\end{array}$ & $\begin{array}{l}\text { Lab-based ceramic } \\
\text { membrane }\end{array}$ & $\begin{array}{l}\text { Characterization of lab-fabricated ceramic (tubular } \\
\mathrm{TiO}_{2} / \mathrm{Al}_{2} \mathrm{O}_{3} \text { ) membrane }\end{array}$ \\
\hline $\begin{array}{l}\text { Kuhn et al. } \\
{[186]}\end{array}$ & $\begin{array}{l}\text { Lab-based ceramic } \\
\text { membrane }\end{array}$ & $\begin{array}{l}\text { Characterization of lab-fabricated multichannel } \\
\text { ceramic (zeolite) membrane }\end{array}$ \\
\hline
\end{tabular}




\begin{tabular}{|l|l|l|}
\hline $\begin{array}{l}\text { Schillo et al. } \\
\text { [187] }\end{array}$ & $\begin{array}{l}\text { Lab-based ceramic } \\
\text { membrane }\end{array}$ & $\begin{array}{l}\text { Characterization of the lab-fabricated ceramic } \\
\text { (alumina) membrane during the rapid thermal } \\
\text { processing }\end{array}$ \\
\hline $\begin{array}{l}\text { Lindmark et } \\
\text { al. [188] }\end{array}$ & $\begin{array}{l}\text { Lab-based ceramic } \\
\text { membrane }\end{array}$ & $\begin{array}{l}\text { Permporometry was used to investigate the PSD } \\
\text { towards selectivity enhancement of zeolite } \\
\text { membranes }\end{array}$ \\
\hline $\begin{array}{l}\text { Hofs et al. } \\
\text { [189] }\end{array}$ & $\begin{array}{l}\text { Commercial ceramic } \\
\text { and PES/PVP } \\
\text { membranes }\end{array}$ & $\begin{array}{l}\text { Characterization of the ceramic and polymeric } \\
\text { membranes for permeability and fouling } \\
\text { assessments. }\end{array}$ \\
\hline $\begin{array}{l}\text { Zeidler et al. } \\
\text { [190] }\end{array}$ & $\begin{array}{l}\text { Lab-based ceramic } \\
\text { membrane }\end{array}$ & $\begin{array}{l}\text { Characterization of the low molecular weight cut- } \\
\text { off ceramic membranes }\end{array}$ \\
\hline $\begin{array}{l}\text { Karimi et al. } \\
\text { [191] }\end{array}$ & $\begin{array}{l}\text { Lab-based ceramic } \\
\text { membrane }\end{array}$ & $\begin{array}{l}\text { Characterization of the zeolite membranes during } \\
\text { the defect blocking process }\end{array}$ \\
\hline $\begin{array}{l}\text { Blumenschein } \\
\text { et al. [192] }\end{array}$ & $\begin{array}{l}\text { Commercial ceramic } \\
\text { membranes }\end{array}$ & $\begin{array}{l}\text { Characterization of the ceramic membranes to } \\
\text { better describe the rejection curves during the } \\
\text { organic solvent nanofiltration }\end{array}$ \\
\hline $\begin{array}{l}\text { Chang et al. } \\
\text { [193] }\end{array}$ & $\begin{array}{l}\text { Lab-based ceramic } \\
\text { membrane }\end{array}$ & $\begin{array}{l}\text { Characterization of the lab- fabricated ceramic } \\
\text { (zeolite) membrane during the rapid thermal } \\
\text { processing }\end{array}$ \\
\hline $\begin{array}{l}\text { Simon et al. } \\
\text { [194] }\end{array}$ & $\begin{array}{l}\text { Lab-based ceramic } \\
\text { membrane }\end{array}$ & $\begin{array}{l}\text { Characterization of the lab-fabricated ceramic } \\
\text { (zeolite) membrane during the micro-defect sealing } \\
\text { by chemical vapor deposition }\end{array}$ \\
\hline
\end{tabular}

\subsection{Gas Adsorption-Desorption (GAD)}

\subsubsection{Setup}

Among the techniques of membrane characterization based on the Kelvin equation, the Gas Adsorption-Desorption (GAD) technique is one of the most commonly used. With appropriate modeling, GAD is able to supply information about the PSD of microporous and mesoporous membranes, as well as other types of porous materials. The technique is also known as nitrogen physisorption [195] and low-pressure nitrogen gas adsorption (LP-N $\left.{ }_{2} G A\right)$ [196]. Most of the GAD studies deal with porous materials (e.g., coals, carbons, other rocks) other than membranes [197-199]. Despite the same theoretical background, the GAD method is less popular than permporometry. While permporometry characterizes only continuous (active) pores, GAD characterizes both dead-end and continuous pores.

The GAD analysis is done with the well-established and commercial gas sorption analyzers. A test cell, which holds the membrane sample, is located in the analyzer, and the pore size characterization is done by determining the gas volume that is sent to the sample. Before the experiments, the membranes are dried at high temperatures. The selected gas, which is generally helium, must be non-condensable at the liquid nitrogen temperature. The gas is flowed to the sample at a known flux value, and the pressure measurements are done concurrently to 
determine the dead volume of the membrane sample. Then, the sample discharging process is carried out until the maximum vacuum value, after which the constant-flux nitrogen flow is sent to the sample and a reference cell, whilst the pressure and time data are collected in parallel. The comparison between the sample and reference cells allows us to analyze the adsorption isotherm of the sample. More details on the gas adsorption-desorption setup can be found in earlier reports [195, 200]. The GAD technique is used to determine the surface area of porous materials, based on the determination of the BET isotherm. The resulting method gives the socalled BET surface area. It is common to use nitrogen as the adsorbate, though other gases could be used depending on the membrane adsorption characteristics [201]. In the following, the GAD procedure to measure surface area and pore sizes of porous materials is presented, along with the associated assumptions and calculations.

\subsubsection{Determination of Surface Area}

The use of the Brunauer-Emmett-Teller (BET) method is generally considered the standard to obtain the whole surface area of a porous sample. The method, based on the adsorption kinetics model [202], relies on several assumptions whose validity must be ensured: (1) in all layers except the first, the molar enthalpy of adsorption corresponds to the enthalpy of condensation, $L$; (2) in all layers except the first, condensation-evaporation conditions are equal; (3) at the saturation pressure (i.e., $p_{r}=1$ ), all gases are condensed on the solid surface tending to an infinite number of adsorption layers. Based on the validity of such assumptions, Brunauer et al. [202] obtained a simple linear relationship between the adsorbed volume and pressure:

$$
\frac{p}{V\left(p_{0}-p\right)}=\frac{1}{V_{m} C}+\frac{C-1}{V_{m} C} \frac{p}{p_{0}}
$$

where $V_{m}$ is the total volume adsorbed in the monolayer per unit mass, $V$ the volume adsorbed per unit mass, and $C$ a constant related to the isotherm shape. According to Eq. (6), a plot of $p / V\left(p_{0}-p\right)$ versus $p_{r}$ results in a straight line, whose fitting allows us to obtain the two unknown parameters, namely, $C$ and $V_{m}$, from the slope and the intercept, respectively. To ensure the validity of this model, which works nicely for relatively low pressures, only results corresponding to relative pressures in the range of 0.05 to 0.3 can be fitted. The final calculation of the BET surface area is related to a geometrical consideration for the adsorbate molecule. Usually, this molecule is nitrogen, and thus using a value of $16.2 \AA^{2}$ for molecular crosssectional area $A_{\mathrm{m}}$ of the nitrogen molecule, the surface area can be calculated by:

$$
A(B E T)=\left(\frac{V_{m}}{V_{g}}\right) N_{A} A_{m}
$$

where $V_{g}$ is the gas molar volume at STP conditions and $N_{A}$ the Avogadro number. 


\subsubsection{Determination of Mean Pore Size and Pore Size Distribution (PSD)}

In contrast to the BET surface area determination, whose procedure is well known and used in many cases in the same manner as a recognized standard for surface area calculation), the use of GAD to determine the porous characteristics of a certain material lacks a uniform approach and is highly dependent on the shape of the adsorption isotherm, which is strongly tied to the presence of mesopores (i.e., between 2 and $50 \mathrm{~nm}$ in diameter) and micropores (i.e., lower than $2 \mathrm{~nm}$ in diameter). In the case of macropores (i.e., larger than $50 \mathrm{~nm}$ in diameter), the use of GAD leads to operation at pressures very close to the saturation one $\left(p_{r}=1\right)$, which makes inaccurate any calculation of such pores.

\subsubsection{Mesopore Analysis}

In the case of mesopores, the adsorption of gas onto porous materials is mostly due to capillary condensation. The adsorbate molecules (except the first adsorbed layer) can be considered as a liquid in such a way that the interphase between gas and adsorbed molecules is at vapor-liquid equilibrium. As is well acknowledged, such equilibria are determined by the meniscus curvature, which can be related to the geometry of the pore via the Kelvin equation:

$$
r_{k}=\frac{2 \gamma V_{l}}{R T \ln \left(p_{r}\right)}
$$

where $r_{k}$ is the radius of the equivalent hemispherical meniscus (or Kelvin radius), $\gamma$ the surface tension, and $V_{1}$ the molar volume of the liquid condensate.

Supposing cylindrical pores, the pore radius is given by $r_{p}=r_{k}+t$, where $t$ is the correction made to $r_{k}$ to account for the thickness of a layer already adsorbed on the pore walls. The accuracy of the mesopores analysis strongly depends on the calculation of $t$. Ideally, $t$ should be determined from a measurement of adsorption onto a completely flat surface from the same material under study; however, such measurement is not practical (and at times impossible) for most cases. Therefore, some sort of phenomenological correlation should be used. Among the correlations developed to address this problem, the Halsey correlation [203, 204], obtained from abundant measurements on different flat materials, seems to give goods results for most samples with mesopores. This correlation gives $t$, in Angstroms, as:

$$
t=0.354\left[\frac{5}{\ln \left(\frac{p_{0}}{p}\right)}\right]^{1 / 3}
$$

The same correlation can be used also for parallel slit pores, in which case the slit width, $d_{p}$, is given by $d_{p}=r_{k}+2 t$. Based on this correlation, a number of computational procedures have 
been proposed to deal with mesopores from adsorption experiments. One of the most known is that proposed by Dollimore and Heal for cylindrical pores [92, 205].

Finally, it should be noted that both isotherms, during adsorption and desorption, can be used to determine the PSD of a mesoporous membrane, but they do not match exactly due to certain hysteresis (e.g., attributed to the presence of pore interconnectivity [206]) in the filling process. Normally, the adsorption isotherm is considered more precise to determine the PSD of the sample.

\subsubsection{Micropore Analysis}

Unfortunately, the Kelvin equation loses validity for micropores, because substitution of the capillary condensation mechanism by multilayer adsorption leads to distortion of the usual mesopores isotherm shape. Approaches proposed to address this range from simple reformulations of the Kelvin equation to more complex descriptions of the process. Regarding the reformulation of the Kelvin equation to account for the adsorbed layer thickness, it has been shown to give inconsistent results [207]. Methods like Dubinin-Radushkevich [208-210] or Horväth-Kawazoe [211, 212] have been used to obtain information about micropores. One of the most interesting ones is the HgP-method, which is based on the $t$-plot developed by Lippens and De Boer [213]. These methods depart from a plot of the adsorption isotherms in terms of the adsorbed layer. Here, $t$ values can be obtained by using an empirical correlation by Harkins and Jura [214]:

$$
t=\left[\frac{13.99}{0.034+\ln \left(\frac{p_{0}}{p}\right)}\right]^{1 / 2}
$$

\subsubsection{Determination of Overall Porosity}

Apart from determining the BET surface area and getting the PSD of a porous sample, GAD can be also used to determine the porosity of the membrane. For such purpose, a quite simple procedure has been developed by some of the authors of this review [215, 216]. The method is based on determinations of the pressure of Helium gas introduced into the sample holder as a function of time. Working at low enough pressures (recommended values range between 7 and $16 \mathrm{kPa}$ ), helium can be considered to behave as a perfect gas. So, the following equation can be used to fit the experimental data:

$$
p=k_{1}+\frac{k_{2}}{V_{g}}
$$

where $k_{1}$ and $k_{2}$ are unknown constants to be determined from experimental data-fitting and $V_{\mathrm{g}}$ the volume occupied by the gas. For practical purposes, the measurement consists of the 
determination at three different situations (namely, empty holder, a non-porous sample of known volume, and the membrane sample), from which the actual solid volume of the sample can be determined. From the geometric volume of the sample (accounting for the maximum dimensions and not the existence of inner pores), the ratio of both volumes gives the sample porosity.

The reason for using helium as the intruding gas is its small molecular size and the fact it does not adsorb onto the holder walls and on the pore walls at the operating temperature (i.e., $77 \mathrm{~K}$, since the holder is placed in a Dewar containing liquid nitrogen). At the same time, nitrogen gas is introduced in the reference holder. The saturation pressure measured in this holder serves to normalize the sample pressure, thus avoiding the influence of atmospheric pressure variations.

\subsubsection{Commercial Equipment}

The market offers a range of technical solutions and instruments for gas adsorption analysis, including the 2020 and 2020 Plus Series of Micromeritics, the wide range covered by Autosorb, NOVAtouch, and Quadrasorb Series developed by Quantachrome, the Belsorp series (from BEL Japan), 3P Inst. (formerly Quantachrome GmbH developed the 3P micro 300 and 3P meso 400, aimed for micro and mesopores analysis, respectively), and the Omnisorp Series by Coulter (not continued later by Beckmann-Coulter). Apart from design and robustness, the main differences between these types of equipment come from the method used to determine the amount of gas adsorbed onto the sample, which can be categorized as three main groups: (a) volumetric, which measures the volume and pressure of the gas at equilibrium conditions (both static and continuously); (b) chromatographic; and (c) gravimetric, which determines the variation of the solid mass with the aid of an accurate microbalance [4].

\subsubsection{Comparison of GAD results}

The GAD method is generally used in comparison studies that consist of both indirect and direct techniques. These studies have been devoted to the characterization of several kinds of membranes [217-221] and supports [222]. In inorganic membrane applications, Cini et al. [223] applied the GAD technique for the low surface area and macroporous ceramic membranes to characterize pore size and understand the fouling phenomena. Bailey et al. [224] performed a comparative pore size characterization study for the ceramic membranes by using GAD and atomic force microscopy (AFM), which respectively represent indirect and direct techniques, and found good agreement between the obtained average pore sizes. Basumatary et al. [225] 
developed a ceramic membrane for the separation of chromic acid from aqueous solutions, and determined the pore size with GAD, as well as crystallinity and surface morphology respectively with XRD and FESEM. Maghsodi et al. [226] proposed a hydrothermal ultrasonic method to remove arsenic from the aqueous solution via a ceramic membrane, which was characterized by using the GAD method. Apart from the inorganic membranes, the GAD technique has also been used for the characterization of organic membranes. Prádanos et al. [200] focused on the analysis of the internal surface area, volume, surface, and the number of pores of the microporous symmetric membranes by combining the AFM and GAD techniques. For GAD, it was found that the desorption process achieved a more realistic pore size estimation, and, in the case of a significant share of dead-end pores in the membrane, the PSD shifted to smaller pore size values. On the other hand, the AFM did not need any pretreatment step for characterization and it was found feasible for both wet and dry membrane samples. However, the AFM technique estimated the PSD to be slightly greater than the GAD method due to the relationship between the shapes of the pore entrance and the AFM probe tip. Following that study, two polyethersulphonic microporous composite membranes with two different nominal molecular weight cut-off values of 4000 and 30000 Da were characterized by the indirect $\mathrm{GAD}$ and direct AFM techniques, indicating good agreement of the results between both techniques [217]. The same group also compared the surface and bulk porosities of ten different polycarbonate membranes using GAD and AFM [220]. Both AFM and GAD techniques agreed for pores in the UF range, but GAD did not reliably estimate pore sizes above $50 \mathrm{~nm}$. For gas separation purposes, Zhang et al. [227] developed a nanoporous carbon membrane, and the characterization was carried out by both indirect (i.e, GAD) and direct (namely, FTIR, TEM and SEM) methods. The GAD technique was preferred to determine the PSD and average pore size, while the direct methods were used in other membrane morphological observation purposes. Nonetheless, the PSDs obtained by both GAD and TEM were in a good agreement. A more theoretical approach can be found in the recent work by Zeng et al. [228], in which the microscopic mechanisms of adsorption and desorption in uniform-sized pores were studied via numerical simulations, with the aim to elucidate the origin of hysteresis. In dead-end pores, two possible reasons were put forth for the hysteresis: (i) weak adsorbents in the case of non-wetting adsorbate molecules; and (ii) adsorbate become solidlike, since the GAD temperature value is lower than the triple-point temperature. In continuous pores, the hysteresis was observed when the critical hysteresis temperature is greater than the GAD temperature. 


\section{Gibbs-Thomson Equation-Based Techniques}

\subsection{Thermoporometry (ThP)}

The Gibbs-Thomson-based measurements are thermoporometry measurements that characterize the pore size and PSD according to the phase-change curves (thermograms) via calorimeters. Two thermograms, namely, solidification and fusion, are used in the thermoporometry tests. Before the experiments, the sample is frozen and melted in sequence to obtain a crystallized phase. This process also prevents thermal flash because the initial overcooling propagates the penetration of the solid into the pores [229]. Like the GAD technique, thermoporometry is also one of the oldest pore size characterization techniques for porous media [34]. The methodology and theory were firstly proposed and validated for porous powders; then, it was better described for the membrane pore size characterization studies [229]. Although thermoporometry can be implemented with different kinds of liquids, all studies were generally conducted using water, mainly because of the easy observation of waterice phase change plots via thermograms.

Table 6 summarizes the thermoporometry studies on membranes. One of the pioneer thermoporometry studies of membranes was done by Zeman et al. [230], who characterized polysulfone ultrafiltration membranes. Following that study, Quinson et al. [231, 232] characterized the swelling phenomena of polycarbonate membranes with average pore diameters of $15 \mathrm{~nm}$. Broek et al. [233] conducted thermoporometry for hollow fiber cellulosebased hemodialysis membranes in artificial kidney studies to determine the pore structure. Cuperus et al. [234] performed thermoporometry tests for both ceramic (alumina) and polymeric (polyphenylene, polysulfone, and cellulose acetate) membranes to assess the feasibility of the method on different membrane types with different casting thicknesses. It was observed that the method was reliable for isotropic membranes, but not so for anisotropic membranes because the sublayer of anisotropic membranes may prevent accurate characterization of the active layer of interest. Similar to Maghsodi et al. [226], TerrazasBandala et al. [235] also aimed to remove arsenic from aqueous solutions. Cellulose acetate and active carbon membranes popularly used for that purpose and their characterization procedures were completed via thermoporometry.

Table 6: Summary of thermoporometry studies in the literature.

\begin{tabular}{|l|l|l|}
\hline Study & Membrane type & Liquid medium \\
\hline
\end{tabular}




\begin{tabular}{|l|l|l|}
\hline Brun et al. [34] & Powders $^{1}$ & Water and Benzene \\
\hline Zeman et al. [230] & Polysulfone & Water \\
\hline Quinson et al. [231] & Polycarbonate & Water \\
\hline Quinson et al. [232] & Polycarbonate & Water \\
\hline Broek et al. [233] & Cellulose & Water \\
\hline Cuperus et al. [234] & $\begin{array}{l}\text { Ceramic (alumina), and polymer } \\
\text { (polyphenylene, polysulfone, and } \\
\text { cellulose acetate) }\end{array}$ & Water \\
\hline Jallut et al. [229] & Polysulfone & Water \\
\hline $\begin{array}{l}\text { Terrazas-Bandala et al. } \\
\text { [235] }\end{array}$ & Active carbon and acetate cellulose & Water \\
\hline
\end{tabular}

1: They are not membrane samples, but the study is listed since it was the first study of the detailed theory.

\section{Spectroscopy-Based Techniques}

In addition to the aforementioned indirect methods, spectroscopy-based ones are also available, which are comparatively newer and able to characterize tighter membrane types such as NF and RO membranes. Although spectroscopy is considered a direct high-resolution imaging technique, the collected images can be coupled with mathematical expressions to estimate the pore sizes of the membrane, and thereby classified under indirect methods here. In the following, we review two different spectroscopy-based methods, namely, positron annihilation lifetime spectroscopy (PALS) and synchrotron radiation (SR). Even though limited studies are available, the key advantage is the characterization of sub-nanometer scale membranes, which is not possible by other indirect methods.

\subsection{Positron Annihilation Lifetime Spectroscopy (PALS)}

To date, PALS has been exclusively applied to seawater RO and tight NF membranes. It is worth mentioning that such membranes are generally regarded as non-porous, as the 'pores' are actually the very small interstices in the matrix. Fujioka et al. [35] summarized the main characteristics of the RO and NF membranes tested by PALS in a comprehensive study, in which the beam intensity was in the range of $1.0-2.0 \mathrm{keV}$ that corresponds to the mean positron implementation depth range of 40 to $200 \mathrm{~nm}$ for a material density of $1 \mathrm{~g} / \mathrm{cm}^{3}$ [35]. Kim et al. [236] applied PALS for a low-pressure polyamide RO membrane and determined the pore radius as $0.217 \mathrm{~nm}$. Tung and his colleagues found that the pore radii of virgin and fouled polyamide NF membranes were $0.279 \mathrm{~nm}$ [23] and $0.312 \mathrm{~nm}$ [20], respectively. Chen et al. [237] used PALS for a low-pressure RO and two NF membranes, and found the pore radii to be $0.203 \mathrm{~nm}$ for the low-pressure RO membrane, and 0.265 and $0.275 \mathrm{~nm}$ for the two NF membranes. Fujioka et al. [238] related the rejection of uncharged molecules during the RO 
process to the pore diameter determined by PALS. The PALS results indicate that the seawater RO and low-pressure RO membranes had pore radii of $0.259 \mathrm{~nm}$ and $0.289 \mathrm{~nm}$, respectively, which correlated well with the relatively better rejection exhibited by the seawater RO membrane. Another PALS study by Fujioka et al. [239] analyzed the impact of heat treatment, which is known to improve rejection and reduce fouling but reduce water permeability, on the pore size of RO membranes. PALS results indicate that heat treatment negligibly changed the pore radii of $0.267 \mathrm{~nm}$. Lee et al. [240] found for a polyamide seawater desalination RO membrane with pore radius of $0.240 \mathrm{~nm}$ that increasing humidity causes pore swelling. The recent studies on PALS analysis have focused on different membrane types. Fan et al. [241] characterized the polyvinyl alcohol-graphene oxide nanocomposite membranes with different weight ratios of graphene oxide and polyvinyl alcohol using PALS, and found the pore radii varied between a small range of 0.219 - $0.222 \mathrm{~nm}$ despite different compositions. Kim et al. [242] developed cellulose triacetate and polyamide forward osmosis (FO) membranes and compared the pore size with a seawater RO membrane. The pore diameter was determined with the PALS method, whereas the PSD was obtained via the fractional rejection method. Between the FO and seawater RO membranes, PALS indicated the FO membrane had larger pores in the radii range of $\sim 0.29-0.30 \mathrm{~nm}$, compared to that of 0.20-0.24 nm of the seawater RO membrane. PALS has also been used for inorganic membranes. Ma et al. [243] prepared four zeolite membrane types with different microstructures on alumina supports, with PALS showing that the pore radii were between 2.73 and $3.64 \AA$.

\subsection{Synchrotron Radiation (SR)}

The SR technique has some advantageous characteristics such as wide spectrum range, high intensity, high polarization, small source and therefore greater intensity; it has been beneficial for the applications in the fields of materials characterization and analysis, chemistry, micromechanics, biology, physics, geology, archaeology and medicine [244, 245]. SR-based $\mathrm{X}$-ray diffraction (XRD) and small-angle X-ray scattering (SAXS) characterization methods provide performance-related information about morphology and structural differences [246]. Based on these advantages, the SR method has been applied to polymeric and inorganic membranes since the beginning of the 2000s. Lassinantti Gualtieri et al. [247] used the SR technique as a part of a high-temperature X-ray powder diffraction (HT-XRPD) study for testing both zeolite film and alumina support of the MFI zeolite membranes to understand crack formation during the calcination process. The porous alumina support was found to be expanded while the MFI zeolite crystals contracted during calcination heating. Jeong et al. [248] studied 
the synchrotron X-ray radiation technique to investigate the microstructure of siliceous ZSM-5 (MFI) zeolite membrane during the calcination process. After the calcination process, MFI crystals of the membrane were found under compressive stress and their thermal behavior were different from those in powder, which affirmed that cracks formed under compressive stress and thereby affected the overall membrane performance. Barranco-Garcia et al. [249] investigated the gas transport phenomenon of isotactic polypropylene (iPP) based nanoporous gas separation membrane with different amounts of SBA-15 silica (iPP/SBA-15) via the SAXS SR technique. The confinement effect was monitored, and the silica particles played a filler role that enhanced the rigidity and lowered the deformations. Other studies were performed to investigate the depth-dependent structure during permeation performance, and also the effect of ethanol swelling of poly(urea-urethane) (PU) membranes via small-angle X-ray scattering (SAXS) SR technique [250, 251].

Furthermore, Remigy and Meireles [252] used the SR computed microtomography method to study the pores and 3-D architecture of polysulfone (PSf) and poly(vinylidene fluoride-cohexafluoropropylene) (PVDF-HFP) hollow fiber microfiltration membranes. Pore geometry and morphology of the membranes were observed by analyzing the 2-D images and reconstruction of 3-D architecture via commercial visualization software. Lee et al. [253] studied the structure of nanoporous polymeric membranes via synchrotron X-ray tomography imaging. Membrane porosity, pore channel and interconnectivity, 3D structure and tortuosity characterizations were determined via 3D image analysis, demonstrating that nanoscale imaging can be reliably used for membrane morphology-based mass transfer investigations.

While the possibility of applying the SR method for membrane characterization has been proven, studies on pore size characterization are very limited. Similar to PALS, and in contrast to other indirect methods that cater to UF and MF membranes, SR can be used to nanometerscale and smaller pores.

\section{Conclusions and Future Directions}

The present study reviewed the existing indirect techniques for the analysis of membrane porerelated characteristics. Compared to the direct methods, indirect ones allow for the characterization of larger and thus more representative membranes, and with minimal sample preparation. The techniques have been systematically reviewed with respect to the theoretical background, measurement detail, experimental procedure, and application found in the scientific literature. The methods were classified as Young-Laplace equation-based, Kelvin equation-based, Gibbs-Thomson equation-based and spectroscopy-based techniques. The 
bubble point test, gas-liquid displacement porosimetry (GLDP), liquid-liquid displacement porosimetry (LLDP), and mercury intrusion porosimetry (HgP) were reviewed under the umbrella of Young-Laplace equation-based methods, whereas evapoporometry (EP), permporometry (PmP), and gas adsorption-desorption (GAD) were reviewed as Kelvin equation-based methods. In addition, the thermoporometry technique was explained under Gibbs-Thomson equation-based methods. Finally, positron annihilation spectroscopy and synchrotron radiation were examined jointly as spectroscopy-based techniques. The conclusions of the present review are summarized in Table 7.

Table 7: Key features (positive ( $)$ or negative (v)) of the indirect methods reviewed for membrane pore characterization.

\begin{tabular}{|c|c|c|}
\hline $\begin{array}{l}\text { Underlying } \\
\text { Theory }\end{array}$ & Method & Features \\
\hline \multirow{2}{*}{ 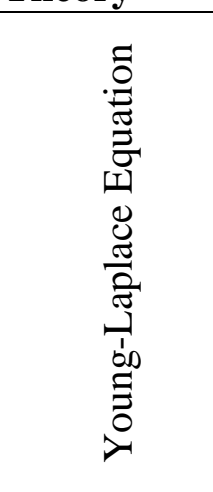 } & $\begin{array}{l}\text { Liquid } \\
\text { Displacement } \\
\text { Porosimetry }\end{array}$ & $\begin{array}{l}\text { Flow-based mean pore size and PSD } \\
\text { Fast and precise measurement } \\
\text { pressure for smaller pores (nanometer range) detection }\end{array}$ \\
\hline & $\begin{array}{l}\text { Mercury Intrusion } \\
\text { Porosimetry }\end{array}$ & $\begin{array}{l}\text { Volume-based mean pore size and PSD } \\
\text { porous materials such as powders, rocks, ceramic } \\
\text { membranes, catalytic materials } \\
\text { The requirement of higher pressure makes it } \\
\text { uncommonly used for polymeric membranes }\end{array}$ \\
\hline 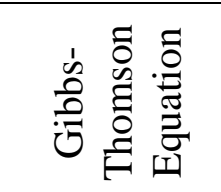 & Thermoporometry & $\begin{array}{l}\text { Mass-based mean pore size and PSD } \\
\text { Needs pore geometry assumption } \\
\text { Limited accuracy of heat measurement }\end{array}$ \\
\hline \multirow{2}{*}{ 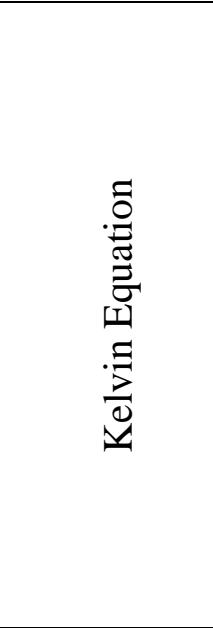 } & Permporometry & $\begin{array}{l}\text { Flow-based mean pore size and PSD } \\
\text { Measures continuous pores } \\
\text { Limited to MF and UF membranes } \\
\text { pressure and flow rate measurement }\end{array}$ \\
\hline & Evapoporometry & $\begin{array}{l}\text { Mass-based mean pore size and PSD } \\
\text { pressure } \\
\text { ended pores, and pore connectivity in polymeric } \\
\text { membranes } \\
\text { Can characterize fouled membranes } \\
\text { Cimited to UF and tight MF membranes }\end{array}$ \\
\hline
\end{tabular}




\begin{tabular}{|c|c|c|}
\hline & $\begin{array}{l}\text { Gas Adsorption- } \\
\text { Desorption }\end{array}$ & $\begin{array}{l}\text { Volume-based mean pore size and PSD } \\
\text { Can be used for MF, UF and NF membranes } \\
\text { Needs pore geometry assumption } \\
\text { Expensive equipment, and limited accuracy of } \\
\text { pressure and volume measurements }\end{array}$ \\
\hline 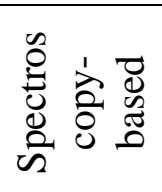 & $\begin{array}{l}\text { Positron } \\
\text { Annihilation } \\
\text { Lifetime } \\
\text { Spectroscopy }\end{array}$ & $\begin{array}{l}\text { Quantifies mean pore size based on high-resolution } \\
\text { images } \\
\text { Useful for tight NF and RO membranes } \\
\text { Requires vacuum process for the test sample }\end{array}$ \\
\hline
\end{tabular}

Any of the reviewed methods can be useful for providing information about the pore size and porosity of membranes. LLDP and EP are considered the more precise methods giving an accurate, complete picture of the PSD for any membrane in the MF - UF range, while the extension to NF relies on the spectroscopy-based methods. While such porosimetric methods are very useful for preliminary selection of samples for selected applications, such selection must be complemented by appropriate retention experiments of the real feeds of interest.

One major drawback of all these PSD characterization techniques is related to the actual microstructure of a porous medium, which in many cases is quite different from a simple bundle of parallel cylindrical tubes. Porous systems are rather characterized by a system of more or less interconnected pores. Several studies dealing with the pore network simulation (PNS) method of fluid displacement [254-258] are inspired by the classical invasion-percolation algorithm. It combines the tracking of the fluid-fluid interfaces and the invasion of the throats (corresponding to the constrictions of the pore space) whose threshold capillary pressures, as given by the Young-Laplace equation, are lower than the existing pressure difference between the two fluids [257]. In the case of PNS simulation of EP, it is made by combining the computation of vapor diffusion in the fraction of the pore space invaded by the gas phase present in the network and the identification of the throat of lower capillary pressure invasion threshold [257]. As a result, the information on the PSD obtained from LLDP and EP techniques can be questioned in some cases and must be assessed for improved accuracy by comparison between experimental results and PNS calculations.

Although the indirect methods are established techniques for different membrane types, improvements can be made through further research. For the case of MF and UF membranes, all the Young-Laplace-, Kelvin- and Gibbs-Thomson-based techniques can be improved via the use of different liquids. It would be useful to assess the impact of the thermophysical properties (e.g., surface tension, wettability) of the liquid on pore size estimation, since the interaction 
between liquid and membrane material can slightly or dramatically change the PSD profiles. Furthermore, some subjectivity is involved in these techniques (e.g., determination of the transition between free-standing liquid evaporation and evaporation from the pore in EP), which means the average PSD and pore size estimation may vary somewhat between operators. To make for an objective assessment, machine learning algorithms can be developed for data management and to plot fittings of the PSDs, which would make membrane characterization faster and more reliable. For the nanometer and sub-nanometer pores, the PALS and SR techniques have been gaining importance since they can provide a comprehensive understanding of the void structures. Since PALS and SR provide reliable pore size characterization for the sub-nanometer-scale membrane structures, the relationship between fouling mechanism and change in pore size/structure can be studied in more detail. In parallel, simulations can be performed to contribute towards the relationship between transport properties and pore sizes.

\section{Acknowledgments}

M. B. Tanis-Kanbur and J.W. Chew thank the Singapore GSK (GlaxoSmithKline) - EDB (Economic Development Board) Trust Fund, the Pharma Innovation Programme Singapore (PIPS) grant (A20G2a0070) and the Singapore Ministry of Education Tier 1 funding (2019-T1002-065). J.I. Calvo and A. Hernández want to thank the Regional Government of Castilla y León (Projects: CLU2017-09, UIC082 and VA088G19) and the Spanish “Ministerio de Ciencia e Innovación (MCINN)” (project: MAT2016-76413-C2-1-R) through EU-FEDER funds.

\section{References}

[1] G. Owen, M. Bandi, J.A. Howell, S.J. Churchouse, Economic assessment of membrane processes for water and waste water treatment, Journal of Membrane Science, 102 (1995) 77-91.

[2] S. Loeb, LOEB-SOURIRAJAN MEMBRANE: HOW IT CAME ABOUT, in: ACS Symposium Series, 1981, pp. 1-9.

[3] R. Bai, H.F. Leow, mufiltration of polydispersed suspension by a membrane screen/hollow-fiber composite module, Desalination, 140 (2001) 277-287.

[4] A.B. J.I. Calvo, P. Prádanos, L. Palacio and A. Hernández, Membrane Characterization: Porosity, in: Encyclopedia of Membrane Science and Technology, Wiley Interscience Pub, New York (USA), 2013, pp. 1-35.

[5] S.-i. Nakao, Determination of pore size and pore size distribution: 3. Filtration membranes, Journal of Membrane Science, 96 (1994) 131-165.

[6] J.I. Calvo, A. Bottino, G. Capannelli, A. Hernández, Comparison of liquid-liquid displacement porosimetry and scanning electron microscopy image analysis to characterise ultrafiltration tracketched membranes, Journal of Membrane Science, 239 (2004) 189-197. 
[7] N.A. Ochoa, P. Prádanos, L. Palacio, C. Pagliero, J. Marchese, A. Hernández, Pore size distributions based on AFM imaging and retention of multidisperse polymer solutes: Characterisation of polyethersulfone UF membranes with dopes containing different PVP, Journal of Membrane Science, 187 (2001) 227-237.

[8] H. Reingruber, A. Zankel, C. Mayrhofer, P. Poelt, A new in situ method for the characterization of membranes in a wet state in the environmental scanning electron microscope, Journal of Membrane Science, 399-400 (2012) 86-94.

[9] M.B. Tanis-Kanbur, R.I. Peinador, X. Hu, J.I. Calvo, J.W. Chew, Membrane characterization via evapoporometry (EP) and liquid-liquid displacement porosimetry (LLDP) techniques, Journal of Membrane Science, 586 (2019) 248-258.

[10] M. Baklanov, K. P. Mogilnikov, V. Polovinkin, F. Dultsev, Determination of pore size distribution in thin films by ellipsometric porosimetry, 2000.

[11] H.D. Bale, P.W. Schmidt, Small-Angle X-Ray-Scattering Investigation of Submicroscopic Porosity with Fractal Properties, Physical Review Letters, 53 (1984) 596-599.

[12] T.C. Chilcott, M. Chan, L. Gaedt, T. Nantawisarakul, A.G. Fane, H.G.L. Coster, Electrical impedance spectroscopy characterisation of conducting membranes: I. Theory, Journal of Membrane Science, 195 (2002) 153-167.

[13] K. Darowicki, M. Szociński, Local impedance spectroscopy of membranes, Journal of Membrane Science, 303 (2007) 1-3.

[14] J.-D. Jeon, S.J. Kim, S.-Y. Kwak, $1 \mathrm{H}$ nuclear magnetic resonance (NMR) cryoporometry as a tool to determine the pore size distribution of ultrafiltration membranes, Journal of Membrane Science, 309 (2008) 233-238.

[15] K.C. Khulbe, B. Kruczek, G. Chowdhury, S. Gagné, T. Matsuura, S.P. Verma, Characterization of membranes prepared from PPO by Raman scattering and atomic force microscopy, Journal of Membrane Science, 111 (1996) 57-70.

[16] K.C. Khulbe, T. Matsuura, Characterization of synthetic membranes by Raman spectroscopy, electron spin resonance, and atomic force microscopy; a review, Polymer, 41 (2000) 1917-1935.

[17] K.C. Khulbe, T. Matsuura, C.Y. Feng, Study on cellulose acetate membranes for reverse osmosis and polyethersulfone membranes for ultrafiltration by electron spin resonance technique, Desalination, 148 (2002) 329-332.

[18] K.C. Khulbe, T. Matsuura, G. Lamarche, A.M. Lamarche, C. Choi, S.H. Noh, Study of the structure of asymmetric cellulose acetate membranes for reverse osmosis using electron spin resonance (ESR) method, Polymer, 42 (2001) 6479-6484.

[19] R. Lamsal, S.G. Harroun, C.L. Brosseau, G.A. Gagnon, Use of surface enhanced Raman spectroscopy for studying fouling on nanofiltration membrane, Separation and Purification Technology, 96 (2012) 7-11.

[20] D. Nanda, K.-L. Tung, W.-S. Hung, C.-H. Lo, Y.-C. Jean, K.-R. Lee, C.-C. Hu, J.-Y. Lai, Characterization of fouled nanofiltration membranes using positron annihilation spectroscopy, Journal of Membrane Science, 382 (2011) 124-134.

[21] P.S. Singh, P. Ray, Z. Xie, M. Hoang, Synchrotron SAXS to probe cross-linked network of polyamide 'reverse osmosis' and 'nanofiltration' membranes, Journal of Membrane Science, 421-422 (2012) 51-59.

[22] H.-K. Song, Y.-H. Jung, K.-H. Lee, L.H. Dao, Electrochemical impedance spectroscopy of porous electrodes: the effect of pore size distribution, Electrochimica Acta, 44 (1999) 3513-3519.

[23] K.-L. Tung, Y.-C. Jean, D. Nanda, K.-R. Lee, W.-S. Hung, C.-H. Lo, J.-Y. Lai, Characterization of multilayer nanofiltration membranes using positron annihilation spectroscopy, Journal of Membrane Science, 343 (2009) 147-156.

[24] M.B. Tanis-Kanbur, F. Zamani, W.B. Krantz, X. Hu, J.W. Chew, Adaptation of evapoporometry (EP) to characterize the continuous pores and interpore connectivity in polymeric membranes, Journal of Membrane Science, 575 (2019) 17-27. 
[25] K.J. Kim, A.G. Fane, R. Ben Aim, M.G. Liu, G. Jonsson, I.C. Tessaro, A.P. Broek, D. Bargeman, A comparative study of techniques used for porous membrane characterization: pore characterization, Journal of Membrane Science, 87 (1994) 35-46.

[26] C. Zhao, X. Zhou, Y. Yue, Determination of pore size and pore size distribution on the surface of hollow-fiber filtration membranes: a review of methods, Desalination, 129 (2000) 107-123.

[27] M.A. Rahman, M.A. Mutalib, K. Li, M.H.D. Othman, Chapter 10 - Pore Size Measurements and Distribution for Ceramic Membranes, in: N. Hilal, A.F. Ismail, T. Matsuura, D. Oatley-Radcliffe (Eds.) Membrane Characterization, Elsevier, 2017, pp. 183-198.

[28] K.C. Khulbe, T. Matsuura, Synthetic membrane characterisation - a review: part I, Membrane Technology, 2017 (2017) 7-12.

[29] K.C. Khulbe, T. Matsuura, C.Y. Feng, Synthetic membrane characterisation - a review: part II, Membrane Technology, 2017 (2017) 7-12.

[30] K.L. Tung, K.S. Chang, T.T. Wu, N.J. Lin, K.R. Lee, J.Y. Lai, Recent advances in the characterization of membrane morphology, Current Opinion in Chemical Engineering, 4 (2014) 121-127.

[31] N. Hilal, A.F. Ismail, T. Matsuura, D. Oatley-Radcliffe, Membrane Characterization, in: N. Hilal, A.F. Ismail, T. Matsuura, D. Oatley-Radcliffe (Eds.) Membrane Characterization, Elsevier, 2017, pp. xix-xxi.

[32] K. Friess, L. Bartovská, K. Pilnáček, O. Vopička, A. Randová, M. Lanč, Physical Chemistry Characterization of Polymeric Membranes, in, 2017.

[33] D.J. Johnson, D.L. Oatley-Radcliffe, N. Hilal, State of the art review on membrane surface characterisation: Visualisation, verification and quantification of membrane properties, Desalination, 434 (2018) 12-36.

[34] M. Brun, A. Lallemand, J.-F. Quinson, C. Eyraud, A new method for the simultaneous determination of the size and shape of pores: the thermoporometry, Thermochimica Acta, 21 (1977) 59-88.

[35] T. Fujioka, N. Oshima, R. Suzuki, W.E. Price, L.D. Nghiem, Probing the internal structure of reverse osmosis membranes by positron annihilation spectroscopy: Gaining more insight into the transport of water and small solutes, Journal of Membrane Science, 486 (2015) 106-118.

[36] R.W. Siegel, Positron Annihilation Spectroscopy, Annual Review of Materials Science, 10 (1980) 393-425.

[37] W.J. Lau, A.F. Ismail, P.S. Goh, N. Hilal, B.S. Ooi, Characterization methods of thin film composite nanofiltration membranes, Separation and Purification Reviews, 44 (2015) 135-156.

[38] M. Qasim, M. Badrelzaman, N.N. Darwish, N.A. Darwish, N. Hilal, Reverse osmosis desalination: A state-of-the-art review, Desalination, 459 (2019) 59-104.

[39] Y.C. Jean, P.E. Mallon, D.M. Schrader, Introduction to Positron and Positronium Chemistry, in: Principles and Applications of Positron and Positronium Chemistry, pp. 1-15.

[40] H.H. Yin, Y. Zejie, M. Weitao, Z. Daming, A Review of Studies of Polymeric Membranes by Positron Annihilation Lifetime Spectroscopy, Plasma Science and Technology, 7 (2005) 3062-3064.

[41] M. Eldrup, D. Lightbody, J.N. Sherwood, The temperature dependence of positron lifetimes in solid pivalic acid, Chemical Physics, 63 (1981) 51-58.

[42] S.J. Tao, Positronium annihilation in molecular substances, The Journal of Chemical Physics, 56 (1972) 5499-5510.

[43] D.W. Gidley, H.-G. Peng, R.S. Vallery, POSITRON ANNIHILATION AS A METHOD TO CHARACTERIZE POROUS MATERIALS, Annual Review of Materials Research, 36 (2006) 49-79.

[44] P. Dumas, V. Humblot, Chapter 6 - Synchrotron infrared interface science, in: C.M. Pradier, Y.J. Chabal (Eds.) Biointerface Characterization by Advanced IR Spectroscopy, Elsevier, Amsterdam, 2011, pp. 145-166.

[45] S.L. Hulbert, G.P. Williams, 1 - SYNCHROTRON RADIATION SOURCES, in: J.A.R. Samson, D.L. Ederer (Eds.) Vacuum Ultraviolet Spectroscopy, Academic Press, Burlington, 2000, pp. 1-25.

[46] B.A. Cunningham, W. Bras, L.J. Lis, P.J. Quinn, Synchrotron X-ray studies of lipids and membranes: a critique, Journal of Biochemical and Biophysical Methods, 29 (1994) 87-111. 
[47] F.C. Adams, X-Ray Absorption and Diffraction | Overview, in: P. Worsfold, C. Poole, A. Townshend, M. Miró (Eds.) Encyclopedia of Analytical Science (Third Edition), Academic Press, Oxford, 2019, pp. 391-403.

[48] H. Bechhold, The permeability of ultrafilters, Z. Phys. Chem., 64 (1908) 328-342.

[49] J.I. Calvo, Membrane characterization by porosimetric techniques, in: XXIV Summer School on Membranes, Genoa, Italy, 2007.

[50] R. G., Method for Determining the Bubble Point or the Largest Pore of Membranes or Filter Materials, in: U. Patent (Ed.), US, 1988.

[51] G. Reichelt, Bubble point measurements on large membrane areas, in: Polymeric Materials Science and Engineering, Proceedings of the ACS Division of Polymeric Materials Science and Engineering, 1989, pp. 787-788.

[52] G. Reichelt, Bubble point measurements on large areas of microporous membranes, Journal of membrane science, 60 (1991) 253-259.

[53] A. Hernández, J.I. Calvo, P. Prádanos, F. Tejerina, Pore size distributions in microporous membranes. A critical analysis of the bubble point extended method, Journal of Membrane Science, 112 (1996) 1-12.

[54] E. Jakobs, W. Koros, Ceramic membrane characterization via the bubble point technique, Journal of Membrane Science, 124 (1997) 149-159.

[55] D. Hopkinson, M. Zeh, D. Luebke, The bubble point of supported ionic liquid membranes using flat sheet supports, Journal of membrane science, 468 (2014) 155-162.

[56] S. Wickramanayake, D. Hopkinson, C. Myers, L. Sui, D. Luebke, Investigation of transport and mechanical properties of hollow fiber membranes containing ionic liquids for pre-combustion carbon dioxide capture, Journal of Membrane Science, 439 (2013) 58-67.

[57] S.K. Bhatia, J.L. Smith, Comparative study of bubble point method and mercury intrusion porosimetry techniques for characterizing the pore-size distribution of geotextiles, Geotextiles and Geomembranes, 13 (1994) 679-702.

[58] S. Bhatia, J. Smith, Application of the bubble point method to the characterization of the poresize distribution of geotextiles, Geotechnical Testing Journal, 18 (1995) 94-105.

[59] J. Yu, X. Hu, Y. Huang, A modification of the bubble-point method to determine the pore-mouth size distribution of porous materials, Separation and Purification Technology, 70 (2010) 314-319.

[60] V. Nassehi, D.B. Das, I.M. Shigidi, R.J. Wakeman, Numerical analyses of bubble point tests used for membrane characterisation: model development and experimental validation, Asia-Pacific Journal of Chemical Engineering, 6 (2011) 850-862.

[61] F. Erbe, Die Bestimmung der Porenverteilung nach ihrer Größe in Filtern und Ultrafiltern, KolloidZeitschrift, 63 (1933) 277-285.

[62] S.P. Nunes, K.V. Peinemann, Ultrafiltration membranes from PVDF/PMMA blends, Journal of Membrane Science, 73 (1992) 25-35.

[63] H. Steinhauser, Scholz, H., Hübner, A., Ellinghorst, G. , The role of supports for pervaporation composite membranes, in: Proc. ICOM 90, Chicago, 1990.

[64] P. Schneider, P. Uchytil, Liquid expulsion permporometry for characterization of porous membranes, Journal of Membrane Science, 95 (1994) 29-38.

[65] P. Shao, R.Y.M. Huang, X. Feng, W. Anderson, Gas-Liquid Displacement Method for Estimating Membrane Pore-Size Distributions, AIChE Journal, 50 (2004) 557-565.

[66] D. Li, M.W. Frey, Y.L. Joo, Characterization of nanofibrous membranes with capillary flow porometry, Journal of Membrane Science, 286 (2006) 104-114.

[67] S. S Manickam, J.R. McCutcheon, Characterization of polymeric nonwovens using porosimetry, porometry and X-ray computed tomography, Journal of Membrane Science, 407-408 (2012) 108-115. [68] C.M. Gribble, G.P. Matthews, G.M. Laudone, A. Turner, C.J. Ridgway, J. Schoelkopf, P.A.C. Gane, Porometry, porosimetry, image analysis and void network modelling in the study of the pore-level properties of filters, Chemical Engineering Science, 66 (2011) 3701-3709. 
[69] A. Hernández, J. Calvo, P. Prádanos, F. Tejerina, Pore size distributions in microporous membranes. A critical analysis of the bubble point extended method, Journal of Membrane Science, 112 (1996) 1-12.

[70] A. Shrestha, Characterization of porous membranes via porometry, in: Mechanical Engineering, University of Colorado at Boulder, 2012.

[71] J.I. Calvo, A. Hernández, P. Prádanos, L. Martínez, W.R. Bowen, Pore size distributions in microporous membranes II. Bulk characterization of track-Etched filters by air porometry and mercury porosimetry, Journal of Colloid And Interface Science, 176 (1995) 467-478.

[72] R. Gopal, S. Kaur, Z. Ma, C. Chan, S. Ramakrishna, T. Matsuura, Electrospun nanofibrous filtration membrane, Journal of Membrane Science, 281 (2006) 581-586.

[73] W. Piątkiewicz, S. Rosiński, D. Lewińska, J. Bukowski, W. Judycki, Determination of pore size distribution in hollow fibre membranes, Journal of Membrane Science, 153 (1999) 91-102.

[74] X. Liu, Z. Qiankun, H. Zhang, Y. Jiang, Y. He, Development and characterization of microporous Ti3SiC2 ceramic membranes for filtration of microorganisms, Journal of Materials Science, 51 (2015). [75] C. Wang, L. Ling, Y. Huang, Y. Yao, Q. Song, Decoration of porous ceramic substrate with pencil for enhanced gas separation performance of carbon membrane, Carbon, 84 (2015) 151-159.

[76] D.Y. Wenten IG, Metode dan alat bubble point untuk karakterisasi membran mikrofiltrasi in: I.P.N. 033.321A]. (Ed.), Indonesia, 2002.

[77] R. Mourhatch, T.T. Tsotsis, M. Sahimi, Determination of the true pore size distribution by flow permporometry experiments: An invasion percolation model, Journal of Membrane Science, 367 (2011) 55-62.

[78] C. Herrero, P. Prádanos, J.I. Calvo, F. Tejerina, A. Hernández, Flux Decline in Protein Microfiltration: Influence of Operative Parameters, Journal of Colloid and Interface Science, 187 (1997) 344-351.

[79] J. Jacob, P. Prádanos, J.I. Calvo, A. Hernández, G. Jonsson, Fouling kinetics and associated dynamics of structural modifications, Colloids and Surfaces A: Physicochemical and Engineering Aspects, 138 (1998) 173-183.

[80] M. Mietton-Peuchot, C. Condat, T. Courtois, Use of gas-liquid porometry measurements for selection of microfiltration membranes, Journal of Membrane Science, 133 (1997) 73-82.

[81] M.A. Islam, M.S. Hossain, M. Ulbricht, Model-dependent analysis of gas flow/pore dewetting data for microfiltration membranes, Journal of Membrane Science, 533 (2017) 351-363.

[82] M.A. Islam, M. Ulbricht, Microfiltration membrane characterization by gas-liquid displacement porometry: Matching experimental pore number distribution with liquid permeability and bulk porosity, Journal of Membrane Science, 569 (2019) 104-116.

[83] A. E1294-89(1999), Standard Test Method for Pore Size Characteristics of Membrane Filters Using Automated Liquid Porosimeter, in, ASTM International, West Conshohocken, PA 1999.

[84] A. F316-03(2011), Standard Test Methods for Pore Size Characteristics of Membrane Filters by Bubble Point and Mean Flow Pore Test, in, ASTM International, West Conshohocken, PA, 2011. [85] S. Ramaswamy, A. Greenberg, M. Peterson, Non-invasive measurement of membrane morphology via UFDR: Pore-size characterization, Journal of Membrane Science, 239 (2004) 143-154. [86] B. Miller, I. Tyomkin, Liquid Porosimetry: New Methodology and Applications, Journal of Colloid and Interface Science, 162 (1994) 163-170.

[87] A. Jen, K. Gupta, Characterization of pore structure of filter media, Fluid - Particle Separation Journal, 14 (2002).

[88] J.-G. Lee, E.-J. Lee, S. Jeong, J. Guo, A.K. An, H. Guo, J. Kim, T. Leiknes, N. Ghaffour, Theoretical modeling and experimental validation of transport and separation properties of carbon nanotube electrospun membrane distillation, Journal of Membrane Science, 526 (2017) 395-408.

[89] A.H. José Ignacio Calvo, Laura Palacio, Pedro Prádanos, Matteo Ailuno, Aldo, Bottino, G.

Carniglia, Antonio Comité, A. Jezowska, M. Pagliero and Rafaella Firpo, Characterization of porous PTFE membranes and their potential application in osmotic distillation, in: Euromembrane Valencia, Spain, 2018. 
[90] J.T. Gostick, M.A. Ioannidis, M.W. Fowler, M.D. Pritzker, Direct measurement of the capillary pressure characteristics of water-air-gas diffusion layer systems for PEM fuel cells, Electrochemistry Communications, 10 (2008) 1520-1523.

[91] H.E. Kolb, R. Schmitt, A. Dittler, G. Kasper, On the accuracy of capillary flow porometry for fibrous filter media, Separation and Purification Technology, 199 (2018) 198-205.

[92] D. Dollimore, G.R. Heal, An improved method for the calculation of pore size distribution from adsorption data, Journal of Applied Chemistry, 14 (1964) 109-114.

[93] G. Capannelli, F. Vigo, S. Munari, Ultrafiltration membranes - characterization methods, Journal of Membrane Science, 15 (1983) 289-313.

[94] R.E. Kesting, Synthetic polymeric membranes: a structural perspective, Wiley, 1985.

[95] S. Munari, A. Bottino, G. Capannelli, P. Moretti, Membrane morphology and transport properties, Desalination, 53 (1985) 11-23.

[96] S.N. P. Grabar, Sur le diamètre des pores des membranes en collodion utilisées en ultrafiltration, J. Chim. Phys, 33 721-741.

[97] R.I. Peinador, J.I. Calvo, P. Prádanos, L. Palacio, A. Hernández, Characterisation of polymeric UF membranes by liquid-liquid displacement porosimetry, Journal of Membrane Science, 348 (2010) 238-244.

[98] K.S. McGuire, K.W. Lawson, D.R. Lloyd, Pore size distribution determination from liquid permeation through microporous membranes, Journal of Membrane Science, 99 (1995) 127-137.

[99] A.J. Gijsbertsen-Abrahamse, R.M. Boom, A. van der Padt, Why liquid displacement methods are sometimes wrong in estimating the pore-size distribution, AIChE Journal, 50 (2004) 1364-1371.

[100] K.R. Morison, A comparison of liquid-liquid porosimetry equations for evaluation of pore size distribution, Journal of Membrane Science, 325 (2008) 301-310.

[101] M.C. Almécija, J.E. Zapata, A. Martinez-Ferez, A. Guadix, A. Hernández, J.I. Calvo, E.M. Guadix, Analysis of cleaning protocols in ceramic membranes by liquid-liquid displacement porosimetry, Desalination, 245 (2009) 541-545.

[102] E. Anton, J.I. Calvo, J.R. Alvarez, A. Hernandez, S. Luque, Fitting approach to liquid-liquid displacement porosimetry based on the log-normal pore size distribution, Journal of Membrane Science, 470 (2014) 219-228.

[103] J.I. Calvo, A. Bottino, G. Capannelli, A. Hernández, Pore size distribution of ceramic UF membranes by liquid-liquid displacement porosimetry, Journal of Membrane Science, 310 (2008) 531-538.

[104] J.I. Calvo, R.I. Peinador, P. Prádanos, A. Bottino, A. Comite, R. Firpo, A. Hernández, Porosimetric characterization of polysulfone ultrafiltration membranes by image analysis and liquid-liquid displacement technique, Desalination, 357 (2015) 84-92.

[105] J.I. Calvo, R.I. Peinador, P. Prádanos, L. Palacio, A. Bottino, G. Capannelli, A. Hernández, Liquidliquid displacement porometry to estimate the molecular weight cut-off of ultrafiltration membranes, Desalination, 268 (2011) 174-181.

[106] P. Carretero, S. Molina, A. Lozano, J. de Abajo, J.I. Calvo, P. Prádanos, L. Palacio, A. Hernández, Liquid-liquid displacement porosimetry applied to several MF and UF membranes, Desalination, 327 (2013) 14-23.

[107] R.I. Peinador, J.I. Calvo, K. ToVinh, V. Thom, P. Prádanos, A. Hernández, Liquid-liquid displacement porosimetry for the characterization of virus retentive membranes, Journal of Membrane Science, 372 (2011) 366-372.

[108] A. Bottino, G. Capannelli, A. Grosso, O. Monticelli, M. Nicchia, Porosimetric Characterization of Inorganic Membranes, Separation Science and Technology, 29 (1994) 985-999.

[109] A. Bottino, G. Capannelli, P. Petit-bon, N. Cao, M. Pegoraro, G. Zoia, Pore Size and Pore-Size Distribution in Microfiltration Membranes, Separation Science and Technology, 26 (1991) 1315-1327. [110] G. Capannelli, I. Becchi, A. Bottino, P. Moretti, S. Munari, Computer Driven Porosimeter for Ultrafiltration Membranes, in: K.K. Unger, J. Rouquerol, K.S.W. Sing, H. Kral (Eds.) Studies in Surface Science and Catalysis, Elsevier, 1988, pp. 283-294. 
[111] T. Courtois, Dispositif de mesure de caractéristiques liées a la porosité des media poreux, in: $F$. Patent (Ed.), France, 2003.

[112] S. Munari, A. Bottino, P. Moretti, G. Capannelli, I. Becchi, Permoporometric study on ultrafiltration membranes, Journal of Membrane Science, 41 (1989) 69-86.

[113] E.S. Tarleton, J.P. Robinson, M. Salman, Solvent-induced swelling of membranes Measurements and influence in nanofiltration, Journal of Membrane Science, 280 (2006) 442-451. [114] S.B. R. Peinador, La caractérisation des membranes d'Ultrafiltration et Microfiltration par les techniques de pénétration FluideFluide (Gaz-Liquide et Liquide-Liquide), in: Rapport de stage de fin d'études, Université toulouse III - Paul Sabatier, 2019.

[115] M.W. Phillips, A.J. DiLeo, A Validatible Porosimetric Technique for Verifying the Integrity of Virus-Retentive Membranes, Biologicals, 24 (1996) 243-253.

[116] L. Germic, K. Ebert, R.H.B. Bouma, Z. Borneman, M.H.V. Mulder, H. Strathmann, Characterization of polyacrylonitrile ultrafiltration membranes, Journal of Membrane Science, 132 (1997) 131-145.

[117] S.M. Snyder, K.D. Cole, D.C. Szlag, Phase compositions, viscosities, and densities for aqueous two-phase systems composed of polyethylene glycol and various salts at 25 .degree.C, Journal of Chemical \& Engineering Data, 37 (1992) 268-274.

[118] P. Cheng, D. Li, L. Boruvka, Y. Rotenberg, A.W. Neumann, Automation of axisymmetric drop shape analysis for measurements of interfacial tensions and contact angles, Colloids and Surfaces, 43 (1990) 151-167.

[119] P.A. Albertsson, Partition of cell particles and macromolecules Advances in protein chemistry, 24 (1986) 309.

[120] E. Atefi, J.A. Mann, H. Tavana, Ultralow Interfacial Tensions of Aqueous Two-Phase Systems Measured Using Drop Shape, Langmuir, 30 (2014) 9691-9699.

[121] D. Forciniti, C.K. Hall, M.R. Kula, Influence of polymer molecular weight and temperature on phase composition in aqueous two-phase systems, Fluid Phase Equilibria, 61 (1991) 243-262.

[122] D. Forciniti, C.K. Hall, M.R. Kula, Analysis of polymer molecular weight distributions in aqueous two-phase systems, Journal of Biotechnology, 20 (1991) 151-161.

[123] B. Mattiasson, Applications of aqueous two-phase systems in biotechnology, Trends in Biotechnology, 1 (1983) 16-20.

[124] H. Cárdenas, M. Cartes, A. Mejía, Atmospheric densities and interfacial tensions for 1-alkanol (1-butanol to 1-octanol)+water and ether (MTBE, ETBE, DIPE, TAME and THP)+water demixed mixtures, Fluid Phase Equilibria, 396 (2015) 88-97.

[125] J. Viades-Trejo, J. Gracia-Fadrique, Spinning drop method: From Young-Laplace to Vonnegut, Colloids and Surfaces A: Physicochemical and Engineering Aspects, 302 (2007) 549-552.

[126] S. Giglia, D. Bohonak, P. Greenhalgh, A. Leahy, Measurement of pore size distribution and prediction of membrane filter virus retention using liquid-liquid porometry, Journal of Membrane Science, 476 (2015) 399-409.

[127] A.A. Liabastre, C. Orr, An evaluation of pore structure by mercury penetration, Journal of Colloid and Interface Science, 64 (1978) 1-18.

[128] S. Lowell, Powder Surface Area and Porosity, Third Edition. ed., Springer Netherlands, Dordrecht, 1991.

[129] E.W. Washburn, Note on a Method of Determining the Distribution of Pore Sizes in a Porous Material, Proc Natl Acad Sci U S A, 7 (1921) 115-116.

[130] E. Honold, E.L. Skau, Application of Mercury-Intrusion Method for Determination of Pore-Size Distribution to Membrane Filters, Science, 120 (1954) 805-806.

[131] F. Théron, E. Lys, A. Joubert, F. Bertrand, L. Le Coq, Characterization of the porous structure of a non-woven fibrous medium for air filtration at local and global scales using porosimetry and X-ray micro-tomography, Powder Technology, 320 (2017) 295-303.

[132] P. Webb, An Introduction To The Physical Characterization of Materials by Mercury Intrusion Porosimetry with Emphasis On Reduction And Presentation of Experimental Data 2 CONTENTS, Pharm Online, (2001). 
[133] C. Volzone, N. Zagorodny, Mercury intrusion porosimetry (MIP) study of archaeological pottery from Hualfin Valley, Catamarca, Argentina, Applied Clay Science, 91-92 (2014) 12-15.

[134] I. Zake-Tiluga, V. Svinka, R. Svinka, B. Zierath, P. Greil, T. Fey, Thermal conductivity and microstructure characterisation of lightweight alumina and alumina-mullite ceramics, Journal of the European Ceramic Society, 36 (2016) 1469-1477.

[135] L. Palacioa, Y. Bouzerdi, M. Ouammou, A. Albizane, J. Bennazha, A. Hernandez, J.I. Calvo, Ceramic membranes from Moroccan natural clay and phosphate for industrial water treatment, Desalination, 245 (2009) 501-507.

[136] B.F.K. Kingsbury, K. Li, A morphological study of ceramic hollow fibre membranes, Journal of Membrane Science, 328 (2009) 134-140.

[137] S. Koonaphapdeelert, Z. Wu, K. Li, Carbon dioxide stripping in ceramic hollow fibre membrane contactors, Chemical Engineering Science, 64 (2009) 1-8.

[138] Q. Liu, T. Xue, L. Yang, X. Hu, H. Du, Controllable synthesis of hierarchical porous mullite fiber network for gas filtration, Journal of the European Ceramic Society, 36 (2016) 1691-1697.

[139] M.H.D. Othman, N. Droushiotis, Z. Wu, G. Kelsall, K. Li, Dual-layer hollow fibres with different anode structures for micro-tubular solid oxide fuel cells, Journal of Power Sources, 205 (2012) 272280.

[140] M.A. Rahman, F.R. García-García, M.D.I. Hatim, B.F.K. Kingsbury, K. Li, Development of a catalytic hollow fibre membrane micro-reactor for high purity $\mathrm{H} 2$ production, Journal of Membrane Science, 368 (2011) 116-123.

[141] H.L. Ritter, L.C. Drake, Pressure Porosimeter and Determination of Complete Macropore-Size Distributions. Pressure Porosimeter and Determination of Complete Macropore-Size Distributions, Industrial \& Engineering Chemistry Analytical Edition, 17 (1945) 782-786.

[142] H.M. Rootare, A Review of Mercury Porosimetry, in: J.S. Hirschhorn, K.H. Roll (Eds.) Advanced Experimental Techniques in Powder Metallurgy: Based on a Symposium on Advanced Experimental Techniques in Powder Metallurgy sponsored by the Institute of Metals Division, Powder Metallurgy Committee, held at the Spring Meeting of The Metallurgical Society of AIME in Pittsburgh, Pennsylvania, May 1969, Springer US, Boston, MA, 1970, pp. 225-252.

[143] C.A. León y León, New perspectives in mercury porosimetry, Advances in Colloid and Interface Science, 76-77 (1998) 341-372.

[144] A. Barrera, K. Muramatsu, T. Viveros, S. Gómez, J.A. Montoya, P. del Angel, G. Pérez, J. CampaMolina, Influence of the type of sepiolite on the modification of the pore-size distribution in $\mathrm{y}-\mathrm{Al} 2 \mathrm{O} 3$ supports, Applied Clay Science, 42 (2009) 415-421.

[145] N. van Garderen, F. Clemens, J. Kaufmann, M. Urbanek, M. Binkowski, T. Graule, C. Aneziris, Pore analyses of highly porous diatomite and clay based materials for fluidized bed reactors,

Microporous and Mesoporous Materials, 151 (2012) 255-263.

[146] E.P. Favvas, A.A. Sapalidis, K.L. Stefanopoulos, G.E. Romanos, N.K. Kanellopoulos, E.K. Kargiotis, A.C. Mitropoulos, Characterization of carbonate rocks by combination of scattering, porosimetry and permeability techniques, Microporous and Mesoporous Materials, 120 (2009) 109-114.

[147] Y. Yao, D. Liu, Comparison of low-field NMR and mercury intrusion porosimetry in characterizing pore size distributions of coals, Fuel, 95 (2012) 152-158.

[148] R. Zhang, S. Xu, D. Raja, N.B. Khusni, J. Liu, J. Zhang, S. Abdulridha, H. Xiang, S. Jiang, Y. Guan, Y. Jiao, X. Fan, On the effect of mesoporosity of FAU Y zeolites in the liquid-phase catalysis, Microporous and Mesoporous Materials, 278 (2019) 297-306.

[149] A.M. El-Kady, A.F. Ali, Fabrication and characterization of $\mathrm{ZnO}$ modified bioactive glass nanoparticles, Ceramics International, 38 (2012) 1195-1204.

[150] J.M. Manso, Á. Rodriguez, Á. Aragón, J.J. Gonzalez, The durability of masonry mortars made with ladle furnace slag, Construction and Building Materials, 25 (2011) 3508-3519.

[151] S.P. Rigby, K.J. Edler, The Influence of Mercury Contact Angle, Surface Tension, and Retraction Mechanism on the Interpretation of Mercury Porosimetry Data, Journal of Colloid and Interface Science, 250 (2002) 175-190. 
[152] T.H. Sasakawa, Yasuhiro; Takami, Norio, Electrode, secondary battery, battery pack, and vehicle, in: E.P. Appl. (Ed.), 2019.

[153] V. Claude, J.G. Mahy, F. Micheli, J. Geens, S.D. Lambert, Sol-gel Ni/ $Y-A l 2 O 3$ material as secondary catalyst for toluene reforming: Tailoring the $y$-Al2O3 substrate with stearic acid, Microporous and Mesoporous Materials, 291 (2020) 109681.

[154] J.L. Amorós, A. Moreno, E. Blasco, J.J. Pérez, S. Navarro, S. Reverter, Inkjet technology for ceramic products. Influence of some process variables on ink penetration, International Journal of Applied Ceramic Technology, 16 (2019) 2153-2160.

[155] I.K. Park, C.-Y. Ahn, J.H. Lee, D.W. Lee, C.H. Lee, Y.-H. Cho, Y.-E. Sung, Three-dimensionally interconnected titanium foam anode for an energy-efficient zero gap-type chlor-alkali electrolyzer, International Journal of Hydrogen Energy, 44 (2019) 16079-16086.

[156] S. Kerdi, A. Qamar, A. Alpatova, N. Ghaffour, An in-situ technique for the direct structural characterization of biofouling in membrane filtration, Journal of Membrane Science, 583 (2019) 8192.

[157] A. Kosior, M. Antosova, R. Fáber, L. Villain, M. Polakovič, Single-component adsorption of proteins on a cellulose membrane with the phenyl ligand for hydrophobic interaction chromatography, Journal of Membrane Science, 442 (2013) 216-224.

[158] H.J. Lee, J.H. Park, Effect of hydrophobic modification on carbon dioxide absorption using porous alumina (Al2O3) hollow fiber membrane contactor, Journal of Membrane Science, 518 (2016) 79-87.

[159] F. Sandra, A. Ballestero, V.L. Nguyen, M.N. Tsampas, P. Vernoux, C. Balan, Y. Iwamoto, U.B. Demirci, P. Miele, S. Bernard, Silicon carbide-based membranes with high soot particle filtration efficiency, durability and catalytic activity for $\mathrm{CO} / \mathrm{HC}$ oxidation and soot combustion, Journal of Membrane Science, 501 (2016) 79-92.

[160] S.S. Manickam, J. Gelb, J.R. McCutcheon, Pore structure characterization of asymmetric membranes: Non-destructive characterization of porosity and tortuosity, Journal of Membrane Science, 454 (2014) 549-554.

[161] E. Akhondi, F. Zamani, J.W. Chew, W.B. Krantz, A.G. Fane, Improved design and protocol for evapoporometry determination of the pore-size distribution, Journal of Membrane Science, 496 (2015) 334-343.

[162] E. Akhondi, F. Zamani, A.W.K. Law, W.B. Krantz, A.G. Fane, J.W. Chew, Influence of backwashing on the pore size of hollow fiber ultrafiltration membranes, Journal of Membrane Science, 521 (2017) 33-42.

[163] F. Zamani, E. Akhondi, G.H. Koops, W.B. Krantz, A.G. Fane, J.W. Chew, Evapoporometry adaptation to determine the lumen-side pore-size distribution (PSD) of hollow fiber and tubular membranes, Journal of Membrane Science, 526 (2017) 1-8.

[164] F. Zamani, P. Jayaraman, E. Akhondi, W.B. Krantz, A.G. Fane, J.W. Chew, Extending the uppermost pore diameter measureable via Evapoporometry, Journal of Membrane Science, 524 (2017) 637-643.

[165] W. Krantz, A. Greenberg, E. Kujundzic, A. Yeo, S. Hosseini, A Novel Technique for Characterizing Membrane Pore Size - Evapoporometry, 2010.

[166] W. Krantz, A. Greenberg, E. Kujundzic, A. Yeo, S. Hosseini, Evapoporometry - A Novel Method for Determining the Pore-Size Distribution of MF and UF Membranes, 2011.

[167] W.B. Krantz, A.R. Greenberg, E. Kujundzic, A. Yeo, S.S. Hosseini, Evapoporometry: A novel technique for determining the pore-size distribution of membranes, Journal of Membrane Science, 438 (2013) 153-166.

[168] E. Akhondi, F. Wicaksana, W.B. Krantz, A.G. Fane, Evapoporometry determination of pore-size distribution and pore fouling of hollow fiber membranes, Journal of Membrane Science, 470 (2014) 334-345.

[169] C. Eyraud, M. Betemps, J.F. Quinson, F. Chatelut, M. Brun, B. Rasneur, DETERMINATION OF THE PORE-SIZE DISTRIBUTION OF AN ULTRAFILTER BY - GAS-LIQUID PERMPOROMETRY MEASUREMENT COMPARISON BETWEEN FLOW POROMETRY AND CONDENSATE EQUILIBRIUM POROMETRY, Bulletin 
De La Societe Chimique De France Partie I-Physicochimie Des Systemes Liquides Electrochimie Catalyse Genie Chimique, (1984) I237-I244.

[170] A. Mey-Marom, M.G. Katz, Measurement of active pore size distribution of microporous membranes - a new approach, Journal of Membrane Science, 27 (1986) 119-130.

[171] M.G. Katz, G. Baruch, New insights into the structure of microporous membranes obtained using a new pore size evaluation method, Desalination, 58 (1986) 199-211.

[172] F.P. Cuperus, D. Bargeman, C.A. Smolders, Characterization of anisotropic UF-membranes: top layer thickness and pore structure, Journal of Membrane Science, 61 (1991) 73-83.

[173] M.G. Liu, R. Ben Aim, M. Mietton Peuchot, Characterization of Inorganic Membranes by Permporometry Method: Importance of Non Equilibrium Phenomena, Key Engineering Materials, 6162 (1992) 603-606.

[174] G.Z. Cao, J. Meijernik, H.W. Brinkman, A.J. Burggraaf, Permporometry study on the size distribution of active pores in porous ceramic membranes, Journal of Membrane Science, 83 (1993) 221-235.

[175] F.P. Cuperus, D. Bargeman, C.A. Smolders, Permporometry: the determination of the size distribution of active pores in UF membranes, Journal of Membrane Science, 71 (1992) 57-67.

[176] P. Huang, N. Xu, J. Shi, Y.S. Lin, Characterization of asymmetric ceramic membranes by modified permporometry, Journal of Membrane Science, 116 (1996) 301-305.

[177] T. Tsuru, T. Hino, T. Yoshioka, M. Asaeda, Permporometry characterization of microporous ceramic membranes, Journal of Membrane Science, 186 (2001) 257-265.

[178] T. Tsuru, Y. Takata, H. Kondo, F. Hirano, T. Yoshioka, M. Asaeda, Characterization of sol-gel derived membranes and zeolite membranes by nanopermporometry, Separation and Purification Technology, 32 (2003) 23-27.

[179] N. Nishiyama, D.-H. Park, Y. Egashira, K. Ueyama, Pore size distributions of silylated mesoporous silica MCM-48 membranes, Separation and Purification Technology, 32 (2003) 127-132.

[180] S.R. Chowdhury, A.M. Peters, D.H.A. Blank, J.E.t. Elshof, Influence of porous substrate on mesopore structure and water permeability of surfactant templated mesoporous silica membranes, Journal of Membrane Science, 279 (2006) 276-281.

[181] C. Wang, X. Liu, R. Cui, B. Zhang, In situ evaluation of defect size distribution for supported zeolite membranes, Journal of Membrane Science, 330 (2009) 259-266.

[182] J. Hedlund, D. Korelskiy, L. Sandström, J. Lindmark, Permporometry analysis of zeolite membranes, Journal of Membrane Science, 345 (2009) 276-287.

[183] S. Higgins, R. Kennard, N. Hill, J. DiCarlo, W.J. DeSisto, Preparation and characterization of nonionic block co-polymer templated mesoporous silica membranes, Journal of Membrane Science, 279 (2006) 669-674.

[184] S.R. Chowdhury, J. De Lamare, V. Valtchev, Synthesis and structural characterization of EMTtype membranes and their performance in nanofiltration experiments, Journal of Membrane Science, 314 (2008) 200-205.

[185] G.C.C. Yang, C.J. Li, Tubular TiO2/Al2O3 composite membranes: preparation, characterization, and performance in electrofiltration of oxide-CMP wastewater, Desalination, 234 (2008) 354-361.

[186] J. Kuhn, S. Sutanto, J. Gascon, J. Gross, F. Kapteijn, Performance and stability of multi-channel MFI zeolite membranes detemplated by calcination and ozonication in ethanol/water pervaporation, Journal of Membrane Science, 339 (2009) 261-274.

[187] M.C. Schillo, I.S. Park, W.V. Chiu, H. Verweij, Rapid thermal processing of inorganic membranes, Journal of Membrane Science, 362 (2010) 127-133.

[188] J. Lindmark, J. Hedlund, S.K. Wirawan, D. Creaser, M. Li, D. Zhang, X. Zou, Impregnation of zeolite membranes for enhanced selectivity, Journal of Membrane Science, 365 (2010) 188-197. [189] B. Hofs, J. Ogier, D. Vries, E.F. Beerendonk, E.R. Cornelissen, Comparison of ceramic and polymeric membrane permeability and fouling using surface water, Separation and Purification Technology, 79 (2011) 365-374. 
[190] S. Zeidler, P. Puhlfürß, U. Kätzel, I. Voigt, Preparation and characterization of new low MWCO ceramic nanofiltration membranes for organic solvents, Journal of Membrane Science, 470 (2014) 421-430.

[191] S. Karimi, D. Korelskiy, L. Yu, J. Mouzon, A. Ali Khodadadi, Y. Mortazavi, M. Esmaeili, J. Hedlund, A simple method for blocking defects in zeolite membranes, Journal of Membrane Science, 489 (2015) 270-274.

[192] S. Blumenschein, A. Böcking, U. Kätzel, S. Postel, M. Wessling, Rejection modeling of ceramic membranes in organic solvent nanofiltration, Journal of Membrane Science, 510 (2016) 191-200. [193] N. Chang, H. Tang, L. Bai, Y. Zhang, G. Zeng, Optimized rapid thermal processing for the template removal of SAPO-34 zeolite membranes, Journal of Membrane Science, 552 (2018) 13-21. [194] A. Simon, H. Richter, B. Reif, M. Schuelein, D. Sanwald, W. Schwieger, Evaluation of a method for micro-defect sealing in ZSM-5 zeolite membranes by chemical vapor deposition of carbon, Separation and Purification Technology, 219 (2019) 180-185.

[195] K.S.W. Sing, Physisorption of nitrogen by porous materials, Journal of Porous Materials, 2 (1995) 5-8.

[196] B. Nie, X. Liu, L. Yang, J. Meng, X. Li, Pore structure characterization of different rank coals using gas adsorption and scanning electron microscopy, Fuel, 158 (2015) 908-917.

[197] E.M. Cuerda-Correa, M. Díaz-Díez, A. Macías-García, J. Gañán-Gómez, Determination of the fractal dimension of activated carbons: Two alternative methods, Applied Surface Science - APPL SURF SCl, 252 (2006) 6102-6105.

[198] G.-J. Lee, S.-I. Pyun, C.K. Rhee, Characterisation of geometric and structural properties of pore surfaces of reactivated microporous carbons based upon image analysis and gas adsorption, Microporous and Mesoporous Materials - MICROPOROUS MESOPOROUS MAT, 93 (2006) 217-225. [199] M. Schmitt, C.P. Fernandes, J.A.B. da Cunha Neto, F.G. Wolf, V.S.S. dos Santos, Characterization of pore systems in seal rocks using Nitrogen Gas Adsorption combined with Mercury Injection Capillary Pressure techniques, Marine and Petroleum Geology, 39 (2013) 138-149.

[200] P. Prádanos, M.L. Rodriguez, J.I. Calvo, A. Hernández, F. Tejerina, J.A. de Saja, Structural characterization of an UF membrane by gas adsorption-desorption and AFM measurements, Journal of Membrane Science, 117 (1996) 291-302.

[201] C.R. Clarkson, R. Marc Bustin, Variation in micropore capacity and size distribution with composition in bituminous coal of the Western Canadian Sedimentary Basin: Implications for coalbed methane potential, Fuel, 75 (1996) 1483-1498.

[202] S. Brunauer, P.H. Emmett, E. Teller, Adsorption of Gases in Multimolecular Layers, Journal of the American Chemical Society, 60 (1938) 309-319.

[203] E.P. Barrett, L.G. Joyner, P.P. Halenda, The Determination of Pore Volume and Area Distributions in Porous Substances. I. Computations from Nitrogen Isotherms, Journal of the American Chemical Society, 73 (1951) 373-380.

[204] J. Seifert, G. Emig, Mikrostrukturuntersuchungen an porösen Feststoffen durch Physisorptionsmessungen, Chemie Ingenieur Technik, 59 (1987) 475-484.

[205] K.S.W.S. S. J. Gregg, Adsorption, Surface Area and Porosity John Wiley \& Sons, Ltd, London, UK, 1982.

[206] Y. Chen, L. Wei, M. Mastalerz, A. Schimmelmann, The effect of analytical particle size on gas adsorption porosimetry of shale, International Journal of Coal Geology, 138 (2015) 103-112.

[207] K. Kaneko, Determination of pore size and pore size distribution: 1. Adsorbents and catalysts, Journal of Membrane Science, 96 (1994) 59-89.

[208] M.M. Dubinin, The Potential Theory of Adsorption of Gases and Vapors for Adsorbents with Energetically Nonuniform Surfaces, Chemical Reviews, 60 (1960) 235-241.

[209] M.M. Dubinin, Fundamentals of the theory of adsorption in micropores of carbon adsorbents: Characteristics of their adsorption properties and microporous structures, Carbon, 27 (1989) 457467. 
[210] M.M. Dubinin, Fundamentals of the theory of adsorption in micropores of carbon adsorbents: characteristics of their adsorption properties and microporous structures, Pure and Applied Chemistry, 61 (1989) 1841-1843.

[211] A. Gil, A. Díaz, M. Montes, D.R. Acosta, Characterization of the microporosity of pillared clays by nitrogen adsorption - application of the Horvath-Kawazoe approach, Journal of Materials Science, 29 (1994) 4927-4932.

[212] G. Horváth, Kamazoe, K., METHOD FOR THE CALCULATION OF EFFECTIVE PORE SIZE DISTRIBUTION IN MOLECULAR SIEVE CARBON, Journal of Chemical Engineering of Japan, 16 (1983) 470-475.

[213] B.C. Lippens, J.H. de Boer, Studies on pore systems in catalysts: V. The t method, Journal of Catalysis, 4 (1965) 319-323.

[214] W.D. Harkins, G. Jura, Surfaces of Solids. XII. An Absolute Method for the Determination of the Area of a Finely Divided Crystalline Solid, Journal of the American Chemical Society, 66 (1944) 13621366.

[215] L. Palacio, P. Prádanos, J. Calvo, A. Hernández, Porosity Determinations by a New Gas Penetration Volumetric Method, Acta Polithecnica Scandinavica. Chemical Technology Series, 247 (1997) 115-120.

[216] L. Palacio, P. Prádanos, J.I. Calvo, A. Hernández, Porosity measurements by a gas penetration method and other techniques applied to membrane characterization, Thin Solid Films, 348 (1999) 2229.

[217] J.I. Calvo, P. Prádanos, A. Hernández, W.R. Bowen, N. Hilal, R.W. Lovitt, P.M. Williams, Bulk and surface characterization of composite UF membranes Atomic force microscopy, gas adsorptiondesorption and liquid displacement techniques, Journal of Membrane Science, 128 (1997) 7-21. [218] Y. Fang, L. Bian, Q. Bi, Q. Li, X. Wang, Evaluation of the pore size distribution of a forward osmosis membrane in three different ways, Journal of Membrane Science, 454 (2014) 390-397. [219] K. Hazazi, X. Ma, Y. Wang, W. Ogieglo, A. Alhazmi, Y. Han, I. Pinnau, Ultra-selective carbon molecular sieve membranes for natural gas separations based on a carbon-rich intrinsically microporous polyimide precursor, Journal of Membrane Science, 585 (2019) 1-9.

[220] A. Hernández, J.I. Calvo, P. Prádanos, F. Tejerina, Pore size distributions of track-etched membranes; comparison of surface and bulk porosities, Colloids and Surfaces A: Physicochemical and Engineering Aspects, 138 (1998) 391-401.

[221] Y. Sada, T. Yoshioka, K. Nakagawa, T. Shintani, R. lesako, E. Kamio, H. Matsuyama, Preparation and characterization of organic chelate ligand $(\mathrm{OCL})$-templated $\mathrm{TiO} 2-\mathrm{ZrO} 2$ nanofiltration membranes, Journal of Membrane Science, 591 (2019) 117304.

[222] S. Dong, L. Wang, X. Gao, W. Zhu, Z. Wang, Z. Ma, C. Gao, Freeze casting of novel porous silicate cement supports using tert-butyl alcohol-water binary crystals as template: Microstructure, strength and permeability, Journal of Membrane Science, 541 (2017) 143-152.

[223] P. Cini, S.R. Blaha, M.P. Harold, K. Venkataraman, Preparation and characterization of modified tubular ceramic membranes for use as catalyst supports, Journal of Membrane Science, 55 (1991) 199-225.

[224] D.A. Bailey, C.D. Jones, A.R. Barron, M.R. Wiesner, Characterization of alumoxane-derived ceramic membranes, Journal of Membrane Science, 176 (2000) 1-9.

[225] A.K. Basumatary, R.V. Kumar, A.K. Ghoshal, G. Pugazhenthi, Synthesis and characterization of MCM-41-ceramic composite membrane for the separation of chromic acid from aqueous solution, Journal of Membrane Science, 475 (2015) 521-532.

[226] A. Maghsodi, L. Adlnasab, M. Shabanian, M. Javanbakht, Optimization of effective parameters in the synthesis of nanopore anodic aluminum oxide membrane and arsenic removal by prepared magnetic iron oxide nanoparicles in anodic aluminum oxide membrane via ultrasonic-hydrothermal method, Ultrasonics Sonochemistry, 48 (2018) 441-452.

[227] B. Zhang, Y. Shi, Y. Wu, T. Wang, J. Qiu, Preparation and characterization of supported ordered nanoporous carbon membranes for gas separation, Journal of Applied Polymer Science, 131 (2014). 
[228] Y. Zeng, L. Prasetyo, S.J. Tan, C. Fan, D.D. Do, D. Nicholson, On the hysteresis of adsorption and desorption of simple gases in open end and closed end pores, Chemical Engineering Science, 158 (2017) 462-479.

[229] C. Jallut, J. Lenoir, C. Bardot, C. Eyraud, Thermoporometry.: Modelling and simulation of a mesoporous solid, Journal of Membrane Science, 68 (1992) 271-282.

[230] L. Zeman, G. Tkacik, P. Le Parlouer, Characterization of porous sublayers in uf membranes by thermoporometry, Journal of Membrane Science, 32 (1987) 329-337.

[231] J.F. Quinson, N. Mameri, L. Guihard, B. Bariou, The study of the swelling of an ultrafiltration membrane under the influence of solvents by thermoporometry and measurement of permeability, Journal of Membrane Science, 58 (1991) 191-200.

[232] J.F. Quinson, N. Nameri, B. Bariou, Textural Characterization of Ultrafiltration Membranes by Thermoporometry and Liquid Flow Measurement, in: F. Rodriguez-Reinoso, J. Rouquerol, K.S.W. Sing, K.K. Unger (Eds.) Studies in Surface Science and Catalysis, Elsevier, 1991, pp. 209-216.

[233] A.P. Broek, H.A. Teunis, D. Bargeman, E.D. Sprengers, C.A. Smolders, Characterization of hollow fiber hemodialysis membranes: pore size distribution and performance, Journal of Membrane Science, 73 (1992) 143-152.

[234] F.P. Cuperus, D. Bargeman, C.A. Smolders, Critical points in the analysis of membrane pore structures by thermoporometry, Journal of Membrane Science, 66 (1992) 45-53.

[235] L.P. Terrazas-Bandala, G. Gonzalez-Sanchez, R. Garcia-Valls, T. Gumi, I. Beurroies, R. Denoyel, C. Torras, L. Ballinas-Casarrubias, Influence of humidity, temperature, and the addition of activated carbon on the preparation of cellulose acetate membranes and their ability to remove arsenic from water, Journal of Applied Polymer Science, 131 (2014).

[236] S.H. Kim, S.-Y. Kwak, T. Suzuki, Positron Annihilation Spectroscopic Evidence to Demonstrate the Flux-Enhancement Mechanism in Morphology-Controlled Thin-Film-Composite (TFC) Membrane, Environmental Science \& Technology, 39 (2005) 1764-1770.

[237] Z. Chen, K. Ito, H. Yanagishita, N. Oshima, R. Suzuki, Y. Kobayashi, Correlation study between free-volume holes and molecular separations of composite membranes for reverse osmosis processes by means of variable-energy positron annihilation techniques, Journal of Physical Chemistry C, 115 (2011) 18055-18060.

[238] T. Fujioka, N. Oshima, R. Suzuki, S.J. Khan, A. Roux, Y. Poussade, J.E. Drewes, L.D. Nghiem, Rejection of small and uncharged chemicals of emerging concern by reverse osmosis membranes: The role of free volume space within the active skin layer, Separation and Purification Technology, 116 (2013) 426-432.

[239] T. Fujioka, N. Oshima, R. Suzuki, M. Higgins, W.E. Price, R.K. Henderson, L.D. Nghiem, Effect of heat treatment on fouling resistance and the rejection of small and neutral solutes by reverse osmosis membranes, Water Science and Technology: Water Supply, 15 (2015) 510-516.

[240] J. Lee, C.M. Doherty, A.J. Hill, S.E. Kentish, Water vapor sorption and free volume in the aromatic polyamide layer of reverse osmosis membranes, Journal of Membrane Science, 425-426 (2013) 217-226.

[241] J. Fan, W. Zhou, Q. Wang, Z. Chu, L. Yang, L. Yang, J. Sun, L. Zhao, J. Xu, Y. Liang, Z. Chen, Structure dependence of water vapor permeation in polymer nanocomposite membranes investigated by positron annihilation lifetime spectroscopy, Journal of Membrane Science, 549 (2018) 581-587.

[242] S.-J. Kim, S. Kook, B.E. O'Rourke, J. Lee, M. Hwang, Y. Kobayashi, R. Suzuki, I.S. Kim, Characterization of pore size distribution (PSD) in cellulose triacetate (CTA) and polyamide (PA) thin active layers by positron annihilation lifetime spectroscopy (PALS) and fractional rejection (FR) method, Journal of Membrane Science, 527 (2017) 143-151.

[243] X. Ma, H. Wang, H. Wang, J.O. Brien-Abraham, Y.S. Lin, Pore structure characterization of supported polycrystalline zeolite membranes by positron annihilation spectroscopy, Journal of Membrane Science, 477 (2015) 41-48.

[244] A. Pifferi, Radiation Sources: X-Ray Sources, in: Reference Module in Materials Science and Materials Engineering, Elsevier, 2016. 
[245] C. Streli, P. Wobrauschek, P. Kregsamer, X-ray Fluorescence Spectroscopy, Applications, in: J.C. Lindon (Ed.) Encyclopedia of Spectroscopy and Spectrometry, Elsevier, Oxford, 1999, pp. 2478-2487. [246] C.R.A. Catlow, Synchrotron radiation techniques in materials and environmental science, Philosophical Transactions of the Royal Society A: Mathematical, Physical and Engineering Sciences, 373 (2015) 20130162.

[247] M. Lassinantti Gualtieri, C. Andersson, F. Jareman, J. Hedlund, A.F. Gualtieri, M. Leoni, C. Meneghini, Crack formation in $\alpha$-alumina supported MFI zeolite membranes studied by in situ high temperature synchrotron powder diffraction, Journal of Membrane Science, 290 (2007) 95-104. [248] H.-K. Jeong, Z. Lai, M. Tsapatsis, J.C. Hanson, Strain of MFI crystals in membranes: An in situ synchrotron X-ray study, Microporous and Mesoporous Materials, 84 (2005) 332-337.

[249] R. Barranco-García, J.M. López-Majada, V. Lorenzo, J.M. Gómez-Elvira, E. Pérez, M.L. Cerrada, Confinement of iPP chains in the interior of SBA-15 mesostructure ascertained by gas transport properties in iPP-SBA-15 nanocomposites prepared by extrusion, Journal of Membrane Science, 569 (2019) 137-148.

[250] H. Grigoriew, S. Bernstorff, A. Wolińska-Grabczyk, J. Domagała, A.G. Chmielewski, Depthinfluenced structure through permeating polymer membrane using SAXS synchrotron method, Journal of Membrane Science, 186 (2001) 1-8.

[251] H. Grigoriew, A. Wolinska-Grabczyk, A.G. Chmielewski, H. Amenitsch, S. Bernstorff, SAXS study of the influence of ethanol on the microstructure of polyurethane-based membrane, Journal of Membrane Science, 170 (2000) 275-279.

[252] J.-C. Remigy, M. Meireles, Assessment of pore geometry and 3-D architecture of filtration membranes by synchrotron radiation computed microtomography, Desalination, 199 (2006) 501503.

[253] S.-H. Lee, W.-S. Chang, S.-M. Han, D.-H. Kim, J.-K. Kim, Synchrotron X-ray nanotomography and three-dimensional nanoscale imaging analysis of pore structure-function in nanoporous polymeric membranes, Journal of Membrane Science, 535 (2017) 28-34.

[254] R. Chandler, J. Koplik, K. Lerman, J.F. Willemsen, Capillary displacement and percolation in porous media, Journal of Fluid Mechanics, 119 (1982) 249-267.

[255] V. Joekar-Niasar, S.M. Hassanizadeh, Analysis of Fundamentals of Two-Phase Flow in Porous Media Using Dynamic Pore-Network Models: A Review, Critical Reviews in Environmental Science and Technology, 42 (2012) 1895-1976.

[256] R. Lenormand, E. Touboul, C. Zarcone, Numerical models and experiments on immiscible displacements in porous media, Journal of Fluid Mechanics, 189 (1988) 165-187.

[257] O.M. R. Peinador-Dàvila, M.B. Tanis-Kanbur, J. W. Chew, D. Lasseux, M. Prat Liquid-Liquid Porometry, Evapoporometry and Pore Network Simulations of Ultrafiltration Membranes, in: 13th World Filtration Congress, San Diego, California, USA, 2020.

[258] D. Stauffer, A. Aharony, Introduction To Percolation Theory, Taylor \& Francis, 1994. 